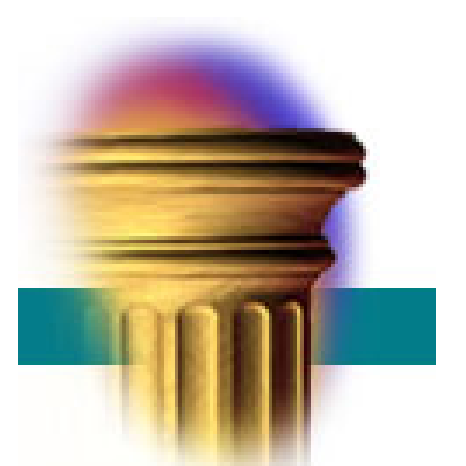

\title{
8 \\ Accounting for Macro-Finance Trends: Market Power, Intangibles, and Risk Premia
}

告

Emmanuel Farhi and François Gourio

\author{
REVISED \\ February 2019
}

\section{WP 2018-19}

https://doi.org/10.21033/wp-2018-19

${ }^{*}$ Working papers are not edited, and all opinions and errors are the responsibility of the author(s). The views expressed do not necessarily reflect the views of the Federal Reserve Bank of Chicago or the Federal Reserve System. 


\title{
Accounting for Macro-Finance Trends:
}

\section{Market Power, Intangibles, and Risk Premia*}

\author{
Emmanuel Farhi ${ }^{\dagger}$ and François Gourio ${ }^{\ddagger}$
}

February 2019

\begin{abstract}
Real risk-free interest rates have trended down over the past 30 years. Puzzlingly in light of this decline, (1) the return on private capital has remained stable or even increased, creating an increasing wedge with safe interest rates; (2) stock market valuation ratios have increased only moderately; (3) investment has been lackluster. We use a simple extension of the neoclassical growth model to diagnose the nexus of forces that jointly accounts for these developments. We find that rising market power, rising unmeasured intangibles, and rising risk premia, play a crucial role, over and above the traditional culprits of increasing savings supply and technological growth slowdown.
\end{abstract}

JEL codes: E34, G12.

Keywords: equity premium, risk-free rate, investment, profitability, valuation ratios, labor share, competition, markups, safe assets.

\section{Introduction}

Over the past thirty years, most developed economies have experienced large declines in risk-free interest rates and increases in asset prices such as housing or stock prices, with occasional sudden crashes. At the same time, and apart from a short period in the 1990s, economic growth, in particular productivity growth, has been rather disappointing, and investment has been lackluster. Earnings growth of corporations has been strong however, leading in most countries to an increase in the capital share and to stable or slightly rising profitability ratios. Making sense of these trends is a major endeavor for macroeconomists and for financial economists.

\footnotetext{
*The views expressed here are those of the authors and do not necessarily represent those of the Federal Reserve Bank of Chicago or the Federal Reserve System. We thank participants in presentations at the Brookings conference, at the ECB 2018 research conference, SED 2017, SAET 2017, CEPR Asset-prices and the macroeconomy 2018, NBER Capital Markets and the Economy 2018, the 2018 San Francisco Fed financial research conference, at the Chicago and Minneapolis Fed, and in the Hoover institute conference in honor of John Cochrane, for their comments. We especially thank Stefania d'Amico, Marco Bassetto, Bob Barsky, Gadi Barlevy, Jeff Campbell, Nicolas Crouzet, John Cochrane, Lars Hansen, Monika Piazzesi, Martin Schneider, Sam Schulhofer-Wohl, Venky Venkateswaran, François Velde, our discussants Riccardo Colacito, Mark Gertler, Martin Lettau, Dimitris Papanikolaou, Matthew Rognlie, and Jaume Ventura, and the editors Jan Eberly and James Stock for their comments.

${ }^{\dagger}$ Harvard University and NBER; email: efarhi@fas.harvard.edu.

${ }^{\ddagger}$ Federal Reserve Bank of Chicago; email: francois.gourio@chi.frb.org.
} 
Given the complexity of these phenomena, it is tempting to study them in isolation. For instance, a large literature has developed that tries to understand the decline in risk-free interest rates. But studying these trends independently may miss confounding factors or implausible implications. For instance, an aging population leads to higher savings supply which might well explain the decline in interest rates. However, higher savings supply should also increase capital accumulation, i.e. investment, and hence reduce profitability; it should also increases stock prices as the discount rate falls. Hence, a potential driver that is compelling judged on its ability to explain a single trend, may be implausible overall, because it makes it harder to account for the other trends.

Another way to highlight these tensions is to note that the stable profitability of private capital and declining risk-free rate lead to a rising spread, or wedge, between these two rates of return. What gives rise to this spread? A narrative that has recently attracted significant interest is the possibility of rising market power. On the other hand, rising risk premia could also account for the wedge. The only way to disentangle these potential causes is to consider additional implications - for instance, everything else equal, rising market power should imply a lower labor share, and rising risk premia should be reflected in lower prices of risky assets such as stocks.

These simple observations motivate our approach. We believe that a successful structural analysis of the past thirty years should account for these trends jointly. A novel feature of our analysis is that we aim to account both for macro trends and finance trends. The first step of our paper is to document a set of broad macro-finance trends which we believe are of particular interest. We focus on six indicators: economic growth, risk-free interest rates, profitability, the capital share, investment, and valuation ratios (such as the price-dividend or price-earnings ratio).

The second step in our paper is to develop an accounting framework to disentangle several potential drivers of these trends. We focus on five narratives that have been put forward to explain some or all of these trends. The first narrative is that the economy experienced a sustained growth decline, owing to lower population growth, investment-specific technical progress, or productivity growth. The second narrative is that savings supply has increased, perhaps owing to population aging (or to the demand of emerging markets for store of values). A third narrative involves rising market power of corporations. A fourth narrative focuses on technological change, coming from the introduction of information technology, which may have favored capital or skilled labor over unskilled labor, or the rise of hard-to-measure intangible forms of capital. A fifth narrative, which we will emphasize, involves changes in perceived macroeconomic risk, or of tolerance towards it.

Our approach is simple enough to allow for a relatively clear identification of the impact of these drivers on the facts that we target. Here our contribution is to propose a simple macroeconomic framework - a modest extension of the neoclassical growth model - that accounts for the "big ratios" familiar to macroeconomists as well as for the "financial ratios" of financial economists. Our model does this in a way that allows for interesting feedbacks between macroeconomic and financial variables. For example, the investment-output ratio is affected by market power and macroeconomic risk as well as savings supply and technological parameters. At the same time, our framework preserves the standard intuition and results of macroeconomists and financial economists, and hence is a useful pedagogical device. ${ }^{1}$

\footnotetext{
${ }^{1}$ Our model, of course, has to contend with the usual disconnect between macro and finance, i.e. the equity premium
} 
In our baseline estimation, we abstract from intangibles. Our main empirical result here is that the rising spread between the return on capital is the risk-free rate is driven mostly by a confluence of two factors: rising market power and rising macroeconomic risk. This rising macroeconomic risk in turns implies that the equity premium, which previous researchers have argued fell in the 1980s and 1990s, may have risen since around 2000. This higher risk is also an important driver of the decline of risk-free rates. We also find little role for technical change. Moreover, we show how previous researchers, who have used models without risk, have attributed too big a role to rising market power. When we incorporate intangibles, we see that a significant increase in their unmeasured component can help explain the rising wedge between the measured marginal product of capital and the risk-free rate. Interestingly, we find that intangible capital reduces the estimated role of market power in our accounting framework, while preserving the role of risk. Overall, our estimates offer a more nuanced understanding of the drivers of investment, profitability, and valuation ratios.

The rest of the paper is organized as follows. The remainder of the introduction discusses the related literature. Section 2 documents the main trends of interest. Section 3 presents our model. Section 4 explains our empirical methodology and identification. Section 5 presents the main empirical results. Section 6 discusses some extensions and robustness. Finally, section 7 reviews some outside evidence on the rise in the equity premium, markups, and intangibles. Section 8 concludes.

\subsection{Literature review}

Our paper, given its broad scope, makes contact with many other studies that have separately tried to understand one of the key trends we document. We discuss in more detail the relation of our results to the recent literature on market power, intangibles and risk premia in section 7 .

First, there is a large literature that studies the decline of interest rates on government bonds. Hamilton et al. (2015) provide a long-run perspective, and discuss the connection between growth and interest rates. Rachel and Smith (2017) is an exhaustive analysis of the role of many factors that affect interest rates. Carvalho et al. (2016) and Gagnon et al. (2016) study the role of demographics in detail. Del Negro et al. (2017) emphasize, like us, the role of the safety and liquidity premia. Bernanke (2005) and Caballero et al. (2005) emphasize the role of safe asset supply and demand. Our analysis will incorporate all these factors, though in a simple way.

Second, a large literature documents and tries to understand the decline of the labor share in developed economies. Elsby et al. (2013) document the facts and discuss various explanations using US data, while Karabarbounis and Neiman (2013) study international data and argue that the decline is driven by investment-biased technical change. Rognlie (2015) studies the role of housing. A number of other papers discuss the impact of technical change for a broader set of facts; see for instance Acemoglu and Restreppo (2017), Autor et al. (2017), Kehrig and Vincent (2018).

The most closely related papers are Caballero et al. (2017), Marx, Mojon and Velde (2017) and the contemporaneous work by Eggertsson, Robins and Wold (2018). Marx, Mojon and Velde (2017)

puzzle, and hence requires high risk or high risk aversion to generate plausible quantitative implications. (While we do not address the excess volatility puzzle in this paper, the framework can be extended along the line of Gourio (2012) to fit that as well.) 
also find, using a different methodology, that an increase in risk helps explain the rising spread between the MPK and the risk-free rate. They do not explicitly target the evolution of other variables such as investment or the price-dividend ratio. On the other hand, Eggertsson, Robins and Wold (2018) target some of the same big ratios that we study, but there are differences in terms of methodology and in terms of results. Methodologically, our approach uses a simple standard model, which allows a closed-form solution and clear identification. Substantively, we find a more important role for macroeconomic risk whereas they contend that rising savings supply and rising market power are the main driving forces.

\section{Some macro-finance trends}

This section presents simple evidence on the trends affecting some key macro-finance moments. We focus on six groups of indicators: interest rates on safe and liquid assets such as government bonds, measures of the rate of return on private capital, valuation ratios (i.e., price-dividend or price-earnings ratio for publicly listed companies), private investment in new capital, the labor share, and growth trends. We first present simple graphical depictions, then add some statistical measures.

Our focus is on the United States, but we believe that these facts hold in other developed economies and hence likely reflect worldwide trends. Like many macroeconomic studies, we will mostly consider the post-1984 period, which is associated with low and stable inflation together with relative macroeconomic stability (the "Great Moderation"). We present the changes in the simplest possible way by breaking our sample equally in the middle, i.e. at the millennium. However, we will also discuss briefly the longer trends and present continuous indicators using moving averages.

One important decision is whether to study the entire private sector, or to exclude housing and focus for instance on nonfinancial corporations. On one hand, the savings of households include all assets, in particular housing; on the other hand, the housing sector may need to be modeled differently, or we might want to explicitly recognize the heterogeneity of capital goods. We will in this section present indicators that cover both, but our estimation targets will cover the entire private sector. For the most part, the trends that we document are apparent both for nonfinancial corporations and in the aggregate.

\subsection{Graphical evidence}

We summarize the evolution of the six groups of indicators as six facts.

\section{Fact \#1: Real risk-free interest rates have fallen substantially}

The top panels of figure 1 present proxies for the one-year and ten-year real interest rates by substracting inflation expectations from nominal Treasury yields. ${ }^{2}$ As many authors have noted before, there has been a strong downward trend in these measures since 1984. The short-rate exhibits some clear cyclical fluctuations, while the long rate has a smoother decline. Table 1 shows that the average

\footnotetext{
${ }^{2}$ We use median consumer price inflation expectations from the Philadelphia Fed survey of professional forecasters (SPF). Very similar results for the trend are obtained if one uses the mean expectation rather than the median; or the Michigan survey of consumers rather than the SPF. For the one-year rate, one can also replace expectations with ex-post inflation or lagged inflation. For the ten-year rate, one can also use the TIPS yield where available (i.e. post 1997).
} 
one-year rate falls from around $2.8 \%$ in the first half of our sample (1984-2000) to $-0.3 \%$ in the second half of our sample (2001-2016). The long-term rate similarly falls from $3.9 \%$ in the first half to $1.1 \%$ in the second half.

Fact \#2: The profitability of private capital has remained stable or increased slightly

In contrast, there is little evidence that the return on private capital has fallen; if anything, it appears to have increased slightly. Gomme, Ravikumar and Rupert (2011; thereafter GRR) construct from national income (NIPA) data a measure of aggregate net return on physical capital, roughly profits over capital. The bottom left panel of figure 1 depicts their series. The rising spread between their measure, which can be thought as a proxy for the marginal product of capital, and the interest rate on US Treasuries, is an important trend to be explained for macro- and financial economists.

GRR construct their series using detailed data from NIPA and other sources, but one can construct a simple approximation using the ratio of operating surplus to capital for the nonfinancial corporate sector; Table 1 show that this ratio is also fairly constant. In our estimation exercise, we will focus on gross profitability, and, to ensure consistency between our measures, will construct it simply as the ratio of the profit-output ratio that we will use (i.e., one minus the labor share) to the capital-output ratio. This measure is depicted in the bottom right panel of figure 1; the overall level is higher, in part because it is gross rather than net, but the trend is similar to the GRR measure.

\section{Fact \#3: Valuation ratios are stable or have increased moderately}

The top two panels of figure 2 present measures of valuation ratios for the US stock market. The top left panel shows the ratio of price to dividends from CRSP, while the top right panel shows the priceoperating earnings ratio for the SP500. ${ }^{3}$ The later is essentially trendless, while the former exhibits a large boom and bust in 2000 before settling down to a higher value. Another commonly used valuation ratio is the price-smoothed earnings ratio of Shiller (CAPE), which divides the SP500 price by a ten-year moving average of real earnings, and is reported in table 1 . While all these ratios are quite volatile, overall they exhibit only a moderate increase from the first period to the second period. Our analysis will emphasize that this limited increase is puzzling given the large decline of the risk-free rate (Fact $\# 1)$.

\section{Fact \#4: The share of investment in output or in capital has fallen slightly}

The bottom two panels of figure 2 depict the behavior of investment. As several authors have noted recently (e.g. Eberly and Lewis (2016), Gutierrez and Philippon (2017)), investment has been relatively lackluster over the past decade or more; but the magnitude of this decline is quite different depending on how exactly one measures it. Because the price of investment goods falls relative to the price of consumption goods, it is simpler to focus on the expenditure share of GDP (left panel) or the ratio of nominal investment to capital (evaluated at current cost; right panel). Both ratios ought to be stationary in standard models, and they appear nearly trendless over long samples. Investment

\footnotetext{
${ }^{3}$ We focus on operating earnings which exclude exceptional items such as write-offs and hence are less volatile. In particular, total earnings were negative in 2008Q4 because banks marked down the values of their assets substantially.
} 

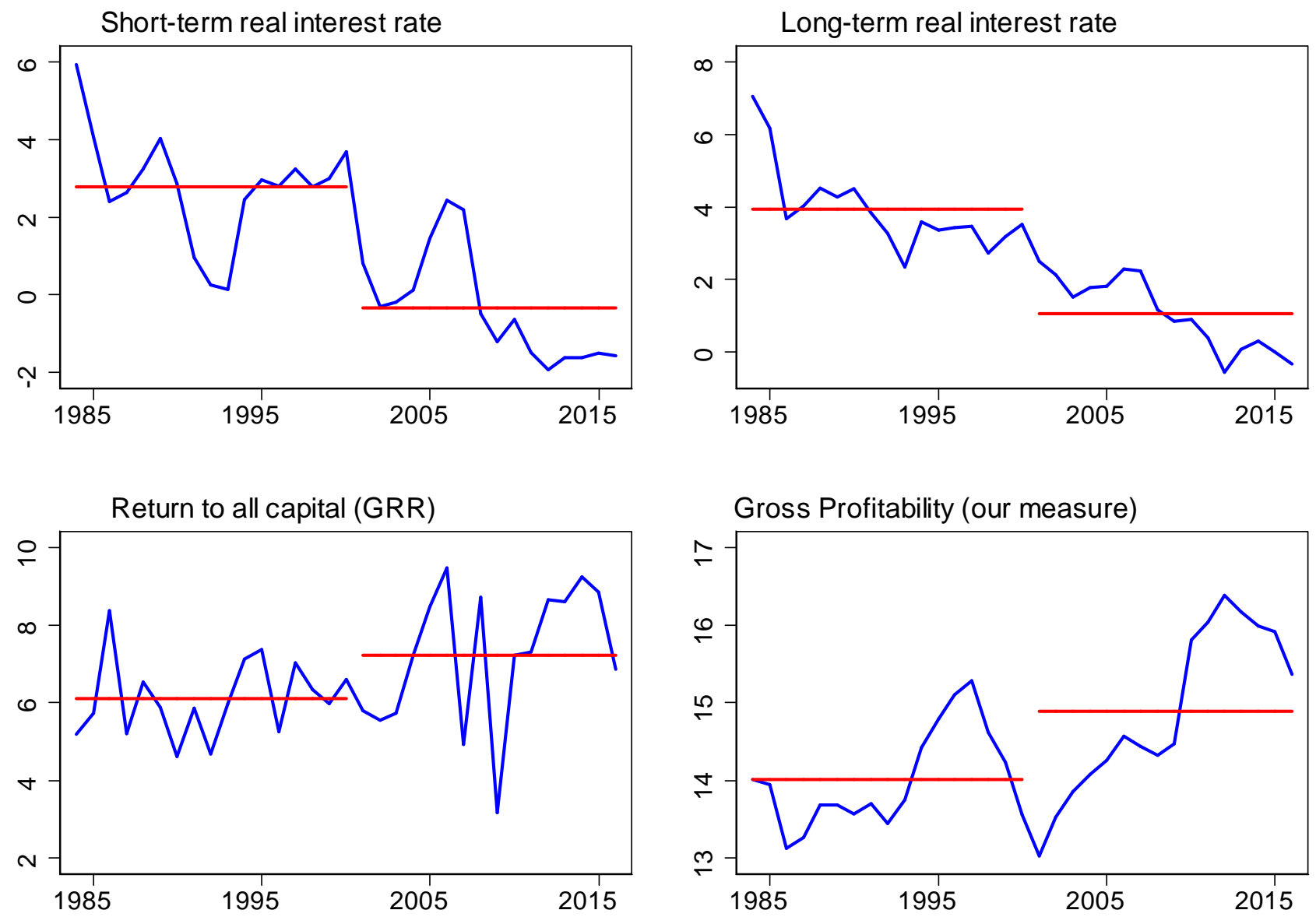

Figure 1: The top left panel displays the difference between the 1-year Treasury bill rate and the median 1-year ahead CPI inflation expectations from the Survey of Professional Forecasters (SPF). The top right panel displays the difference between the 10-year Treasury note rate and the median 10-year ahead CPI inflation expectations from the SPF. The bottom left panel presents the estimate of the pretax return on all capital from Gomme, Ravikumar and Rupert (2011). The bottom right panel presents our measure of gross profitability, the ratio of (1-labor share) to the capital-output ratio. The horizontal lines represent the mean in the first and second half of the samples (1984-2000 and 2001-2016 respectively). 

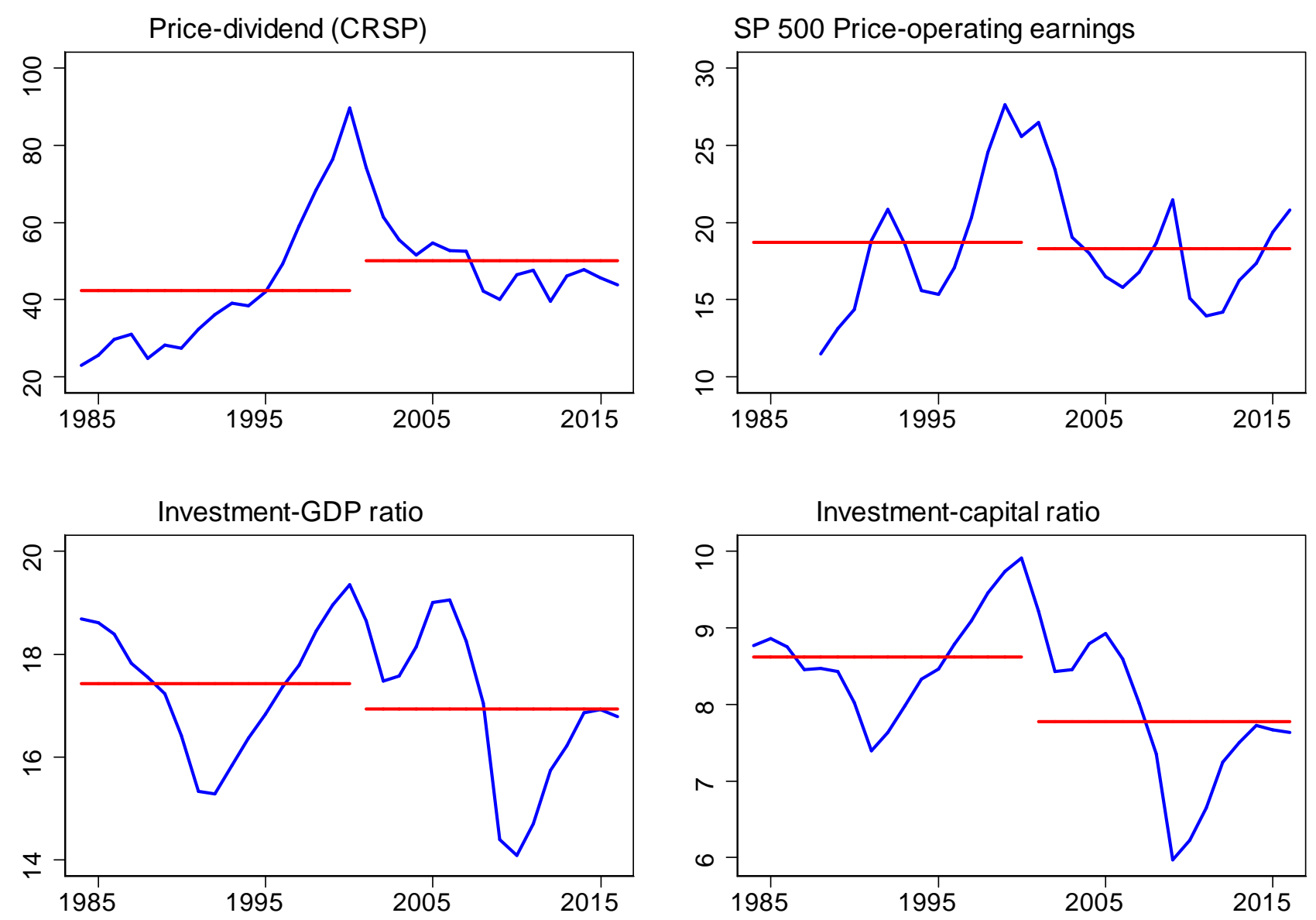

Figure 2: The top left panel displays the price-dividend ratio from CRSP. The top right panel shows the ratio of price to operating earnings for the SP500. The bottom left panel is the ratio of nominal investment spending to nominal GDP. The bottom right panel is the ratio of nominal investment to capital (at current cost). The horizontal lines represent the mean in the first and second half of the samples (1984-2000 and 2001-2016 respectively). 
spending exhibits a strong cyclical pattern, increasing faster than GDP during expansions and falling faster than GDP during recessions, but overall both ratios appear to exhibit small to moderate declines across our two subsamples. Table 1 also reports the ratios for the nonresidential sector (i.e., business fixed investment), which behaves very similarly, indicating that our results are not driven by housing. Note that business fixed investment includes equipment, structures and intellectual property products. The table also reports two measures of the evolution of the capital-output ratio; first, the ratio of capital at current cost to GDP; and second, the ratio of a real index of capital services ${ }^{4}$ (from the BLS) to real output.(which we normalize to one in 1984). Both ratios exhibit an increase of about $0.15 .^{5}$

\section{Fact \#5: Total factor productivity and investment-specific growth have slowed down, and the employment-population ratio has fallen}

There has been much public discussion that overall GDP growth has declined over the past couple of decades. This decline is in part attributable to a decline in the employment/population ratio, largely due to demographic factors (Aaronson et al. (2015)), shown as the top right panel in Figure 3. However, the decline between the two samples in output per worker growth is still large, from $1.8 \%$ per year to $1.2 \%$ per year according to table 1 . This decline is largely driven by lower total factor productivity (TFP) growth and lower investment-specific technical progress. Table 1 shows that the growth rate of the Fernald TFP measure goes from $1.1 \%$ per year to less than $0.8 \%$ per year, while the growth rate of the relative price of investment goods to nondurable and service consumption goes from $-1.8 \%$ per year to $-1.1 \%$ per year. These series are depicted in the bottom panels of Figure 3 .

\section{Fact \#6: The labor share has fallen}

Finally, the top left panel of figure 3 presents a measure of the gross labor share for the nonfinancial corporate sector; table 1 also includes a measure that covers the entire US economy. As has been noted by many authors (e.g., Karabarbounis and Neiman (2013); Elsby et al. (2013); Rognlie (2015)), the labor share exhibits a decline especially after 2000 in the United States.

Of course, all of these facts are somewhat difficult to ascertain graphically given the short samples and the noise in some series. This leads us to evaluate next the statistical significance of these changes.

\subsection{Statistical evaluation}

To summarize the trends in these series in a more formal way, Table 1 reports several statistics for the series presented in figures 1-3 above as well as for some alternative series that capture the same concepts. Columns 1-4 report the means in the first and second subsamples, which are depicted in figures 1-3 as horizontal lines, together with standard errors. Column 5 reports the difference between the means in the second and first sample, and column 6 is the associated standard error. Column 7 is the regression

\footnotetext{
${ }^{4}$ This index aggregates underlying capital goods using rental prices, which is the correct measure for an aggregate production function. In contrast, the capital at current cost is a nominal value which sums purchase prices.

${ }^{5}$ Over the long term, these ratios behave differently. The BLS index exhibits an upward trend since the mid 1970s due to the decline of the price of investment goods, but this trend has slowed down recently. In contrast, the current cost capital/output ratio is nearly trendless.
} 
Business sector gross labor share

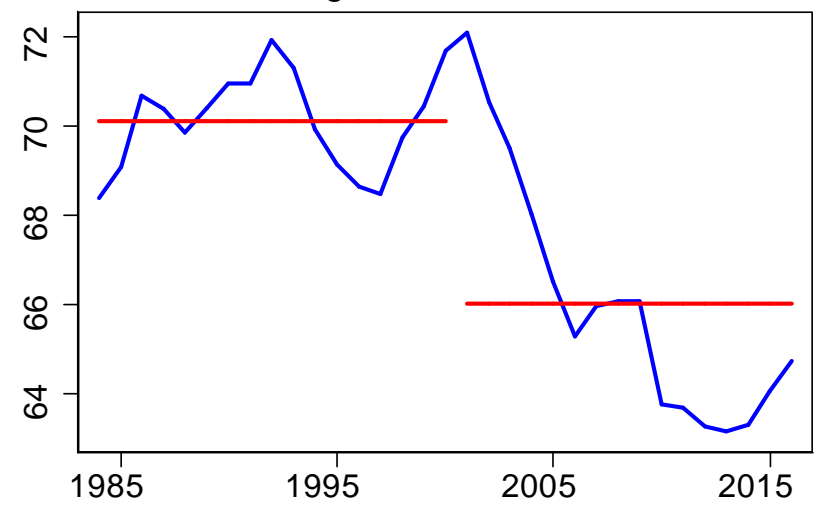

TFP growth

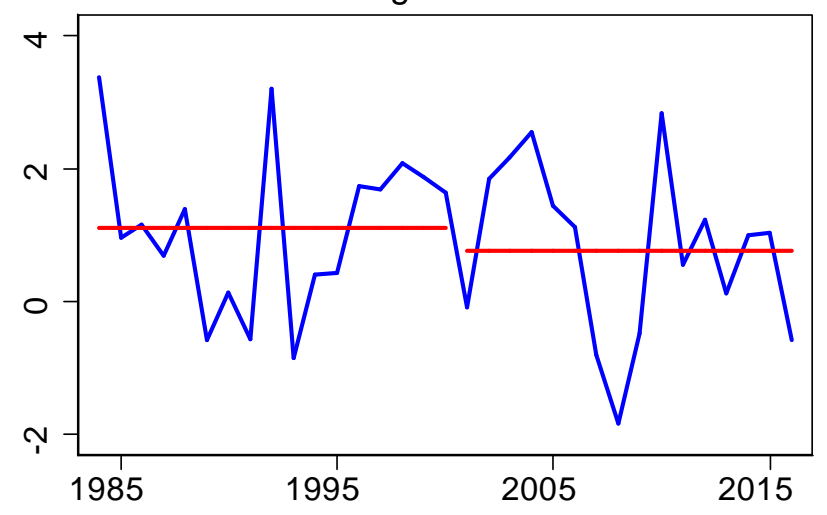

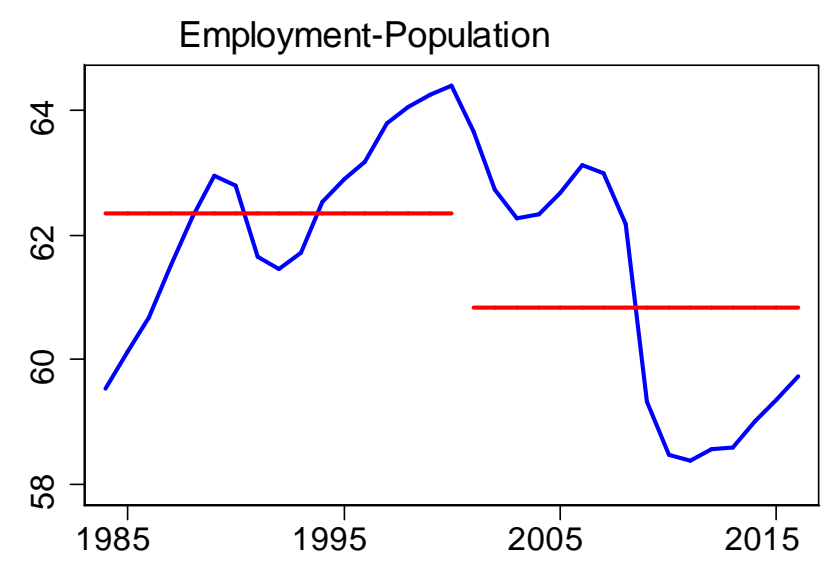

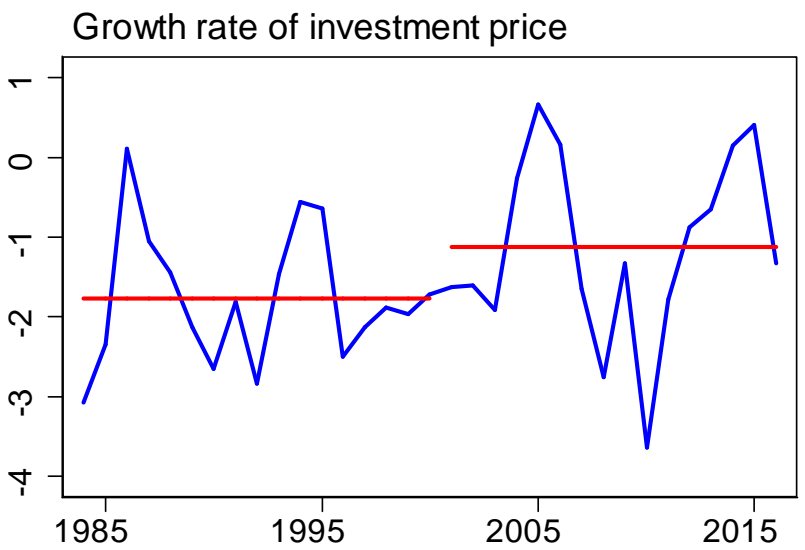

Figure 3: The top left panel shows the gross labor share for the nonfinancial corporate sector, measured as the ratio of nonfinancial business labor compensation to gross nonfinancial business value added. The top right panel is the employment-population ratio. The bottom left panel shows the growth rate of total factor productivity (TFP). The bottom right panel is the growth rate of the relative price of investment goods and consumption goods. The horizontal lines represent the mean in the first and second half of the samples (1984-2000 and 2001-2016 respectively). 
coefficient of the variable of interest on a linear time trend, and column 8 is the associated standard error. (All standard errors are calculated using the Newey-West method with five (annual) lags.)

For some indicators, there is little evidence of a break between the samples, while for others, there is overwhelming evidence of a break. Specifically, interest rates, the labor share, total factor productivity growth, and the investment-capital ratios are markedly lower in the second sample. On the other hand, valuation ratios and the return on capital appear fairly stable.

\subsection{Longer historical trends}

Figure 4 presents the evolution of nine of the moments we described above, but over a longer sample, since 1950. (These nine moments will be our estimation target below.) For clarity, we add a 11-year centered moving average to each series, so we depict the evolution from 1955 to 2011. One motivation for studying a longer sample is that real interest rates were also low in the 1970s and to some extent the 1960s, and hence one question is whether the abnormal period is the early 1980s when real interest rates were very high. The figure shows, however, that the similarities between the 1960s or 1970s and the 2000s are limited to a few variables. It is true that profitability was high in the 1960s, but the pricedividend ratio was lower, and the labor share and the investment-capital ratio were relatively high, in contrast to the more recent period. Overall, neither the 1960s nor the 1970s are similar in all respects to the 2000s. Moreover, a serious consideration of the role of inflation is warranted to study the 1970s and early 1980s, as inflation likely affected many of the macroeconomic aggregates depicted here. This is why, for now, we focus on the post 1984 sample. However we present below some results starting in 1950 to illustrate what our approach implies for these earlier periods.

\section{Model}

This section introduces a simple model to account for the macro-finance moments. Our framework adds macroeconomic risk and monopolistic competition to the standard neoclassical growth model. Given our focus on medium-run issues, we abstract from nominal rigidities and adjustment costs.

\subsection{Model setup}

We consider a standard dynastic model with inelastic labor supply. In order to highlight the role of risk, we use Epstein-Zin preferences:

$$
V_{t}=\left((1-\beta) L_{t} c_{p c, t}^{1-\sigma}+\beta E_{t}\left(V_{t+1}^{1-\theta}\right)^{\frac{1-\sigma}{1-\theta}}\right)^{\frac{1}{1-\sigma}},
$$

where $V_{t}$ is utility, $L_{t}$ is population size (which is exogenous and deterministic), $c_{p c, t}$ is per-capita consumption at time $t, \sigma$ is the inverse of the intertemporal elasticity of substitution of consumption, and $\theta$ the coefficient of relative risk aversion. We assume that labor supply is exogenous and equal to $N_{t}=\bar{N} L_{t}$, where $\bar{N}$ is a parameter that captures the employment-population ratio. 


\begin{tabular}{|c|c|c|c|c|c|c|c|c|c|}
\hline \multirow[t]{2}{*}{ Group } & \multirow[t]{2}{*}{ Variable } & \multicolumn{6}{|l|}{ Averages } & \multicolumn{2}{|l|}{ Trend } \\
\hline & & $1984-^{\prime} 00$ & $\mathrm{SE}$ & 2001-'16 & $\mathrm{SE}$ & Diff. & $\mathrm{SE}$ & Coeff. & $\mathrm{SE}$ \\
\hline \multirow[t]{4}{*}{ Real interest rate } & One-year maturity* & 2.79 & .45 & -.35 & .59 & -3.14 & .75 & -.17 & .02 \\
\hline & Ten-year maturity & 3.94 & .41 & 1.06 & .46 & -2.88 & .69 & -.18 & .01 \\
\hline & AA rate & 4.69 & .48 & 1.09 & .57 & -3.6 & .8 & -.21 & .02 \\
\hline & Ten-year adj. for term premium & 1.52 & .26 & -.09 & .35 & -1.61 & .4 & -.08 & .02 \\
\hline \multirow[t]{4}{*}{ Return on capital } & GRR: all, pretax & 6.1 & .2 & 7.24 & .45 & 1.14 & .45 & .07 & .02 \\
\hline & GRR: business, pretax & 8.59 & .32 & 10.46 & .62 & 1.87 & .62 & .11 & .03 \\
\hline & Nonfin. corps. GOS/NRK & 7.59 & .34 & 7.87 & .36 & .27 & .51 & .04 & .01 \\
\hline & Gross profitability* (see text) & 14.01 & .26 & 14.89 & .49 & .88 & .6 & .07 & .02 \\
\hline \multirow[t]{3}{*}{ Valuation ratios } & Price-dividend ratio* CRSP & 42.34 & 8.56 & 50.11 & 3.4 & 7.78 & 8.39 & .67 & .36 \\
\hline & Price-operating earnings SP500 & 18.7 & 2 & 18.31 & 1.09 & -.39 & 1.75 & .03 & .12 \\
\hline & Price-smoothed earnings Shiller & 22.07 & 4.41 & 24.36 & 1.25 & 2.29 & 4.5 & .33 & .17 \\
\hline \multirow[t]{4}{*}{ Investment } & Investment share in GDP & 17.43 & .53 & 16.93 & .65 & -.5 & .76 & -.04 & .04 \\
\hline & Nonres. invest. share in GDP & 12.94 & .40 & 12.79 & .18 & -.15 & .43 & 0 & .02 \\
\hline & Investment-capital: all* & 8.1 & .25 & 7.23 & .35 & -.88 & .38 & -.04 & .02 \\
\hline & Investment-cap.: nonresidential & 10.95 & .39 & 10.2 & .24 & -.76 & .4 & -.03 & .02 \\
\hline \multirow[t]{2}{*}{ Capital-output } & Fixed asset & 2.13 & .03 & 2.28 & .03 & .15 & .04 & .01 & 0 \\
\hline & Real index (BLS) & 1.06 & .02 & 1.18 & .01 & .13 & .02 & .01 & 0 \\
\hline \multirow[t]{2}{*}{ Labor share } & Nonfarm business (BLS) gross & 62.07 & .31 & 58.56 & 1.01 & -3.51 & 1.11 & -.21 & .04 \\
\hline & Nonfinancial corps. gross* & 70.11 & .34 & 66.01 & 1.21 & -4.1 & 1.29 & -.24 & .05 \\
\hline \multirow[t]{8}{*}{ Growth } & Output per worker & 1.80 & .22 & 1.22 & .23 & -.58 & .29 & -.03 & .02 \\
\hline & Total factor productivity* & 1.10 & .31 & .76 & .32 & -.34 & .36 & -.02 & .02 \\
\hline & Population* & 1.17 & .08 & 1.1 & .06 & -.07 & .08 & 0 & 0 \\
\hline & Price of investment: all* & -1.77 & .15 & -1.13 & .34 & .64 & .26 & .03 & .02 \\
\hline & Price of investment: nonresid. & -2.38 & .19 & -1.75 & .29 & .63 & .25 & .04 & .02 \\
\hline & Price of invt: equipment & -3.62 & .60 & -3.27 & .53 & .34 & .72 & .02 & .04 \\
\hline & Price of invt: IPP & -1.71 & .30 & -2.15 & .36 & -.44 & .52 & 0 & .02 \\
\hline & Employment-pop. ratio* & 62.34 & .58 & 60.84 & 0.94 & -1.51 & 1.06 & -.07 & .06 \\
\hline
\end{tabular}

Table 1: The table reports, for each variable, the mean in the 1984-2000 sample, in the 2001-2016 sample, their difference, and the coefficient on a linear time trend, all with standard errors. Stars indicate moments targeted in our estimation exercise. GRR stands for Gomme, Ravikumar and Rupert (2011), GOS for gross operating surplus, NRK for non-residential capital, and IPP for intellectual property products. Variables' construction is detailed in the appendix. 

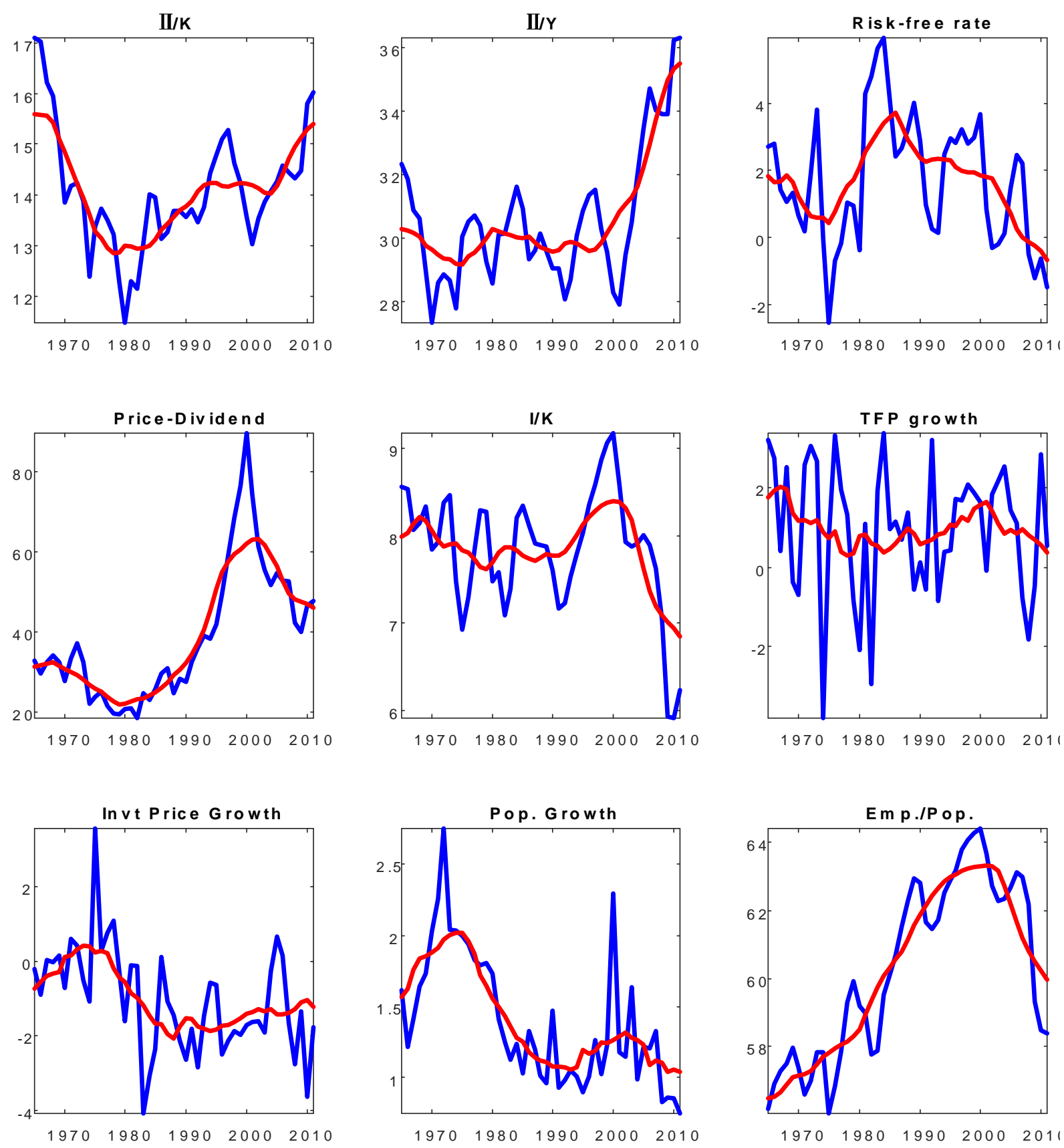

Figure 4: This figure presents the nine series used in our estimation exercise over the 1955-2011 sample, together with a 11-year centered moving average. 
Final output is produced using constant return to scale from differentiated inputs,

$$
Y_{t}=\left(\int_{0}^{1} y_{i t^{\frac{\varepsilon-1}{\varepsilon}}} d i\right)^{\frac{\varepsilon}{\varepsilon-1}},
$$

where $\varepsilon>1$ is the elasticity of substitution. These intermediate goods are produced using a CobbDouglas production function,

$$
y_{i t}=Z_{t} k_{i t}^{\alpha}\left(S_{t} n_{i t}\right)^{1-\alpha},
$$

where $k_{i t}$ and $n_{i t}$ are capital and labor in firm $i$ at time $t, Z_{t}$ is an exogenous deterministic productivity trend, and $S_{t}$ is a stochastic productivity process, which we assume to be a martingale:

$$
S_{t+1}=S_{t} e^{\chi_{t+1}}
$$

where $\chi_{t+1}$ is iid.

Capital is accumulated using a standard investment technology, but is subject to an aggregate "capital quality" shock $\psi_{t+1}$, which we also assume to be iid:

$$
k_{i t+1}=\left((1-\delta) k_{i t}+Q_{t} x_{i t}\right) e^{\psi_{t+1}}
$$

Here $Q_{t}$ is an exogenous deterministic trend reflecting investment-specific technical progress as in Greenwood, Hercowitz, and Krusell (1997). The relative price of investment and consumption goods is $1 / Q_{t}$.

Capital and labor can be reallocated frictionlessly across firms at the beginning of each period after the shocks $\chi$ and $\psi$ have been realized. Given the constant-return-to-scale technology, firms then face a constant (common) marginal cost. It is easy to see (see appendix for details) that the economy aggregates to a production function

$$
Y_{t}=Z_{t} K_{t}^{\alpha}\left(S_{t} N_{t}\right)^{1-\alpha},
$$

and that markups distort the firms' first order conditions, leading to

$$
\begin{aligned}
(1-\alpha) \frac{Y_{t}}{N_{t}} & =\mu w_{t}, \\
\alpha \frac{Y_{t}}{K_{t}} & =\mu R_{t},
\end{aligned}
$$

where $\mu=\frac{\varepsilon}{\varepsilon-1}>1$ is the gross markup, $w_{t}$ is the real wage and $R_{t}$ the rental rate of capital.

Moreover, the law of motion for capital accumulation also aggregates,

$$
K_{t+1}=\left((1-\delta) K_{t}+Q_{t} X_{t}\right) e^{\psi_{t+1}}
$$

The choice of investment is determined by the (common) marginal product of capital, leading to the Euler equation:

$$
E_{t}\left[M_{t+1} R_{t+1}^{K}\right]=1
$$

where $M_{t+1}$ is the real stochastic discount factor and $R_{t+1}^{K}$ is the return on capital, which is given by:

$$
R_{t+1}^{K}=\left(\frac{\alpha Y_{t+1}}{\mu K_{t+1}}+\frac{1-\delta}{Q_{t+1}}\right) Q_{t} e^{\psi_{t+1}}
$$

This expression is a standard user cost formula, which incorporates the rental rate of capital of equation (5) but also depreciation, the price of investment goods, and the capital quality shock. Given the 
preferences assumed in equation (1), the stochastic discount factor is

$$
M_{t+1}=\beta\left(\frac{c_{p c, t+1}}{c_{p c, t}}\right)^{-\sigma}\left(\frac{V_{p c, t+1}}{E_{t}\left(V_{p c, t+1}^{1-\theta}\right)^{\frac{1}{1-\theta}}}\right)^{\sigma-\theta},
$$

where $V_{p c, t}$ is the utility normalized by population, $V_{p c, t}=V_{t} / L_{t}^{1 /(1-\sigma)}$.

The resource constraint reads

$$
C_{t}+X_{t}=Y_{t},
$$

where $C_{t}=L_{t} c_{p c, t}$ is total consumption, and $X_{t}$ are investment expenses measured in consumption good units.

The equilibrium of this economy is $\left\{c_{p c, t}, C_{t}, X_{t}, K_{t}, Y_{t}, R_{t+1}^{K}, M_{t+1}, V_{p c, t}, V_{t}\right\}$ that solve the system of equations (1)-(10), given the exogenous processes $\left\{L_{t}, Z_{t}, Q_{t}, S_{t}, \chi_{t+1}, \psi_{t+1}\right\}$. As is well known, such a model admits in general no closed form solution. Many authors build their intuition by studying either the nonstochastic steady-state or numerical approximations. This makes it somewhat difficult to understand the role that macroeconomic risk plays. We will show, in contrast, that for an interesting special case, our model can be solved easily for a "risky balanced growth path".

\section{$3.2 \quad$ Risky balanced growth}

We make two simplifying assumptions. First, to obtain a balanced growth path, we make the usual assumption that the exogenous trends (population $L_{t}$, total factor productivity $Z_{t}$, and investmentspecific technical progress $Q_{t}$ ) all grow at (possibly different) constant rates, so that $L_{t+1} / L_{t}=1+g_{L}$, $Z_{t+1} / Z_{t}=1+g_{Z}, Q_{t+1} / Q_{t}=1+g_{Q}$ for all $t \geq 0$. Second, we assume that the productivity shock and capital quality shock are equal:

$$
\chi_{t+1}=\psi_{t+1} .
$$

In that case, it is straightforward to verify that the equilibrium has the following structure:

$$
\begin{aligned}
X_{t} & =T_{t} S_{t} x^{*} \\
Y_{t} & =T_{t} S_{t} y^{*}
\end{aligned}
$$

and similarly for $C_{t}$, while for capital and utility we have $K_{t}=T_{t} S_{t} Q_{t} k^{*}$ and $V_{t}=L_{t}^{\frac{\sigma}{1-\sigma}} T_{t} S_{t} v^{*}$. Here the lower case starred values denote constants; $S_{t}$ is the stochastic trend defined in equation (2) corresponding to the accumulation of past productivity/capital quality shocks $\chi_{t}$; and $T_{t}$ is a deterministic trend defined as:

$$
T_{t}=L_{t} Z_{t}^{\frac{1}{1-\alpha}} Q_{t}^{\frac{\alpha}{1-\alpha}}
$$

which growth rate is denoted $g_{T}$ and satisfies the usual condition:

$$
1+g_{T}=\left(1+g_{L}\right)\left(1+g_{Z}\right)^{\frac{1}{1-\alpha}}\left(1+g_{Q}\right)^{\frac{\alpha}{1-\alpha}}
$$

where $\alpha$ is the Cobb-Douglas parameter, $g_{Q}$ the rate of growth of investment-specific technical progress, $g_{L}$ is population growth, and $g_{Z}$ is productivity growth. The trend growth rate of output per capita is:

$$
1+g_{P C}=\frac{1+g_{T}}{1+g_{L}} .
$$


Finally, the stochastic discount factor is

$$
M_{t+1}=\beta\left(1+g_{P C}\right)^{-\sigma} e^{-\theta \chi_{t+1}} E\left(e^{(1-\theta) \chi_{t+1}}\right)^{\frac{\theta-\sigma}{1-\theta}},
$$

where $\theta$ is risk aversion and $\sigma$ the inverse of the IES. We can then easily calculate all objects of interest in the model, including $x^{*}, y^{*}$, as we show in the next section and in the appendix.

Figure 5 presents an example of the time series produced by the model. The equilibrium corresponds to a "balanced growth path", but one where macroeconomic risk still affects decisions and realizations. Specifically, the realization of the macroeconomic shock $\chi_{t+1}$ affects the stochastic trend $S_{t+1}$ and hence $X_{t+1}, Y_{t+1}$, etc., while the effect of risk, on the other hand, is reflected in the constants $x^{*}, y^{*}$. The bottom line is that the "big ratios" such as $I_{t} / Y_{t}, \Pi_{t} / Y_{t}, \Pi_{t} /\left(K_{t} / Q_{t}\right)$, etc. are constant, as in the standard Kaldor calculations, but now incorporate risk; we discuss these ratios in the next section. ${ }^{6}$ This result holds regardless of the probability distribution of $\chi_{t+1}$.

The treatment of deterministic trends is completely standard. What is less standard is that in our model, a common stochastic trend affect all variables equally, which generates great tractability. In the standard RBC model, there are no capital quality shocks, i.e. $\psi_{t+1}=0$, and a (permanent) productivity

shock $\chi_{t+1}$ leads to a transition as the economy adjusts its capital stock to the newly desired level, before eventually reaching the new steady-state. By assuming $\chi_{t+1}=\psi_{t+1}$, this transition period is eliminated because the capital stock "miraculously" adjusts by the correct amount. This simplifies the solution of the model because agents' expectations of future paths are now easy to calculate. ${ }^{7,8}$ The capital quality shock is also important if the economy is to generate a significant equity premium, for it makes the return on capital volatile rather than bounded below by $1-\delta$.

\subsection{Model implications}

This section presents model implications for the "big ratios" and other key moments of interest along the risky balanced growth path. We will present the Euler equation, which leads to a standard user cost calculation, then discuss valuation ratios and rate of returns.

It is useful to define the composite parameter

$$
\beta^{*}=E_{t}\left(M_{t+1} e^{\chi_{t+1}}\right)
$$

which equals

$$
\beta^{*}=\beta\left(1+g_{P C}\right)^{-\sigma} \times E\left(e^{(1-\theta) \chi_{t+1}}\right)^{\frac{1-\sigma}{1-\theta}}
$$

and its rate of return version $r^{*}=1 / \beta^{*}-1 \simeq-\log \beta^{*}$, which satisfies

$$
r^{*} \simeq \rho+\sigma g_{P C}+\sigma \frac{1-1 / \sigma}{1-\theta} \log E\left(e^{(1-\theta) \chi_{t+1}}\right),
$$

\footnotetext{
${ }^{6}$ Of course, the economy can also exhibit transitional dynamics if its initial capital is too low or too high, before it reaches the balanced growth path.

${ }^{7}$ Since we will not study the actual responses to $\chi_{t+1}$ shocks, there is little loss in this simplification: what is key for us is that agents regard the future as uncertain, and that bad realizations of $\chi_{t+1}$ will have reasonable consequences (e.g. a low return on capital), which lead agents ex-ante to adjust their choices (e.g. investment).

${ }^{8}$ This argument (formulated in Gabaix (2011) and Gourio (2012)) can be applied to larger models; for instance see Gourio, Kashyap and Sim (2018) or Isore and Szczerbowicz (2018) for New Keynesian models with disaster risk.
} 

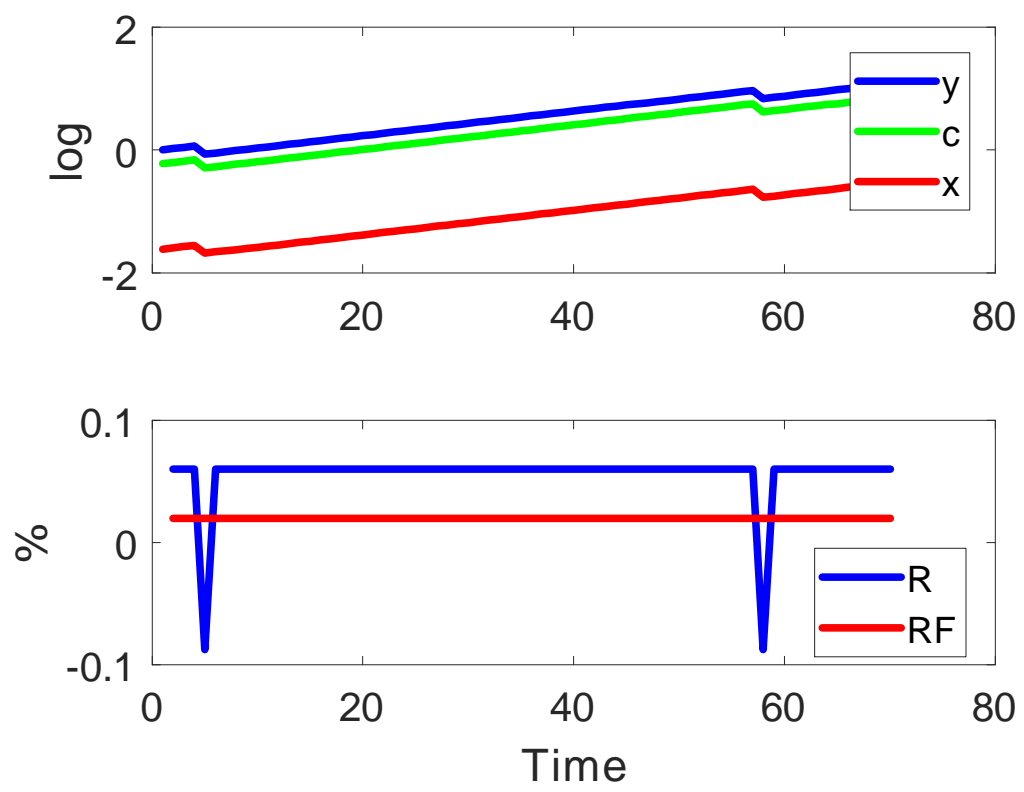

Figure 5: The figure presents an example of the time series generated by the model. Top panel: output, consumption and investment (in log); bottom panel: return on capital and risk-free rate. In this example, the economy is affected by two realizations of $\chi$ shocks, at $t=4$ and $t=57$.

where $\rho=1 / \beta-1 \simeq-\log \beta .^{9}$ The parameter $r^{*}$ will turn out to equal in equilibrium the expected return on capital, and to be a "sufficient statistic" to solve for the "big ratios" - that is, we do not need to know $\rho$ (i.e. $\beta), \theta, \sigma$, or the distribution of $\chi$, but only $r^{*}$.

\subsubsection{Capital accumulation}

To solve the model, we use the Euler equation (7), which along the risky balanced growth path reads

$$
\frac{1}{\beta^{*}}=\left(\frac{\alpha}{\mu} Q^{*}\left(\frac{k^{*}}{\bar{N}}\right)^{\alpha-1} \frac{1}{1+g_{Q}}+\frac{1-\delta}{1+g_{Q}}\right),
$$

where $Q^{*}$ is the level of investment technical progress $Q_{t}$, i.e. $Q_{t}=Q^{*}\left(1+g_{Q}\right)^{t}$; so $1 / Q^{*}$ affects the level of the relative price of investment and consumption. This equation pins down $k^{*}$ and the capital-labor ratio, and it generalizes the familiar condition of the neoclassical growth model to incorporate risk, through $\beta^{*}$. We can rewrite this as the equality of the user cost of capital and marginal revenue:

$$
\frac{1}{Q^{*}}\left(r^{*}+\delta+g_{Q}\right) \approx \frac{\alpha}{\mu}\left(\frac{k^{*}}{N^{*}}\right)^{\alpha-1}
$$

Equation (16) directly shows how higher market power or a higher required risky return lower the desired capital-labor ratio.

To calculate the other big ratios, first note that $K_{t} / Q_{t}$ is the capital stock, evaluated at current cost. The capital-output ratio is obtained from equation (16) as:

$$
\frac{K_{t} / Q_{t}}{Y_{t}} \approx \frac{\alpha}{\mu} \frac{1}{r^{*}+\delta+g_{Q}},
$$

\footnotetext{
${ }^{9}$ Here and thereafter, the $\simeq$ signs reflects the first-order approximation $\log (1+x) \simeq x \simeq 1 /(1-x)$.
} 
and the investment-capital ratio is

$$
\frac{X_{t}}{K_{t} / Q_{t}} \approx g_{Q}+g_{T}+\delta
$$

which reflects the familiar balanced growth relation. Last, the investment-output ratio is obtained by combining equations (17) and (18):

$$
\frac{X_{t}}{Y_{t}} \approx \frac{\alpha}{\mu} \frac{g_{T}+\delta+g_{Q}}{r^{*}+\delta+g_{Q}}
$$

\subsubsection{Income Distribution}

The labor share in gross value added is, using equation (4):

$$
s_{L}=\frac{w_{t} N_{t}}{Y_{t}}=\frac{1-\alpha}{\mu},
$$

and hence the measured capital share is

$$
s_{K}=1-s_{L}=\frac{\mu+\alpha-1}{\mu} .
$$

This capital share can be decomposed into a pure profit share, that rewards capital owners for monopoly rents, and a true capital remuneration share, corresponding to rental payments to capital, i.e. $s_{K}=$ $s_{\pi}+s_{C}$, with

$$
s_{\pi}=\frac{\mu-1}{\mu}
$$

and

$$
s_{C}=\frac{\alpha}{\mu}
$$

\subsubsection{Valuation ratios}

The firm value is the present discounted value of the dividends $D_{t}=\Pi_{t}-X_{t}$. In equilibrium, this value equals the value of installed capital plus monopolistic rents. Formally, the ex-dividend firm value $P_{t}$ satisfies the standard recursion,

$$
P_{t}=E_{t}\left(M_{t+1}\left(P_{t+1}+D_{t+1}\right)\right) .
$$

Given that the equilibrium is iid, the price-dividend ratio is constant, and satisfies the familiar Gordon formula:

$$
\frac{P^{*}}{D^{*}}=\frac{\beta^{*}\left(1+g_{T}\right)}{1-\beta^{*}\left(1+g_{T}\right)} \approx \frac{1+g_{T}}{r^{*}-g_{T}} .
$$

Tobin's $Q$ is defined as

$$
\frac{P_{t}}{K_{t} / Q_{t}} \approx\left(1+g_{T}\right)\left(1+\frac{\mu-1}{\alpha} \frac{r^{*}+\delta+g_{Q}}{r^{*}-g_{T}}\right) .
$$

Because we do not incorporate adjustment costs, Tobin's $Q$ equals (approximately) one when there is no market power, i.e. $\mu=1 .{ }^{10}$ But if there is some market power, the value of Tobin's $Q$ depends on several parameters, which affect (i) the size of the economy and hence the rents, (ii) the discount rate applied to all future rents.

\footnotetext{
${ }^{10}$ Tobin's $Q$ is usually defined as $P_{t} /\left(K_{t+1} / Q_{t+1}\right)$, but with capital quality shocks $K_{t+1}$ is unknown at time $t$, leading us to adopt this definition, which creates the $1+g_{T}$ wedge. One could also define Tobin's $Q$ as $P_{t} /\left(E_{t} K_{t+1} / Q_{t+1}\right)$, which eliminates the wedge provided that $E_{t} e^{\chi_{t+1}}=1$, an assumption that we maintain through most of the paper.
} 


\subsubsection{Rates of Return}

We now compare three benchmark rate of returns in this economy: the risk-free rate, the return on equity, and the profitability of capital, which is often used in macroeconomics as a proxy for the marginal product of capital. The gross risk-free rate (which can be priced even though it is not traded in equilibrium) is

$$
R F=\frac{1}{E\left(M_{t+1}\right)}=\frac{E\left(e^{(1-\theta) \chi_{t+1}}\right)}{\beta^{*} E\left(e^{-\theta \chi_{t+1}}\right)}
$$

which we can rewrite as the net risk-free rate, i.e. $r^{f}=R F-1$ :

$$
r_{f} \approx r^{*}+\log E\left(e^{(1-\theta) \chi_{t+1}}\right)-\log E\left(e^{-\theta \chi_{t+1}}\right) .
$$

The average profitability of capital can be inferred, as in Gomme, Ravikumar and Rupert (2011) and Mulligan (2002), as the ratio of (measured) profits to the stock of capital. This can be calculated either gross or net of depreciation. For instance, in gross terms, we have

$$
\begin{aligned}
M P K & =\frac{\Pi_{t}}{K_{t} / Q_{t}}, \\
& =\frac{\mu+\alpha-1}{\alpha}\left(r^{*}+\delta+g_{Q}\right) .
\end{aligned}
$$

Conceptually, this $M P K$ exceeds the risk-free rate for three reasons; first, it is gross of both physical and economic depreciation; second, it incorporates profit rents; third, it is risky. We can decompose the spread between the $M P K$ and the risk-free rate to reflect these three components:

$$
M P K-r_{f}=\delta+g_{Q}+\frac{\mu-1}{\alpha}\left(r^{*}+\delta+g_{Q}\right)+r^{*}-r_{f} .
$$

A main goal of our empirical analysis is to evaluate the importance of these different components.

The expected equity return is defined as

$$
E\left(R_{t+1}\right)=E\left(\frac{P_{t+1}+D_{t+1}}{P_{t}}\right)
$$

and it is easy to show using equation (23) that

$$
E\left(R_{t+1}\right)=\frac{1}{\beta^{*}} E\left(e^{\chi_{t+1}}\right) .
$$

In the case where $E\left(e^{\chi_{t+1}}\right)=1$, which we will use in our applications, the gross expected return on equity is exactly $1 / \beta^{*}$, and the net return is $r^{*}$. The same expected return also applies the return on physical capital $R_{t+1}^{K}=\left(\frac{\alpha Y_{t+1}}{\mu K_{t+1}}+\frac{1-\delta}{Q_{t+1}}\right) Q_{t} e^{\chi_{t+1}}$ defined in equation (8). Conceptually, the firm value here stems from capital and rents, but it turns out that both components have equal risk exposure and hence equal expected returns.

Finally, the equity risk premium $E R P$ is obtained by combining equations (25) and (28):

$$
E R P=\frac{E\left(R_{t+1}\right)}{R_{f, t+1}}=\frac{E\left(e^{-\theta \chi_{t+1}}\right) E\left(e^{\chi_{t+1}}\right)}{E\left(e^{(1-\theta) \chi_{t+1}}\right)} .
$$

\subsection{Comparative statics}

We now use the expressions developed in the previous section to illustrate some key comparative statics of the risky balanced growth path. These comparative statics are useful to understand identification of 
our model. Most of the parameters have the usual effects; we will focus on parameters that are typically absent from the neoclassical growth model, or parameters that play an important role in our empirical results.

\subsubsection{Effect of risk}

The effect of higher risk on macroeconomic variables is mediated through $\beta^{*}$. The cleanest thought experiment is to consider a shift of the distribution of the shock $\chi$ in the sense of second-order stochastic

dominance, so that $\chi$ becomes more risky. Such a shift reduces $E\left(e^{(1-\theta) \chi}\right)^{\frac{1}{1-\theta}}$, and hence leads to a lower $\beta^{*}$ if and only if $\sigma<1$, i.e. the intertemporal elasticity of substitution is greater than unity. A lower $\beta^{*}$ in turn leads to a lower capital-output ratio, a lower investment-output ratio, and a higher profit-capital ratio, according to equations (17), (19), and (26) respectively. The logic is that risk deters investment in that case, leading to less capital accumulation. This reduction in the supply of capital increases the marginal product of capital given a stable demand for capital. Moreover, as is well known in the macro-finance literature, and as shown by equation (23), higher risk decreases the $P D$ ratio if the IES is greater than unity. On the other hand, if the IES is low, higher risk leads to a lower expected return, and hence higher capital accumulation, and a higher price-dividend ratio. Risk has no effect on the labor share or long-term growth (though higher risk has a level effect on capital and GDP, i.e. $k^{*}$ and $\left.y^{*}\right)$. The equity risk premium $r^{*}-r_{f}$ is increasing in risk, regardless of the IES. The spread between the $M P K$ and the risk-free rate is hence increasing in risk, at least if $\mu$ is small enough so that the middle term does not dominate the third term.

We have not specified the distribution of the shock $\chi$, but for some particular distributions one can obtain exact formulas. For instance, if $\chi$ is normal with variance $\sigma_{\chi}^{2}$ and mean $\mu_{\chi}=-\sigma_{\chi}^{2} / 2$, so that an increase in $\sigma_{\chi}$ is a pure increase in risk, we have, denoting $\widehat{\beta}=\beta\left(1+g_{P C}\right)^{-\sigma}$,

$$
\begin{aligned}
\log \beta^{*} & =\log \widehat{\beta}-(1-\sigma) \theta \frac{\sigma_{\chi}^{2}}{2}, \\
\log R F & =-\log \widehat{\beta}-(1+\sigma) \theta \frac{\sigma_{\chi}^{2}}{2}, \\
\log E R P & =\theta \sigma_{\chi}^{2} .
\end{aligned}
$$

These formulas capture the usual effect of risk aversion and the quantity of risk on the $E R P$ and the risk-free rate, but are now valid in a production economy, and furthermore $\beta^{*}$ links macroeconomic risk to macroeconomic variables such as the capital-output ratio as discussed above. We provide more discussion in appendix for different assumptions about the distribution of $\chi$.

\subsubsection{Effect of savings supply}

In our model, the effects of a change in the discount factor $\beta$ are the same as a change in risk, since both are mediated through $\beta^{*}$. The one exception is the risk-free rate, which is affected directly by $\beta^{*}$ but also directly by risk measures, e.g. risk aversion $\theta$ or the quantity of risk $\chi$. In the case where the IES is greater than unity, higher $\beta$ has the same implications as lower risk. Hence, higher savings supply leads to higher capital accumulation, higher investment-output ratio and a lower marginal product of capital, and a higher price-dividend ratio, while the risk-free rate falls. The spread between the $M P K$ 
and the risk-free rate, shown in equation (27) is little affected by $\beta$ : $\beta$ only affects the quantity of rents through $r^{*}$, while the equity risk premium $r^{*}-r_{f}$ is independent of $\beta$.

\subsubsection{Effect of market power}

One potentially important factor that has been invoked to explain of the trends we document is market power. In our model, an increase in $\mu$ has no effect on long-term growth, the risk-free rate, or the pricedividend ratio, but it has a significant effect on other variables. Higher markups reduce both the labor share and the "true capital share" $s_{c}$, but increases the pure profit share $s_{\pi}$. According to equations (19) and (17), higher market power also reduces investment-output and capital-output ratios, as firms have less incentive to build capacity. The spread between the $M P K$ and the risk-free rate is increasing in market power (equation (27)). Finally, higher market power reduces the level of GDP by reducing capital accumulation.

\subsubsection{Effect of trend growth}

Trend growth $g_{T}$ - which can traced back to productivity growth, population growth, or investmentspecific technical growth - affects $\beta^{*}$ but also affects independently the ratios of interest. Higher growth generally increases the investment-capital and investment-output ratios and increases the risk-free rate and valuation ratios, while the effect on profitability ratios depends on the exact source of growth.

\section{Accounting framework}

This section describes our empirical approach and discusses identification.

\subsection{Methodology}

We use a simple method of moment estimation. In the interest of clarity and simplicity, we perform an exactly identified estimation with 9 parameters and 9 moments. In a first exercise, we estimate the model separately over our two samples: 1984-2000 and 2001-2016. We then discuss which parameters drive variation in each moment. In a second exercise, we estimate the model over 11-year rolling windows, starting with 1950-1961, and ending with 2006-2016. In all cases, we fit the model risky balanced growth path to the model moments. In doing so, we abstract from business cycle shocks, in line with our focus on longer frequencies. ${ }^{11}$

The moments we target are motivated by the observations in introduction and in the first section:

(M1) the measured gross profitability $\Pi / K$;

(M2) the measured gross capital share $\Pi / Y$;

(M3) the investment-capital ratio $I / K$;

(M4) the risk-free rate $R F$;

\footnotetext{
${ }^{11}$ This exercise involves some schizophrenia, because our model assumes that parameters are constant, even though they are estimated to change over time; and when parameters change, the model would exhibit some transitional dynamics, which we abstract from for now; see Section 6. Further, the agents inside our model do not understand that parameters might change, let alone anticipate some of these changes.
} 
(M5) the price-dividend ratio $P D$;

(M6-M8) the growth rates of population, total factor productivity, and investment prices;

(M9) the employment-population ratio.

As we will see, these moments will lead to a clear identification of our nine parameters, which are:

(P1) the discount factor $\beta$;

(P2) risk, modeled as the probability of an economic crisis or "disaster" $p$;

(P3) the markup $\mu$;

(P4) the depreciation rate of capital $\delta$;

(P5) the Cobb-Douglas parameter $\alpha$;

(P6-P8) the growth rates of total factor productivity $g_{Z}$, investment-specific progress $g_{Q}$, and population $g_{L}$;

(P9) the labor supply parameter $\bar{N}$.

The choice of moments is motivated, of course, by the questions of interest - explaining the joint evolution of interest rates, profitability, investment, valuation, and trend growth - but also by the clarity with which these moments map into estimated parameters. For instance, because we target $\Pi / K, \Pi / Y$ and $I / K$ (and that we have taken care to construct these moments in a consistent manner), the model will mechanically match the evolution of the investment-output ratio $I / Y$ or the capital-output ratio $K / Y$. Hence, we could have taken $I / Y$ as a target moment, which would have led to the exact same estimates and implications, but the identification is clearer with $I / K$. Beyond this, some changes in identification strategy are possible however; for instance, one could target the price-earnings ratio instead, or GDP growth per worker; these yield quite similar results.

We also note that the parameters can be mapped into the narratives often put forth when discussing the trends, at least at a high level; in particular, changes in longevity map into a change in the discount factor $\beta$; more generally, changes in savings supply can be captured as changes in $\beta$; changes in the competitive environment are captured by a change in $\mu$; changes in technology should be reflected in $\alpha, \delta$, or the growth rates of the technological factors $g_{Z}$ and $g_{Q}$; etc. However, it is also possible that some economic factors affect all our parameters at the same time.

There are three parameters that we do not estimate; we discuss why, and how this affects our results in the next section on identification. The three parameters are the elasticity of intertemporal substitution $1 / \sigma$, the coefficient of risk aversion $\theta$, and the size of macroeconomic shocks $b$. Specifically, we will assume that $\chi_{t+1}$ follows a "disaster risk" three-point distribution, i.e.

$$
\begin{aligned}
& \chi_{t+1}=0 \text { with probability } 1-2 p, \\
& \chi_{t+1}=\log (1-b) \text { with probability } p, \\
& \chi_{t+1}=\log \left(1+b_{H}\right) \text { with probability } p,
\end{aligned}
$$

where $b_{H}$ is chosen so that $E\left(e^{\chi+1}\right)=1$. We estimate $p$ but fix $b$ (and hence $b_{H}$ ). 


\subsection{Identification}

In this section we provide a heuristic discussion of identification, and make two main points. First, the identification is nearly recursive, so that it is easy to see which moments affect which parameters. Second, and consequently, the identification of some parameters does not depend on all the data moments.

The identification is easily seen to be nearly recursive. First, some parameters are obtained directly as their counterparts are assumed to be observed: population growth, investment price growth (the opposite of $g_{Q}$ ), and the employment-population ratio. The growth rate $g_{Z}$ is next chosen to match measured total factor productivity. ${ }^{12}$ One hence obtains $g_{T}$, the trend growth rate of GDP, given by equation (11). The depreciation rate $\delta$ is then chosen to match $I / K$ according to the familiar balanced growth relation (equation (18)):

$$
\frac{I}{K} \simeq \delta+g_{Q}+g_{T}
$$

The model then uses the Gordon growth formula (23) to infer the expected return on risky assets, $r^{*}$ given the observed price-dividend ratio:

$$
\frac{P^{*}}{D^{*}} \simeq \frac{1+g_{T}}{r^{*}-g_{T}} .
$$

Importantly, to infer $r^{*}$, we do not need data on the risk-free rate, or assumptions about the value of $\beta$, risk aversion $\theta$, or the distribution of $\chi$.

The next step is to identify the parameters $\alpha$ and $\mu$ to match the profit share of output and the ratio of profits to capital using the equations (20) and (27), i.e.

$$
s_{L}=\frac{1-\alpha}{\mu},
$$

and

$$
M P K=\frac{\mu+\alpha-1}{\alpha}\left(r^{*}+\delta+g_{Q}\right)
$$

where $s_{L}$ and $M P K=\Pi / K$ are the observables and $\alpha$ and $\mu$ the unknowns.

The solution is, denoting by $u c=r^{*}+\delta+g_{Q}$ the frictionless user cost, to set

$$
\mu=\frac{M P K}{s_{L} M P K+\left(1-s_{L}\right) u c},
$$

and

$$
\alpha=\frac{u c\left(1-s_{L}\right)}{s_{L} M P K+\left(1-s_{L}\right) u c} .
$$

Intuitively, the first equation infers market power (here the Lerner index) from the discrepancy between the $M P K$ and the frictionless user cost of capital $u c$. The parameter $\alpha$ is then obtained to fit the

\footnotetext{
${ }^{12}$ This step is however not completely straightforward, which is why we only say that the identication is nearly recursive. TFP in the data is measured using the revenue-based labor share, which in the model is $s_{L}=(1-\alpha) / \mu$, rather than the cost-based labor share, which in the model is $1-\alpha$. As a result, the TFP that an economist would measure in our model is

$$
g_{T}-s_{L} g_{N}-\left(1-s_{L}\right) g_{K}=\left(\frac{s_{L}}{1-\alpha} g_{Z}+\left(\frac{s_{L} \alpha}{1-\alpha}-\left(1-s_{L}\right)\right) g_{Q}\right)
$$

and hence is not equal to $g_{Z}$ since $s_{L} \neq 1-\alpha$. In particular matching TFP requires to know $\alpha$, which is why it is not fully recursive. This turns out to have relatively small effects in our empirical work.
} 
observed labor share. A key remark is that our identification of $\alpha$ and $\mu$ does not require data on the risk-free rate or to make any assumption about risk aversion $\theta$ or the distribution of $\chi$ - we simply use the sufficient statistic $r^{*}$ which has been previously identified.

Economically, our approach boils down to using the traditional Gordon growth formula - which holds in our standard neoclassical framework - to deduce the required return on capital from the price-dividend ratio and the growth rate, and hence to construct a user cost of capital $r^{*}+\delta+g_{Q}$ that incorporates risk. $^{13}$

At this point, we can also bring in data on the risk-free rate to infer the equity premium $r^{*}-r_{f}$. Here again, note that the behavior of the equity premium is therefore inferred without making assumptions about risk aversion $\theta$ or the distribution of $\chi$. However, to understand what drives the risk-free rate, one needs to separately infer $\beta$, risk aversion $\theta$, and the quantity of risk $\chi$. Doing so requires extra assumptions about these variables and about the intertemporal elasticity of substitution (which is not identified in our model given that growth rates are $i i d)$, as can be seen from equation (14):

$$
r^{*} \simeq \rho+\sigma g_{P C}+\sigma \frac{1-1 / \sigma}{1-\theta} \log E\left(e^{(1-\theta) \chi_{t+1}}\right) .
$$

We present our baseline result with an IES of 2, a rare disaster distribution for $\chi$ with a shock of $15 \%\left(e^{b}=0.85\right)$ and a probability $p$ that we estimate, and a risk aversion coefficient of 12 . As should be clear by now, none of these choices affects our inferences about $\alpha, \mu$, or the equity premium. Concretely, given these additional assumptions, we can solve for the quantity of risk $p$ that satisfies

$$
r^{*}-r_{f}=\log E\left(e^{-\theta \chi_{t+1}}\right)-\log E\left(e^{(1-\theta) \chi_{t+1}}\right)
$$

and we can then use the equation above for $r^{*}$ to deduce $\rho$ i.e. $\beta$. In Section 6 , we present the results when the IES is assumed to be 0.5 instead, and we also discuss results when we choose other distributions for $\chi$, or if we instead fix the amount of risk and estimate the risk aversion coefficient $\theta$.

\section{Empirical Results}

We first compare the two subsamples, then we contrast the results with more standard macroeconomic approaches which do not entertain a role for risk, and finally we present results over rolling windows in a long sample.

\subsection{Comparison of two subsamples}

Table 2 shows the estimated parameters for each subsample and the change of parameters between subsamples. Overall, our results substantiate many of the narratives that have been advanced and that we mention in the introduction. The discount factor $\beta$ rises by 1.2 point, reflecting higher savings supply. Market power increases significantly, by 6.7 points. Technical progress slows down and labor supply falls (relative to population). The model also estimates a significant increase in macroeconomic risk (the probability of a crisis), which goes from $3.4 \%$ per year to $6.5 \%$ per year. We will return to

\footnotetext{
${ }^{13}$ Our procedure is closely related to the approach of Barkai (2016), the main difference being the way we incorporate risk. Barkai (2016) simply uses a treasury rate or corporate bond yield to construct the user cost.
} 


\begin{tabular}{l|l|l|l|l}
\hline \hline Parameter name & \multirow{2}{*}{ Symbol } & \multicolumn{3}{|c}{ Estimates } \\
& & $1984-2000$ & $2001-2016$ & Difference \\
\hline Discount factor & $\beta$ & 0.961 & 0.972 & 0.012 \\
Markup & $\mu$ & 1.079 & 1.146 & 0.067 \\
Disaster probability & $p$ & 0.034 & 0.065 & 0.031 \\
Depreciation & $\delta$ & 2.778 & 3.243 & 0.465 \\
Cobb-Douglas & $\alpha$ & 0.244 & 0.243 & -0.000 \\
Population growth & $g_{N}$ & 1.171 & 1.101 & -0.069 \\
TFP growth & $g_{Z}$ & 1.298 & 1.012 & -0.286 \\
Invt technical growth & $g_{Q}$ & 1.769 & 1.127 & -0.643 \\
Labor supply & $\bar{N}$ & 0.623 & 0.608 & -0.015 \\
\hline \hline
\end{tabular}

Table 2: The table reports the estimated parameters in our baseline model for each of the two subsamples, 1984-2000 and 2001-2016, and the change between subsamples.

the interpretation of this result later. On the other hand, there is only moderate technological change: depreciation increases, reflecting the growing importance of high-depreciation capital such as computers, but the Cobb-Douglas parameter remains fairly stable. This stability of the production function is an interesting result. Overall, the model gives some weight to four of the most popular explanations $(\beta, \mu, p, g \mathrm{~s})$. But exactly how much does each story explain?

Table 3 provides one answer. By construction, the model fits perfectly all nine moments in each subsample using the nine parameters. We can decompose how much of the change in each moment between the two subsamples is accounted for by each parameter. Because our model is nonlinear, this is not a completely straightforward task; in particular, when changing a parameter from first subsample value to second subsample value, the question is at which value to evaluate the other parameters (e.g., the first or second subsample value). If the model were linear, or the changes in parameters small, this would not matter, but such is not the case here, in particular for the price-dividend ratio. In this table, we simply report the average over all possible orders of changing parameters, as we move from the first to the second subsample. ${ }^{14}$

\footnotetext{
${ }^{14}$ Formally, let $\Theta^{a}=\left(\theta_{1}^{a}, \ldots \theta_{K}^{a}\right)$ and $\Theta^{b}=\left(\theta_{1}^{b}, \ldots \theta_{K}^{b}\right)$ denote the parameter vectors in subsample $a$ and $b$ respectively, and consider a model moment which is a function of the parameters: $m=f(\Theta)$. Consider a permutation $\sigma:[1, K] \rightarrow[1, K]$ that describes an order in which we change parameters from their initial to final value; we first change $\theta_{\sigma(1)}$, then $\theta_{\sigma(2)}$, etc. Then calculate the change implied when we change parameter $l \in[1, K]$ along this order, i.e.

$$
\Delta_{l}(\sigma)=f\left(\theta_{z_{2}}^{b} ; \theta_{-z_{2}}^{a}\right)-f\left(\theta_{z_{1}}^{b} ; \theta_{-z_{1}}^{a}\right)
$$

where $z_{2}=\sigma\left(1: \sigma^{-1}(l)\right)$ are the parameters that have been switched already from initial to final values, and $z_{1}=\sigma(1:$ $\left.\sigma^{-1}(l)-1\right)$ the ones which are not switched yet. The change in $m$ due to parameter $l \in[1, K]$ is defined as

$$
\Delta_{l}=\frac{1}{N_{\sigma}} \sum_{\sigma} \Delta_{l}(\sigma)
$$

where the sum ranges over all possible permutations. By construction, $\sum_{l=1}^{K} \Delta_{l}=f\left(\Theta^{b}\right)-f\left(\Theta^{a}\right)$ accounts exactly for the model implied change in the moment, which, because the model fits the target moments perfectly, accounts also exactly
} 


\begin{tabular}{l|l|l|l|l|lllllllll}
\hline \hline & \multicolumn{9}{|l|}{ Target Moment } & \multicolumn{9}{|c}{ Contribution of each parameter to change in moment } \\
& $1984-00$ & $2001-16$ & Diff. & $\beta$ & $\mu$ & $p$ & $\delta$ & $\alpha$ & $g_{N}$ & $g_{Z}$ & $g_{Q}$ & $\bar{N}$ \\
\hline Gross profitability & 14.01 & 14.89 & 0.88 & -1.88 & 2.76 & 0.76 & 0.68 & 0.00 & -0.00 & -0.29 & -1.15 & -0.00 \\
Capital share & 29.89 & 33.99 & 4.10 & 0.00 & 4.13 & 0.00 & 0.00 & -0.03 & 0.00 & 0.00 & 0.00 & 0.00 \\
Risk-free rate & 2.79 & -0.35 & -3.14 & -1.22 & 0.00 & -1.62 & 0.00 & -0.00 & -0.00 & -0.19 & -0.10 & 0.00 \\
Price-dividend ratio & 42.34 & 50.11 & 7.78 & 30.67 & 0.00 & -13.19 & 0.00 & -0.02 & -1.86 & -5.07 & -2.76 & 0.00 \\
Investment-capital & 8.10 & 7.23 & -0.88 & 0.00 & 0.00 & 0.00 & 0.47 & -0.00 & -0.07 & -0.39 & -0.88 & 0.00 \\
Growth of TFP & 1.10 & 0.76 & -0.34 & 0.00 & -0.14 & 0.00 & 0.00 & -0.00 & -0.00 & -0.26 & 0.06 & 0.00 \\
Growth of invt. price & -1.77 & -1.13 & 0.64 & 0.00 & 0.00 & 0.00 & 0.00 & 0.00 & 0.00 & 0.00 & 0.64 & 0.00 \\
Growth population & 1.17 & 1.10 & -0.07 & 0.00 & 0.00 & 0.00 & 0.00 & 0.00 & -0.07 & 0.00 & 0.00 & 0.00 \\
Employment-pop. & 62.34 & 60.84 & -1.51 & 0.00 & 0.00 & 0.00 & 0.00 & 0.00 & 0.00 & 0.00 & 0.00 & -1.51 \\
\hline \hline
\end{tabular}

Table 3: The table reports the target moments in each of the two subsamples 1984-2000 and 2001-2016, as well as the change between samples, and the contribution of each parameter to each change in moment (so that column 3 equals the sum of columns 4 to 12). See text for details.

Overall, we see that the decline in the risk-free rate of $3.1 \%$ (314bps) is explained mostly by two factors, higher perceived risk $p$, and higher savings supply $\beta$, with lower growth playing only a moderate role. ${ }^{15}$ Why does the model not attribute all the change in the risk-free rate to savings supply? Simply because it would make it impossible to match other moments, in particular the $P D$ ratio. Even as it is, if only the change in savings supply $\beta$ were at work, the $P D$ ratio would increase by over 30 points. The model attributes offsetting changes to risk and growth, explaining in this way that the $P D$ ratio increased only moderately over this period despite the lower interest rates.

Similarly, profitability would decrease by almost 2 points if the change in $\beta$ was the only one at work - all rate of returns ought to fall if the supply of savings increases. The model reconciles the stable profitability with the data by inferring higher markups and higher risk. Overall, we see how the model needs multiple forces to account for the lack of changes observed in some ratios. The higher capital share is attributed entirely to higher markups, as capital-biased technical change appears to play little role.

We can now use these model estimates to understand the evolution of some other moments; these are reported in table 4. First, as we discussed in Section 3 (equation 27), the spread between the measured marginal product of capital and the risk-free rate can be decomposed in three components:

$$
M P K-r_{f}=\delta+g_{Q}+\frac{\mu-1}{\alpha}\left(r^{*}+g_{Q}+\delta\right)+r^{*}-r_{f},
$$

for the change in the data: $f\left(\Theta^{b}\right)-f\left(\Theta^{a}\right)=m^{b}-m^{a}$. In appendix, we also report the upper and lower bounds when consider all possible combinations of other parameters. This provides a way to bound the importance of each factor. See Gourio and Schulhofer-Wohl (2018) for more details.

${ }^{15}$ This conclusion does depend somewhat on our assumed intertemporal elasticity of substitution, as we discuss in detail below. 
where the three components are depreciation $\left(\delta+g_{Q}\right)$, rents, and risk $\left(r^{*}-r_{f}\right)$. We can calculate this decomposition in the model using the estimated parameters. The table reveals that depreciation changed little overall - faster physical depreciation is offset by slower economic depreciation - but the rents and risk components both rise by about two percentage points. (An alternative way to decompose the change in spread is to read, in the first row, the decomposition of the change in spread due to each parameter change; this yields a similar answer, as the increases in $\mu$ and in $p$ account for the bulk of the increase in the spread.)

We also report the model implied equity return and equity premium. While not a direct target, we estimate a sizeable equity premium, of nearly 5 percent per year in the recent sample. (This premium assumes no leverage; see section 6 for a discussion of leverage.) More interestingly, the premium increased by around 2 percentage points since 2000. In total,expected equity returns have fallen by about one percentage point because the decline in the risk-free rate is larger than this increase in the equity premium.

Regarding valuation ratios, we have already emphasized the moderate increase of the price-dividend ratio due to offsetting factors. Table 4 also shows the analysis of the price-earnings ratio and Tobin's $Q$. The later increases significantly from 2.50 to 3.84 between the two samples, reflecting both the increase in market power and the effect of the change in discount rates at which these rents are discounted.

The model also speaks to the income distribution between labor, capital, and rents. The approach taken here is that we observe accurately the payments to labor in the data, and cannot easily split the remainder between capital and profits. In the model, we can study the decomposition and how it changes between the two subsamples. The nearly 4 point decline in the labor share is accompanied by an even larger increase in the profit share, by nearly 5 points, so that the capital share actually declines slightly.

Finally, we can use the model to see the effect of these changes on macroeconomic variables - for instance the capital-output or investment-output ratios. On one hand, higher savings supply pushes investment up leading to more capital accumulation. For instance, the change in $\beta$ would push the investment-output ratio up by over 2 percentage points, while in the data it fell. On the other hand, rising market power and rising risk push investment down. Our model hence accounts for the coexistence of low investment and low interest rates. Note also that higher depreciation also requires more investment along the balanced growth path, while lower growth implies less investment. The model hence produces a fairly nuanced decomposition for the evolution of this ratio.

We can also ask what is the effect of each parameter on the level of GDP or investment. ${ }^{16}$ For instance, higher market power discourages capital accumulation and reduces output. It is easy to show that the elasticity of GDP to markups in this model is $-\alpha /(1-\alpha)$, or -0.32 for our estimate. Given estimated markups rise by 6.2 percent $(=6.7 / 1.079)$, the effect on GDP is about $-0.32 \times 6.2$, or about minus two percentage points $(-1.95 \%$ in our table). Here too, there are several counteracting factors, however, which imply that the overall level effect on GDP is small (-0.30\%). In particular, higher savings

\footnotetext{
${ }^{16} \mathrm{By}$ level of GDP we mean $y^{*}$, i.e. the level of GDP once the proper deterministic and stochastic trends have been removed. We abstract from the growth effects - e.g., a higher $g_{Z}$ or $g_{Q}$ has the mechanical effect of steepening the overall path of GDP.
} 
supply and lower economic depreciation lead to higher capital accumulation, while higher risk leads to lower capital accumulation. Investment is more negatively affected by the changes, with a level effect of about minus 5 percentage points, owing largely to markups and risk, but also to lower growth and a lower employment-population ratio.

\subsection{Comparison with macroeconomic approaches}

It is interesting to compare our results with alternative procedures followed by macroeconomists. Indeed, our empirical exercise is essentially the calibration of the "steady-state" of a very bare-bone DSGE model. Any DSGE model writer faces the same issues we do to fit these key moments.

Indeed, real business cycle modelers are aware of a trade-off between fitting the capital-output ratio and the risk-free interest rate. Since these models also target the labor share, the discrepancy precisely reflects the gap between the $M P K$ (the profit-capital ratio) and the risk-free interest rate. Often, modelers reject short-term Treasury interest rates as measures of the rate of return on capital, noting that these securities have special safety and liquidity attributes, which are not explicitly modeled. ${ }^{17}$ Mechanically, these models consider that the observed risk-free rate equals the model risk-free rate times an unobserved convenience yield $e^{\xi}$. This yields an additional parameter $\xi$ to estimate. At the same time, these models have traditionally abstracted from aggregate market power, setting $\mu=1,{ }^{18}$ and from risk, so that $p=0$, and have not explicitly targeted the price-dividend ratio. The assumptions lead to a well-defined exactly identified exercise with eight moments (our baseline, minus the pricedividend ratio) and eight parameters (our baseline plus the liquidity wedge $\xi$, less market power $\mu$ and risk $p$ ), which is an alternative to our approach. The last two columns of Table 5 present the results from this exercise, which we call the "macro-without-markups" approach.

This approach leads to a much higher value of $\alpha$ and "explains" the decline of the labor share by an increase of $\alpha$. The decline of the Treasury rate, and the growing gap between the $M P K$ and this rate, are fully accounted for by a very large, and growing, liquidity premium, which equals $-\xi=6.1$ percent in the first sample and 10.2 percent in the second sample. We find both the level and change in this wedge implausible.

An alternative approach is to abstract from this liquidity but to allow for markup, while still omitting the $P D$ ratio from the list of targets and risk from the potential parameters. This is also a well-posed exercise with 8 moments and 8 parameters which we call the "macro-with-markups" approach. In this case, the spread between the $M P K$ and the risk-free rate must reflect depreciation or rents. Intuitively, this approach assumes that the risk-free rate can be used to infer the cost of capital, and hence rents are deduced as a residual. The approach is conceptually quite similar to Barkai (2016), though we present it in a slightly more structural framework. The results are shown in the middle two columns

\footnotetext{
${ }^{17}$ See for instance Campbell et al. (2017) for a presentation of the Chicago Fed DSGE model, which, based on Fisher (2015), introduces a liquidity wedge that accounts for the discrepancy between the rate of return of capital and the risk-free rate.

${ }^{18}$ New Keynesian models are an important exception, but market power is often set on a priori basis in these studies (e.g., a markup of $15 \%$ ), and profits are offset in steady-state by fixed costs.
} 


\begin{tabular}{|c|c|c|c|c|c|c|c|c|c|c|c|c|}
\hline & \multicolumn{3}{|c|}{ Model implied moments } & \multicolumn{9}{|c|}{ Contribution of each parameter } \\
\hline & 1984-00 & $2001-16$ & Diff. & $\beta$ & $\mu$ & $p$ & $\delta$ & $\alpha$ & $g_{N}$ & $g_{Z}$ & $g_{Q}$ & $\bar{N}$ \\
\hline \multicolumn{13}{|l|}{ A. MPK-RF spread } \\
\hline Total spread & 11.22 & 15.24 & 4.02 & -0.66 & 2.76 & 2.39 & 0.68 & 0.00 & -0.00 & -0.10 & -1.05 & -0.00 \\
\hline - Depreciation & 4.55 & 4.37 & -0.18 & 0.00 & 0.00 & 0.00 & 0.47 & 0.00 & 0.00 & 0.00 & -0.64 & 0.00 \\
\hline - Market power & 3.39 & 5.55 & 2.17 & -0.59 & 2.73 & 0.24 & 0.21 & 0.00 & -0.00 & -0.09 & -0.35 & 0.00 \\
\hline - Risk premium & 3.15 & 5.23 & 2.08 & -0.05 & 0.00 & 2.14 & 0.00 & -0.00 & 0.00 & -0.01 & -0.00 & 0.00 \\
\hline \multicolumn{13}{|l|}{ B. Rate of returns } \\
\hline Equity return & 5.85 & 4.90 & -0.96 & -1.22 & 0.00 & 0.56 & 0.00 & -0.00 & -0.00 & -0.19 & -0.10 & 0.00 \\
\hline Equity premium & 3.07 & 5.25 & 2.18 & 0.00 & 0.00 & 2.18 & 0.00 & 0.00 & 0.00 & 0.00 & 0.00 & 0.00 \\
\hline Risk-free rate & 2.79 & -0.35 & -3.14 & -1.22 & 0.00 & -1.62 & 0.00 & -0.00 & -0.00 & -0.19 & -0.10 & 0.00 \\
\hline \multicolumn{13}{|l|}{ C. Valuation ratios } \\
\hline Price-dividend & 42.34 & 50.11 & 7.78 & 30.67 & 0.00 & -13.19 & 0.00 & -0.02 & -1.86 & -5.07 & -2.76 & 0.00 \\
\hline Price-earnings & 17.85 & 25.79 & 7.94 & 10.16 & 5.08 & -4.57 & -0.35 & 0.00 & -0.59 & -1.47 & -0.34 & -0.00 \\
\hline Tobin's Q & 2.50 & 3.84 & 1.34 & 1.05 & 1.34 & -0.48 & 0.11 & 0.00 & -0.08 & -0.28 & -0.31 & -0.00 \\
\hline \multicolumn{13}{|l|}{ D. Income shares } \\
\hline Share Labor & 70.11 & 66.01 & -4.10 & 0.00 & -4.13 & 0.00 & 0.00 & 0.03 & 0.00 & 0.00 & 0.00 & 0.00 \\
\hline Share Capital & 22.59 & 21.24 & -1.35 & 0.00 & -1.33 & 0.00 & 0.00 & -0.03 & 0.00 & 0.00 & 0.00 & 0.00 \\
\hline Share Profit & 7.30 & 12.76 & 5.46 & 0.00 & 5.46 & 0.00 & 0.00 & 0.00 & 0.00 & 0.00 & 0.00 & 0.00 \\
\hline \multicolumn{13}{|l|}{ E. Macroeconomy } \\
\hline $\mathrm{K} / \mathrm{Y}$ & 2.13 & 2.28 & 0.15 & 0.29 & -0.13 & -0.12 & -0.11 & -0.00 & 0.00 & 0.04 & 0.18 & -0.00 \\
\hline $\mathrm{I} / \mathrm{Y}$ & 17.28 & 16.50 & -0.78 & 2.20 & -1.03 & -0.90 & 0.23 & -0.02 & -0.16 & -0.52 & -0.59 & 0.00 \\
\hline Detrend Y (\% chg) & - & - & -0.30 & 4.18 & -1.95 & -1.70 & -1.52 & -0.07 & 0.00 & 0.65 & 2.56 & -2.45 \\
\hline Detrend I (\% chg) & - & - & -4.95 & 17.18 & -8.02 & -6.98 & -0.12 & -0.20 & -0.94 & -2.45 & -0.96 & -2.45 \\
\hline
\end{tabular}

Table 4: The table reports some moments of interest calculated in the model using the estimated parameter values for each of the two subsamples 1984-2000 and 2001-2016, as well as the change between samples, and the contribution of each parameter to each moment change. 


\begin{tabular}{|c|c|c|c|c|c|c|c|c|c|}
\hline & \multicolumn{3}{|c|}{ Baseline approach } & \multicolumn{3}{|c|}{ Macro-with-markups } & \multicolumn{3}{|c|}{ Macro-without-markups } \\
\hline & $1984-{ }^{\prime} 00$ & 2001-'16 & Diff. & $1984-^{\prime} 00$ & 2001-'16 & Diff. & 1984-’00 & 2001-'16 & Diff. \\
\hline$\beta$ & 0.961 & 0.972 & 0.012 & 0.984 & 1.012 & 0.028 & 0.925 & 0.913 & -0.012 \\
\hline$\mu$ & 1.079 & 1.146 & 0.067 & 1.165 & 1.330 & 0.166 & 1 & 1 & 0 \\
\hline$p$ & 0.034 & 0.065 & 0.031 & 0 & 0 & 0 & 0 & 0 & 0 \\
\hline$\delta$ & 2.778 & 3.243 & 0.465 & 2.778 & 3.243 & 0.465 & 2.778 & 3.243 & 0.465 \\
\hline$\alpha$ & 0.244 & 0.243 & -0.000 & 0.183 & 0.122 & -0.061 & 0.299 & 0.340 & 0.041 \\
\hline$g_{P}$ & 1.171 & 1.101 & -0.069 & 1.171 & 1.101 & -0.069 & 1.171 & 1.101 & -0.069 \\
\hline$g_{Z}$ & 1.298 & 1.012 & -0.286 & 1.544 & 1.358 & -0.187 & 1.074 & 0.738 & -0.335 \\
\hline$g_{Q}$ & 1.769 & 1.127 & -0.643 & 1.769 & 1.127 & -0.643 & 1.769 & 1.127 & -0.643 \\
\hline$N$ & 62.344 & 60.838 & -1.507 & 62.344 & 60.838 & -1.507 & 62.344 & 60.838 & -1.507 \\
\hline$\xi$ & 0 & 0 & 0 & 0 & 0 & 0 & -0.061 & -0.102 & -0.041 \\
\hline
\end{tabular}

Table 5: The table reports the estimated parameters in each of the two subsamples 1984-2000 and 2001-2016 in our baseline model, in the macro model with markups, and in the macro model without markups.

of table 5. There are a number of differences between these results and our baseline results. First, the level of markups is much higher, and the increase in markups is much stronger (16.6 points instead of 6.7 points). Second, the increase in markups is so large that the model requires a sharp decline in $\alpha$ (from 0.18 to 0.12 ) to keep the labor share from falling too much. This estimate suggests that technical progress has been biased towards labor over the past thirty years - a somewhat implausible conclusion. On the other hand, this model also implies that $\beta$ rose significantly. We discuss below some further differences for a longer sample.

Table 6 presents the implications of these different "calibrations". Notably, our approach offers a balanced view where markups and risk premia increases jontly explain the rising spread, while the macro model without markups accounts all of it with an unmodeled liquidity premium and the macro model with markups accounts for all of it with rising market power. As a result, that the macro model with markups implies a sharp decline of the level of GDP, by about 8 percentage points. Moreover, the share of income going to capital falls sharply, in opposite to the share of profits which surges. On the other hand, the macro model without markups predict an increase in the level of GDP relative to trend - the liquidity premium does not discourage capital accumulation in that model as much as markups or risk premia do in the other versions of the model.

Another interesting implication is that Tobin's $Q$, which increase significantly in our baseline, in a way broadly consistent with the data, is actually undefined in the macro-with-markups approach, because the low discount rates make the firm value infinite. In this sense, that model cannot match the evolution of valuation ratios, given its target of interest rates. Furthermore, the macro-without-markups approach implies decreasing valuation ratios, at odds with the data, owing to the very large, and rising, 
liquidity premium. These results provide indirect support for our baseline model.

\subsection{Rolling estimation}

An alternative approach to fitting the model is to estimate it using rolling windows rather than two subsamples. In this spirit, figure 6 presents the estimated parameters when we estimate the model each year using a 11-year centered moving average to calculate the target moments. (That is, we target the smooth lines shown in Section 2 in figure 4.) We start our analysis in 1950 to avoid World War II. ${ }^{19}$ As noted above, this calculation assumes that agents are myopic, in the sense that they believe that the currently observed target moments will be constant forever, and it abstracts from transitional dynamics.

We find a $\mathrm{U}$ shape in the parameter $\beta$ (savings supply) and in macroeconomic risk $p$. Hence, our results suggest that risk premia declined in the 1970s and early to mid 1980s before rising. Markups also have a U shape but also an initial increase in the 1950s and 1960s. The capital parameter $\alpha$ has an increase in the late 1970s which is later reversed. Figure 7 compares the evolution of our parameters $\beta, \mu$ to the parameters estimated using the "macro with markups" approach. Our estimated parameters are significantly more stable over time - the $U$ shape is much weaker. We find this interesting because accounting for stock market valuation ratios might be expected to lead to more unstable parameters but we find the opposite.

We can then use these rolling estimates to study the income distribution, the return spread $M P K-$ $R F$, and their drivers. Figure 8 presents the share of pure profits, the true capital share, and the sum of the two for each year. By construction, the total equals one minus the labor share, and matches the data exactly.

The figure shows that the share of pure profits is estimated to have risen in the 1960s, then falling in the 1970s and rising since 1980. Inversely, the capital share fell, then rose and fell. This picture reflects the puzzling pattern of $\mathrm{U}$ shape in profits and inverse $\mathrm{U}$ shape in $\alpha$ emphasized by Karabarbounis and Neiman (2018). However, we find it interesting that the U shape is significantly less strong with our estimation strategy than if one follows the macro with markups strategy. Karabarbounis and Neiman (2018) note that the strong negative correlation between the interest rate and the capital share, and the strong positive correlation between the interest rate and the profit share, are suggestive of measurement problems in the cost of capital. Figure 9 shows the capital share and the pure profit share implied by the two estimations. There is clearly less volatility of the macro-finance estimates.

Figure 10 presents the $M P K-R F$ spread and its three subcomponents: economic and physical depreciation, rents, and risk. The spread falls in the 1970s before rising in the 1980s. The depreciation component moves, if anything, in opposite direction to the spread, and hence does not help explain its movements. Rents are estimated to fall then rise, and so does risk. The empirical success here is that the risk premium - which is estimated without looking at the $M P K$, but rather by single-mindedly observing the $P D$ ratio and growth rates - helps explain some of this variation.

\footnotetext{
${ }^{19}$ We thank Matthew Rognlie for proposing (and executing) this exercise in his discussion at the NBER Summer Institute.
} 


\begin{tabular}{|c|c|c|c|c|c|c|c|c|c|}
\hline & \multicolumn{3}{|c|}{ Baseline approach } & \multicolumn{3}{|c|}{ Macro-with-markups } & \multicolumn{3}{|c|}{ Macro-without-markups } \\
\hline & 1984-'00 & 2001-'16 & Diff. & 1984-’00 & 2001-'16 & Diff. & 1984-'00 & 2001-'16 & Diff. \\
\hline \multicolumn{10}{|l|}{ A. MPK-RF spread } \\
\hline Total spread & 11.22 & 15.24 & 4.02 & 11.22 & 15.24 & 4.02 & 11.22 & 15.24 & 4.02 \\
\hline - Depreciation & 4.55 & 4.37 & -0.18 & 4.55 & 4.37 & -0.18 & 4.55 & 4.37 & -0.18 \\
\hline - Market power & 3.39 & 5.55 & 2.17 & 6.58 & 10.89 & 4.30 & 0.00 & 0.00 & 0.00 \\
\hline - Risk premium & 3.15 & 5.23 & 2.08 & 0.00 & 0.00 & 0.00 & 0.00 & 0.00 & 0.00 \\
\hline - Liquidity premium & 0.00 & 0.00 & 0.00 & 0.00 & 0.00 & 0.00 & 6.51 & 10.75 & 4.24 \\
\hline \multicolumn{10}{|l|}{ B. Rate of returns } \\
\hline Equity return & 5.85 & 4.90 & -0.96 & 2.79 & -0.35 & -3.14 & 9.30 & 10.40 & 1.10 \\
\hline Equity premium & 3.07 & 5.25 & 2.18 & 0.00 & 0.00 & 0.00 & 0.00 & 0.00 & 0.00 \\
\hline Risk-free rate & 2.79 & -0.35 & -3.14 & 2.79 & -0.35 & -3.14 & 2.79 & -0.35 & -3.14 \\
\hline \multicolumn{10}{|l|}{ C. Valuation ratios } \\
\hline Price-dividend & 42.34 & 50.11 & 7.78 & NA & NA & NA & 17.82 & 13.57 & -4.25 \\
\hline Price-earnings & 17.85 & 25.79 & 7.94 & NA & NA & NA & 7.52 & 6.98 & -0.53 \\
\hline Tobin's Q & 2.50 & 3.84 & 1.34 & NA & NA & NA & 1.05 & 1.04 & -0.01 \\
\hline \multicolumn{10}{|l|}{$\underline{\text { D. Income shares }}$} \\
\hline Share Labor & 70.11 & 66.01 & -4.10 & 70.11 & 66.01 & -4.10 & 70.11 & 66.01 & -4.10 \\
\hline Share Capital & 22.59 & 21.24 & -1.35 & 15.75 & 9.17 & -6.58 & 29.89 & 33.99 & 4.10 \\
\hline Share Profit & 7.30 & 12.76 & 5.46 & 14.14 & 24.82 & 10.69 & 0.00 & 0.00 & 0.00 \\
\hline \multicolumn{10}{|l|}{ E. Macroeconomy } \\
\hline $\mathrm{K} / \mathrm{Y}$ & 2.13 & 2.28 & 0.15 & 2.13 & 2.28 & 0.15 & 2.13 & 2.28 & 0.15 \\
\hline $\mathrm{I} / \mathrm{Y}$ & 17.28 & 16.50 & -0.78 & 17.28 & 16.50 & -0.78 & 17.28 & 16.50 & -0.78 \\
\hline Detrend Y (\% chg) & - & - & -0.30 & - & - & -8.00 & - & - & 7.77 \\
\hline Detrend I (\% chg) & - & - & -4.95 & - & - & -12.65 & - & - & 3.12 \\
\hline
\end{tabular}

Table 6: The table reports some moments of interest calculated in the baseline model, in the macro model with markups, and in the macro model without markups, using the estimated parameter values for each of the two subsamples 1984-2000 and 2001-2016, as well as the change between samples. 

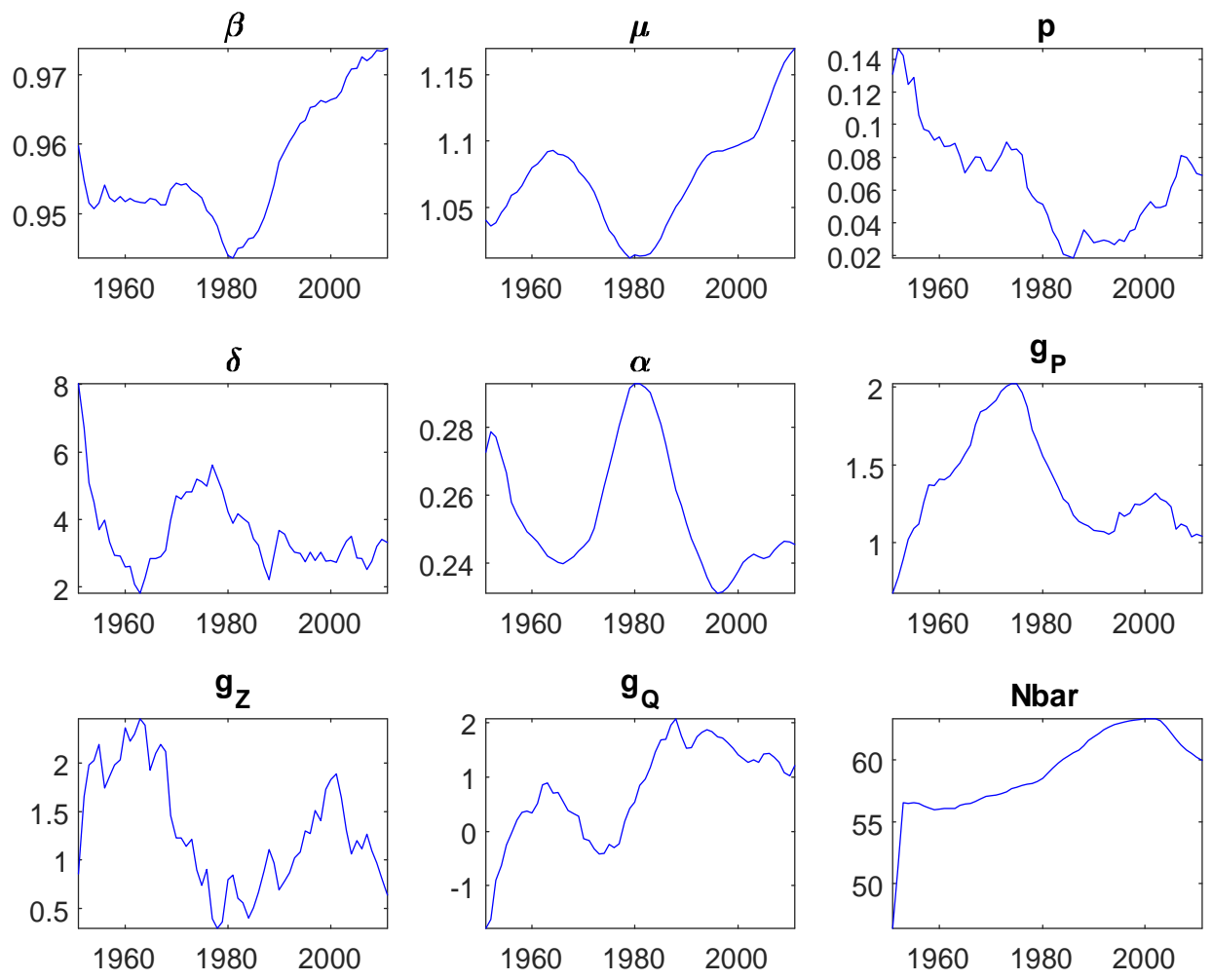

Figure 6: This figure plots the estimated parameters for each year. The target moments are the local moving average over the 11 surrounding years.
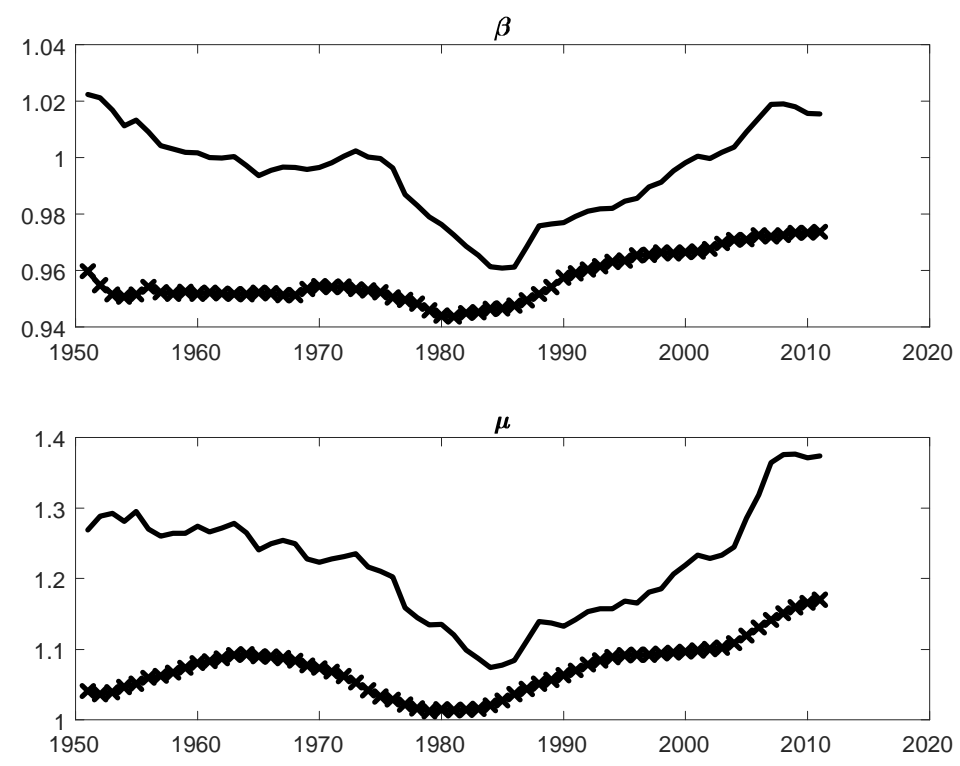

Figure 7: The figure plots the estimated $\beta$ and $\mu$ over rolling windows for the baseline model (starred line) and for the macro approach with markups (full line). 


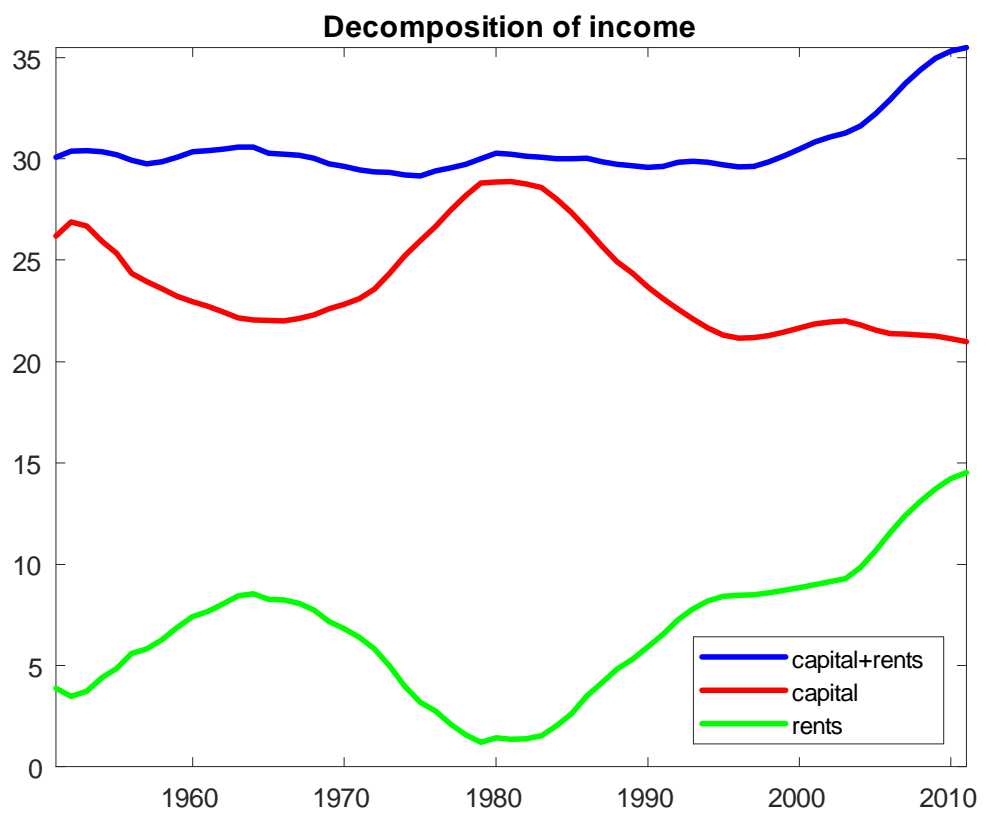

Figure 8: This figure presents the model-implied distribution of income, using the parameters estimated in each year using the rolling window estimation. The labor share is one minus the sum of capital and rents.
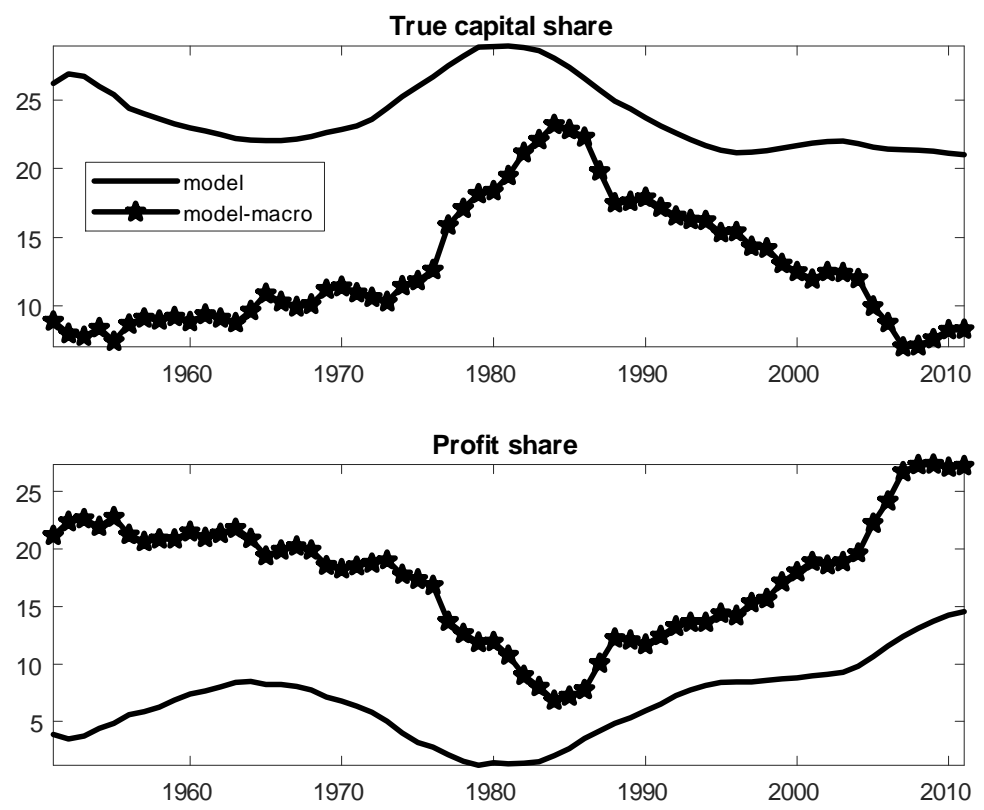

Figure 9: This figure presents the distribution of income, using the parameters estimated at each point in time, for both the macro and macro-finance (baseline) estimations. Top panel: true capital share; Bottom panel: profit share; the lines with stars correspond to the macro estimation, and the full lines to the macro-finance (baseline) estimation. 


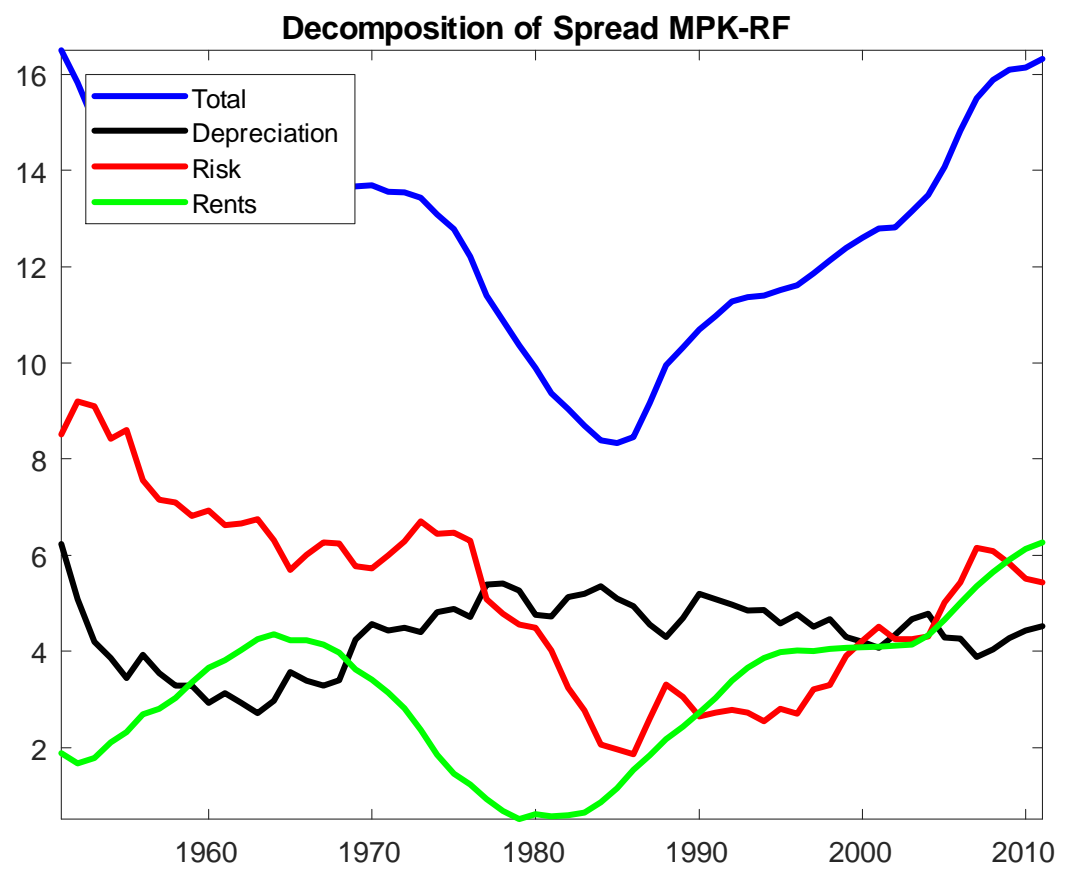

Figure 10: This figure presents the model-implied spread between the average product of capital and the risk-free rate, and the three components which explain this wedge: depreciation, rents, and risk, using the estimated parameters for each year.

Figure 11 again compares these results to those obtained with the more standard macro estimation. Both estimation approaches infer the same depreciation component. The macro approach attributes none of the spread to risk by construction and hence infers a large and highly volatile rent (or profit) component. Finally, figure 12 depicts the implied risk-free rate, expected equity return and equity risk premium. The risk-free rate exactly matches our data target by construction. The equity premium mimics the evolution of $p$ depicted in figure 6 .

\section{Extensions and robustness}

This section presents some extensions of our baseline framework. We first discuss the interpretation of rising risk premia and alternative approaches to modeling them. We next analyze how financial leverage, the intertemporal elasticity of substitution, alternative interest rates that adjust for liquidity or term premia, and capital mismeasurement affect our results. Finally, we present an example to evaluate the importance of transitional dynamics.

\subsection{Interpretation of rising risk premia}

Our baseline results are obtained using a parametrization of $\chi$ as a rare "disaster" corresponding to a permanent decline of $15 \%$ of the level of GDP. Our estimates suggest that the risk of such a large shock was low in the 1990s but rose gradually in the 2000s and 2010s. Part of this increase may be attributed to a recognition post 2008 that financial crises are recurrent events that affect even developed 

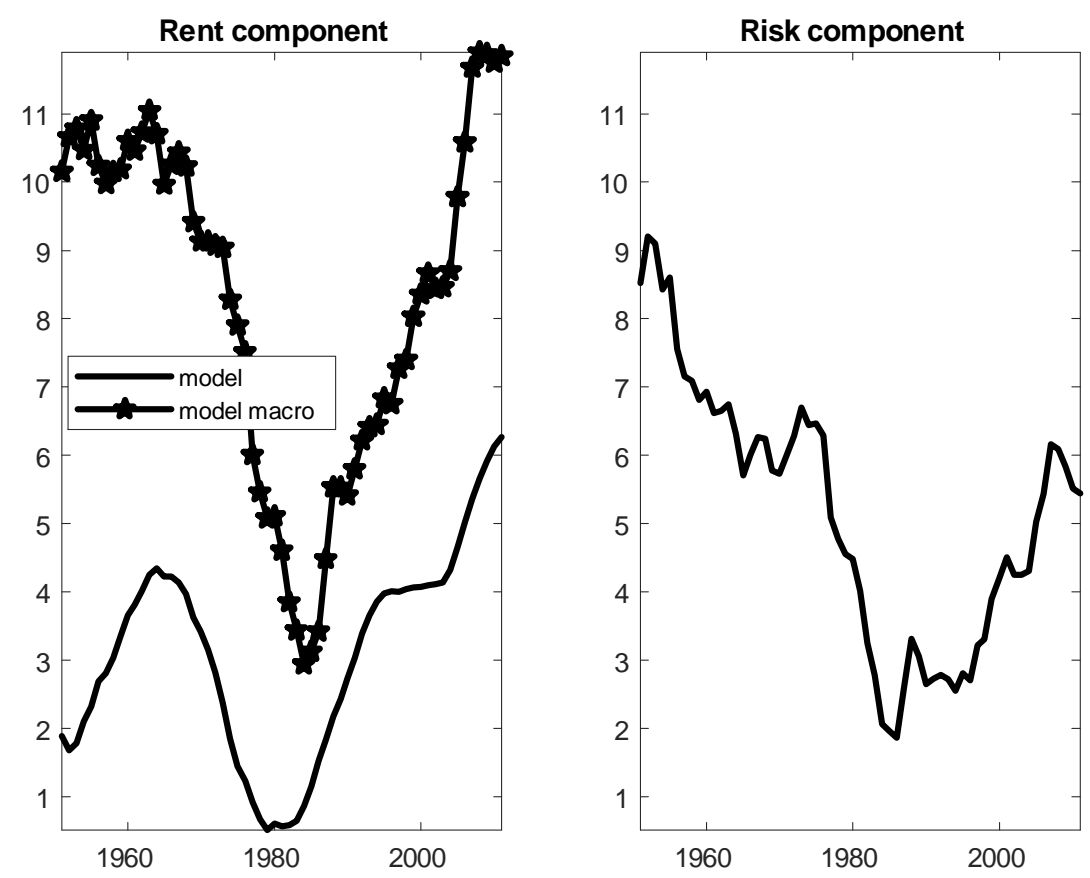

Figure 11: This figure presents the three components of the model-implied spread between the average product of capital and the risk-free rate, for both the baseline (macro-finance) calibration and the macro calibration. Left panel: rent (profit) component; middle panel: risk component; right panel: depreciation component (which is the same across the two calibrations).

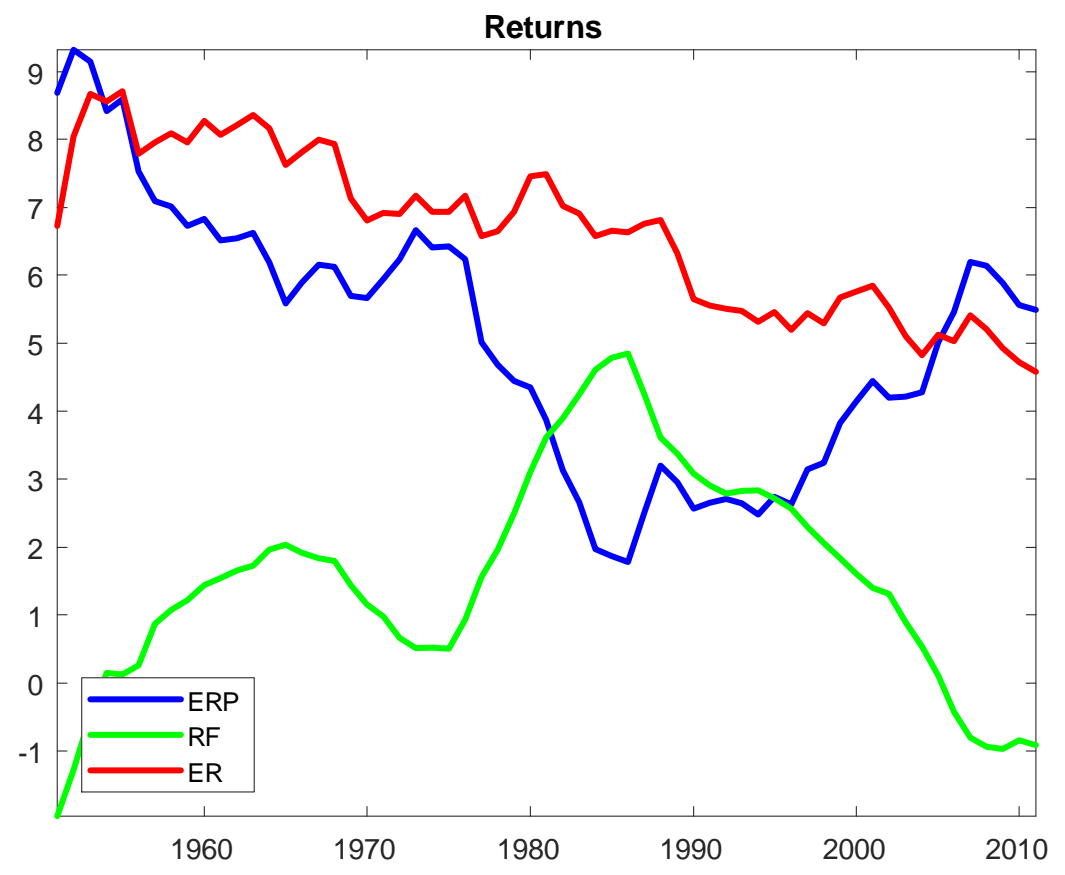

Figure 12: This figure shows the model-implied risk-free rate, expected equity return, and equity risk premium. (By construction, the risk-free rate matches the data.) 


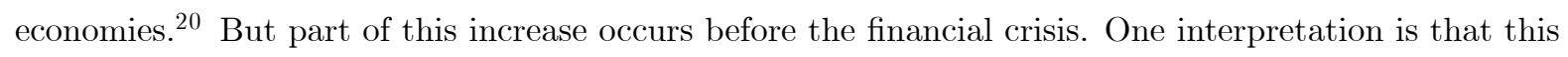
increase corresponds to a higher perception of risk starting in the late 1990s and early 2000s owing to the combination of the Asian financial crisis, LTCM crisis, and the 2001 crash in the US. We must acknowledge however that it is not straightforward to relate our estimate of the probability of a "disaster" to data on beliefs or other asset prices. ${ }^{21}$ This leads us to study in this section alternative risk modeling. For instance, the ageing of developed economies, or the desire of emerging markets to accumulate safe reserves might be interpreted in a reduced form as higher effective risk aversion.

As explained in section 4.2, the precise specification of the risk model is theoretically irrelevant for some conclusions, such as the value of markups $\mu$ or the Cobb-Douglas parameter $\alpha$, or the estimated equity premium ERP. We now illustrate that even for the objects where this specification is potentially relevant, it may not be quantitatively first-order. Table 7 presents estimates of parameters in the first and second samples under some different assumptions. The first row presents the baseline model. The second and third row present alternative disaster models where, rather than a "bonanza" or windfall to offset the disaster risk, we introduce a small positive drift (row 2) or simply do not offset the disaster (row 3). The results are nearly identical. Row 4 considers a log-normal process for $\chi$ rather than a rare disaster. That model requires a large, and rising, standard deviation $\sigma_{\chi}$ of the lognormal shock to account for the data, but as we will see, it behaves quite similarly overall. Rows 5 and 6 display estimates when the disaster size $b$ (resp. risk aversion $\theta$ ), rather than the disaster probability, is allowed to vary. Unsurprisingly, these models require rising disaster size or risk aversion to account for the data. But all of these models generate the same perfect fit of the data moments. Finally, rows 7 and 8 present estimates of the baseline model when the IES is set to unity or half rather than two; we discuss these below.

Table 8 present the "causal" decomposition along the lines of Tables 3 and 4, i.e. they show the effect of the changes in $\beta$, the risk parameter used in the variant $\left(p, \theta, b\right.$ or $\left.\sigma_{\chi}\right)$, or the other parameters (all grouped together for simplicity) on some model moments. We know already that the implications for $\alpha, \mu$, etc. are unchanged; so we focus here on three key financial variables: the risk-free rate, the price-dividend ratio, and Tobin's $Q$. The table shows that across a range of specifications, the decline of the risk-free rate is driven in significant parts by $\beta$ and by the risk parameter - the probability of disaster, or the risk aversion or disaster size, regardless of the exact specification. Similarly, the increase in the price-dividend ratio and in Tobin's $Q$ is the result of offsetting effects of the decline of $\beta$ and the increase of the risk factor. Hence, our results are insensitive to the exact way risk is modeled.

\footnotetext{
${ }^{20}$ Kozlowski, Veldkamp and Venkateswaran (2017) offer a quantitative theory along these lines.

${ }^{21}$ The issues also arise when studying the 1960s and 1970s, where our model says the risk of disaster was larger. The 1970s were a volatile decade, so it is perhaps not surprising that perceived tail risk was high.
} 


\begin{tabular}{llllll}
\hline \hline \multirow{2}{*}{ Baseline } & $\beta$ & Risk & $b$ & $\theta$ & $\sigma$ \\
\hline Baseline with drift & 0.961 & 0.034 & 0.163 & 12 & 0.5 \\
& 0.972 & 0.065 & 0.163 & 12 & 0.5 \\
\hline Baseline with no offset & 0.960 & 0.038 & 0.163 & 12 & 0.5 \\
& 0.971 & 0.071 & 0.163 & 12 & 0.5 \\
\hline Lognormal & 0.962 & 0.034 & 0.163 & 12 & 0.5 \\
& 0.974 & 0.066 & 0.163 & 12 & 0.5 \\
\hline Time-varying disaster size & 0.960 & 0.020 & 0.192 & 12 & 0.5 \\
& 0.962 & 0.050 & 0.163 & 12 & 0.5 \\
\hline Time-varying risk aversion & 0.970 & 0.020 & 0.229 & 12 & 0.5 \\
\hline IES $=1$ & 0.960 & 0.020 & 0.163 & 15.316 & 0.5 \\
& 0.970 & 0.020 & 0.163 & 19.560 & 0.5 \\
\hline IES $=0.5$ & 0.966 & 0.034 & 0.163 & 12 & 1 \\
& 0.970 & 0.065 & 0.163 & 12 & 1 \\
\hline \hline
\end{tabular}

Table 7: The table reports the estimated parameters in each of the two subsamples 1984-2000 and 2001-2016 in the baseline model and in some variants: disaster risk with certain small offsets rather than rare windfalls; disaster risk wthout offset; lognormal risk; time-varying risk aversion; time-varying disaster size; IES $=1 ;$ IES $=0.5$.

\begin{tabular}{l|lll|lll|lll}
\hline \hline & \multicolumn{3}{|l|}{ Risk-free rate } & \multicolumn{3}{l|}{ Price-dividend } & \multicolumn{3}{l}{ Tobin's $Q$} \\
& $\beta$ & risk & others & $\beta$ & risk & others & $\beta$ & risk & others \\
\hline Baseline & -1.22 & -1.62 & -0.29 & 30.67 & -13.19 & -9.70 & 1.05 & -0.48 & 0.77 \\
Baseline with drift & -1.17 & -1.67 & -0.29 & 28.86 & -11.62 & -9.47 & 0.99 & -0.42 & 0.77 \\
Baseline with no offset & -1.32 & -1.53 & -0.29 & 34.55 & -16.52 & -10.25 & 1.17 & -0.60 & 0.77 \\
Lognormal & -1.26 & -1.59 & -0.29 & 32.07 & -14.40 & -9.89 & 1.09 & -0.52 & 0.77 \\
Time-varying disaster size & -1.05 & -1.80 & -0.29 & 24.82 & -8.03 & -9.01 & 0.85 & -0.29 & 0.78 \\
Time-varying risk aversion & -1.04 & -1.81 & -0.29 & 24.45 & -7.70 & -8.97 & 0.84 & -0.28 & 0.78 \\
$I E S=1$ & -0.43 & -2.12 & -0.59 & 9.30 & 0.00 & -1.52 & 0.33 & 0.00 & 1.01 \\
$I E S=0.5$ & 1.14 & -3.11 & -1.17 & -35.66 & 27.75 & 15.68 & -1.32 & 0.95 & 1.71 \\
\hline \hline
\end{tabular}

Table 8: The table reports for each variant of the baseline model, the decomposition of the risk-free rate, the price-dividend ratio, and Tobin's $\mathrm{Q}$, into the changes driven by (i) the discount factor, (ii) the risk parameter, (iii) all the other parameters. 


\subsection{Leverage}

Our model calculations assume an all-equity financed firm. In reality corporations are leveraged, which may affect in particular the price-dividend ratio, which we use as an input in our estimation strategy. In this section, we propose a simple approach to bound the effect of leverage. To take this into account, we assume a Modigliani-Miller world where corporate leverage has no effect on real quantities, and only affects prices and dividends. We assume corporate debt is fully risk-free. We then adjust the price-dividend ratio of the model given an exogenous leverage decision which we take directly from the data. $^{22}$ We then re-estimate the model and obtain the results shown in the third set of columns in tables 9 and $10 .^{23}$

Qualitatively, the findings are quite similar to those of the model without leverage: $\beta, \mu$ and $p$ all go up, and are important contributors to the observed changes in the risk-free rate, profitability, and the price-dividend ratio. However, the role of risk is somewhat smaller than in our baseline version. The logic is clear from the Gordon formula: with leverage, the change in $r^{*}$ required to account for the change in valuation ratio is smaller. (Going in the other direction, however, is that in our data, aggregate leverage declines from the first sample to the second one.) In particular for the spread decomposition $M P K-R F$ in table 10, the share of the spread due to risk is smaller (2.08 and 3.81 percentage points in the first and second sample respectively). However, the share of the increase in the spread due to risk remains substantial. Moreover, in terms of the implied equity premium, the increase is actually similar, because leverage now amplifies the variation in $r^{*}$. These results are conservative, because we have assumed that corporate debt pays the same return as the risk-free asset; in reality, corporate debt yields are higher than Treasuries yields, which would reduce the adjustment to the $P D$ ratio.

\subsection{Intertemporal elasticity of substitution}

We have assumed an elasticity of substitution equal to 2 in our baseline estimation. The IES also cannot be identified given that the model generates iid growth rates for all macroeconomic variables. As noted above, the assumed value for the IES does not affect estimates of $\alpha, \mu, r^{*}$, or the equity premium. This can be verified in tables 9 and 10 where we present parameter estimates for an elasticity equal to 0.5 . Our conclusions that risk and market power increased are hence completely unaffected by this assumption. However, changing the IES does affect the counterfactual decompositions studied above; for instance the effect of an increase in risk on capital accumulation depends on the assumed IES.

Table 8 presents decompositions for three financial variables, and the online appendix provides the decompositions of all variables. With a low IES, the effect of the decline of growth in accounting for the decline of the risk-free rate is larger. The model hence does not require an increase in $\beta$ - rather $\beta$

\footnotetext{
${ }^{22}$ Specifically, we use S\&P data and define leverage as short-term debt plus long-term debt less cash, divided by market value of equity; see data appendix.

${ }^{23} \mathrm{As}$ an alternative approach, one can adjust the $r^{*}$ from the model directly to account for leverage, noting that the $r^{*}$ identified by the model from the PD ratio is actually $(1+\omega) r^{*}-\omega r^{f}$ where $\omega$ is the observed debt-equity ratio. This approach yields nearly identical results to the one where we adjust the $P D$ ratio directly.
} 


\begin{tabular}{l|lll|lll|lll|lll}
\hline \hline & IES=0.5 & & & \multicolumn{3}{|l|}{ Leverage } & & \multicolumn{3}{l}{ AA rate as RF } & & \multicolumn{3}{l}{ 10 year adj. for TP } \\
& $1984-00$ & $2001-16$ & Diff. & $1984-00$ & $2001-16$ & Diff. & $1984-00$ & $2001-16$ & Diff. & $1984-00$ & $2001-16$ & Diff. \\
\hline$\beta$ & 0.976 & 0.965 & -0.011 & 0.968 & 0.982 & 0.014 & 0.957 & 0.969 & 0.012 & 0.963 & 0.972 & 0.008 \\
$\mu$ & 1.079 & 1.146 & 0.067 & 1.106 & 1.191 & 0.084 & 1.079 & 1.146 & 0.067 & 1.079 & 1.146 & 0.067 \\
$p$ & 0.034 & 0.065 & 0.031 & 0.021 & 0.044 & 0.023 & 0.012 & 0.043 & 0.031 & 0.052 & 0.061 & 0.009 \\
$\delta$ & 2.778 & 3.243 & 0.465 & 2.778 & 3.243 & 0.465 & 2.778 & 3.243 & 0.465 & 2.778 & 3.243 & 0.465 \\
$\alpha$ & 0.244 & 0.243 & -0.000 & 0.224 & 0.214 & -0.010 & 0.244 & 0.243 & -0.000 & 0.244 & 0.243 & -0.000 \\
$g_{P}$ & 1.171 & 1.101 & -0.069 & 1.171 & 1.101 & -0.069 & 1.171 & 1.101 & -0.069 & 1.171 & 1.101 & -0.069 \\
$g_{Z}$ & 1.298 & 1.012 & -0.286 & 1.378 & 1.096 & -0.282 & 1.298 & 1.012 & -0.286 & 1.298 & 1.012 & -0.286 \\
$g_{Q}$ & 1.769 & 1.127 & -0.643 & 1.769 & 1.127 & -0.643 & 1.769 & 1.127 & -0.643 & 1.769 & 1.127 & -0.643 \\
$N$ & 62.344 & 60.838 & -1.507 & 62.344 & 60.838 & -1.507 & 62.344 & 60.838 & -1.507 & 62.344 & 60.838 & -1.507 \\
\hline \hline
\end{tabular}

Table 9: The table reports the estimated parameters in each of the two subsamples 1984-2000 and 2001-2016 in the baseline model, in the model with IES=0.5, in the model with financial leverage, and in the model estimated with a different interest rate target (AA).

falls. The change of the risk-free rate due to uncertainty is now larger. In this sense, a lower IES gives a larger role for risk. As emphasized by Bansal and Yaron (2004), higher risk and lower growth both raise the $P D$ ratio because of their strong effect on the risk-free rate.

\subsection{Liquidity and term premia}

As a risk-free rate proxy in the data, we use the one year Treasury rate (minus lagged core inflation). One concern is that our model abstracts from the term and liquidity premia which makes this rate especially low. To gauge the role of the liquidity premium, we instead use as a risk-free rate proxy the rate on AAA/AA corporate bonds, minus the SPF median CPI inflation over the next 10 years. This is rate for securities which do not possess the same unique liquidity attributes as a US Treasury. We then repeat our estimation. The rightmost columns of tables 9 and 10 show the results. Given the identification provided by the model, changing the risk-free rate does not affect $\alpha, \mu$, or $r^{*}$. However, the different risk-free rate target will affect the value of $\beta$ and the amount of risk identified by the model, and their respective changes. Indeed, we see that the estimated $\beta$ does not increase across samples. The level of risk estimated is smaller, but crucially, our model still estimates that risk increased significantly between the two samples. Our conclusion about the relative importance of risk and markups is not affected by this change in target, suggesting that liquidity considerations do not play a very large role in these trends.

A related concern is that long-term rates reflect term premia which may be driven by an inflation premium, which is not present in the model. We hence consider as target for the risk-free rate the 10 year Treasury constant maturity rate, less SPF expected inflation, less the term premium estimate of Adrian, Crump and Moench, which is obtained from a statistical term structure model. Because the term premia estimate decline strongly during this period, the decline in this measure of risk-free rate is only 1.5 point rather than over 3 points. The resulting estimates imply a smaller increase in macroeconomic risk. 


\begin{tabular}{|c|c|c|c|c|c|c|c|c|c|c|c|c|}
\hline & $\begin{array}{l}\mathrm{IES}=0.5 \\
1984-00\end{array}$ & $2001-16$ & Diff. & $\begin{array}{l}\text { Leverage } \\
1984-00\end{array}$ & $2001-16$ & Diff. & $\begin{array}{l}\text { A A rate } \\
1984-00\end{array}$ & $\begin{array}{l}\mathrm{RF} \\
2001-16\end{array}$ & Diff. & $\begin{array}{l}10 \text { year a } \\
1984-00\end{array}$ & $\begin{array}{l}\text { j. for TP } \\
2001-16\end{array}$ & Diff. \\
\hline \multicolumn{13}{|l|}{ A. MPK-RF spread } \\
\hline Total spread & 11.22 & 15.24 & 4.02 & 11.22 & 15.24 & 4.02 & 9.32 & 13.80 & 4.48 & 12.49 & 14.98 & 2.49 \\
\hline - Depreciation & 4.55 & 4.37 & -0.18 & 4.55 & 4.37 & -0.18 & 4.55 & 4.37 & -0.18 & 4.55 & 4.37 & -0.18 \\
\hline - Market power & 3.39 & 5.55 & 2.17 & 4.47 & 6.99 & 2.52 & 3.39 & 5.55 & 2.17 & 3.39 & 5.55 & 2.17 \\
\hline - Risk premium & 3.15 & 5.23 & 2.08 & 2.08 & 3.81 & 1.73 & 1.25 & 3.79 & 2.54 & 4.42 & 4.97 & 0.55 \\
\hline \multicolumn{13}{|l|}{ B. Rate of returns } \\
\hline Equity return & 5.85 & 4.90 & -0.96 & 5.77 & 4.84 & -0.93 & 5.88 & 4.84 & -1.05 & 5.87 & 4.88 & -0.99 \\
\hline Equity premium & 3.07 & 5.25 & 2.18 & 2.99 & 5.19 & 2.20 & 1.19 & 3.75 & 2.56 & 4.35 & 4.97 & 0.62 \\
\hline Risk-free rate & 2.79 & -0.35 & -3.14 & 2.79 & -0.35 & -3.14 & 4.69 & 1.09 & -3.60 & 1.52 & -0.09 & -1.61 \\
\hline \multicolumn{13}{|l|}{$\underline{\text { C. Valuation ratios }}$} \\
\hline Price-dividend & 42.34 & 50.11 & 7.78 & NA & NA & NA & 42.34 & 50.11 & 7.78 & 42.34 & 50.11 & 7.78 \\
\hline Price-earnings & 17.85 & 25.79 & 7.94 & NA & NA & NA & 17.85 & 25.79 & 7.94 & 17.85 & 25.79 & 7.94 \\
\hline Tobin's Q & 2.50 & 3.84 & 1.34 & NA & NA & NA & 2.50 & 3.84 & 1.34 & 2.50 & 3.84 & 1.34 \\
\hline \multicolumn{13}{|l|}{ D. Income shares } \\
\hline Share Labor & 70.11 & 66.01 & -4.10 & 70.11 & 66.01 & -4.10 & 70.11 & 66.01 & -4.10 & 70.11 & 66.01 & -4.10 \\
\hline Share Capital & 22.59 & 21.24 & -1.35 & 20.26 & 17.96 & -2.30 & 22.59 & 21.24 & -1.35 & 22.59 & 21.24 & -1.35 \\
\hline Share Profit & 7.30 & 12.76 & 5.46 & 9.62 & 16.03 & 6.40 & 7.30 & 12.76 & 5.46 & 7.30 & 12.76 & 5.46 \\
\hline \multicolumn{13}{|l|}{ E. Macroeconomy } \\
\hline $\mathrm{K} / \mathrm{Y}$ & 2.13 & 2.28 & 0.15 & 2.13 & 2.28 & 0.15 & 2.13 & 2.28 & 0.15 & 2.13 & 2.28 & 0.15 \\
\hline $\mathrm{I} / \mathrm{Y}$ & 17.28 & 16.50 & -0.78 & 17.28 & 16.50 & -0.78 & 17.28 & 16.50 & -0.78 & 17.28 & 16.50 & -0.78 \\
\hline Detrend Y (\%chg) & - & - & -0.30 & - & - & -1.88 & - & - & -0.30 & - & - & -0.30 \\
\hline Detrend I (\%chg) & - & - & -4.95 & - & - & -6.52 & - & - & -4.95 & - & - & -4.95 \\
\hline
\end{tabular}

Table 10: The table reports some moments of interest calculated in the baseline model, in the model with IES $=0.5$, in the model with financial leverage, and in the model estimated with a different interest rate target (AA), using the estimated parameter values for each of the two subsamples 1984-2000 and 2001-2016, as well as the change between samples. 
Moreover, the spread $M P K-R F$ is also increasing by a smaller amount, and the contribution of risk premia is smaller there as well. We view these results as somewhat less plausible because the decline of term premium implied by this model is very large - we are unaware of macroeconomic models that can rationalize this. Also, to the extent that the decline of term premium is related to macroeconomic risk, it may not be sound to adjust for it.

\subsection{Capital mismeasurement}

One natural explanation for the rising spread $M P K-R F$ is that $K$ is mismeasured, and in particular is underestimated by the BEA analysts, who traditionally focus on tangible assets. To get a sense of how much mismeasurement of capital matters, we present a simple approach in this section. In the online appendix, we then estimate a more detailed model of intangible accumulation. We are interested in two questions: first, can a plausible amount of mismeasurement explain the rising spread? Second, is this mismeasurement also consistent with the other observed features of the data?

In this section, we simply assume that the BEA measures only a fraction $\lambda$ of total investment. When $\lambda=1$, there is no mismeasurement, corresponding to our baseline model. When $\lambda<1$ however, this mismeasurement of investment affects our target moments, and hence possibly our parameter estimates. Denote with a superscript $m$ the measured values of the model variables. ${ }^{24}$ Measured investment is $x^{m}=\lambda x$, and hence along the balanced growth path $k^{m}=\lambda k$. Moreover, GDP and the profit share are now under-estimated since the unmeasured investment $(1-\lambda) x$ is treated as an intermediate input by BEA accountants. As a result, measured GDP is $y^{m}=y-(1-\lambda) x$. Measured profits equal measured GDP less labor compensation, or $\pi^{m}=\pi-(1-\lambda) x$. The profit share is hence underestimated as

$$
\frac{\pi^{m}}{y^{m}}=\frac{\pi-(1-\lambda) x}{y-(1-\lambda) x}<\frac{\pi}{y}
$$

However, dividends are correctly measured since the unmeasured investment reduces both profits and investment: $d=\pi-x=\pi^{m}-x^{m}$. Hence, the asset price is unaffected by measurement error (even if investors do not observe intangible investment).

It is easy to extend our formula (27) for the spread:

$$
M P K-r_{f}=\delta+g_{Q}+\frac{\mu-1}{\alpha}\left(r^{*}+\delta+g_{Q}\right)+r^{*}-r_{f}+\frac{1-\lambda}{\lambda} \frac{d}{k},
$$

and we see that mismeasurement $(\lambda<1)$ now adds an additional component to the measured spread, consistent with basic intuition.

How important is this mismeasurement wedge? First, note that the measured ratio $d /(\lambda k)=d / k^{m}$ is fairly small, around $7.5 \%$ in the second sample (and $6 \%$ in the first sample), according to our data moments. Hence, with $\lambda=0.8$, or a 20 percent under-measurement, the wedge is 1.2-1.5 point, which is significant. Our focus, however, is on the increase in the spread. To explain this increase requires a rising mismeasurement. While there is wide agreement that intangibles play a critical role in modern economies, it is not as clear if mismeasurement has increased over the past few decades. Suppose however, that one wanted to generate an increase the spread by 2 percentage points (or about half of

\footnotetext{
${ }^{24}$ We do the algebra for detrended variables, but one can obviously also apply the same adjustments to the level variables.
} 
the increase in the spread observed during our sample, and about the same as what is explained by risk premia or markups according to our baseline results), the model requires $\lambda$ to go for instance from 1 (perfect measurement) to $\lambda=0.73$, a $27 \%$ underestimation of investment. This rising mismeasurement would reduce measured GDP by $4.4 \%$ and the profit share by 4 percentage points. One tension, hence, is that rising intangibles lead to a measured labor share going up rather than down, as in the data.

To evaluate more precisely how this mismeasurement affects our results, we estimate three versions of our baseline model corresponding to different assumptions about mismeasurement. In the first version, mismeasurement is constant at $10 \%$ in both samples $(\lambda=0.9)$. In the second version, mismeasurement starts at $10 \%$ in the first subsample then rises to $20 \%$ in the second subsample. In the third version, mismeasurement starts at $10 \%$ then rises to $30 \%$. These numbers are largely illustrative; note however that the share in capital of measured "intangibles", that is intellectual property products, is about $6 \%$ recently. We are hence assuming that the unmeasured stock of intangible capital is significantly larger than the current measured stock, and has been rising importantly over the past 15 years.

Table 11 reports the parameter estimates and table 12 reports the implied moments corresponding to different scenarios. There are a few interesting results. First, all parameters are completely unaffected, except for $\mu$ and $\alpha$. In particular, the increase in $\beta$ and in risk are not affected by these assumptions. Second, when mismeasurement is constant at $10 \%$, the model has similar implications to our baseline model (the level of $\alpha$ is higher and the level of $\mu$ lower, but the changes between two subsamples are nearly identical). Third, the estimated increase in markup is smaller when there is an increase in mismeasurement. For instance, with a mismeasurement rising to $30 \%$ of capital, the markup rises by only 4.1 points instead of 6.6 points when mismeasurement is constant and 6.7 points in the baseline model. This is intuitively consistent with the simple formula (29): with more mismeasurement, there is less of a gap between the MPK and the risk-free rate to explain. The other implication is that the estimated $\alpha$ rises. This is because the labor share rises with mismeasurement; to offset this, the model needs an increase in capital-biased technical change, i.e. $\alpha$.

Overall, in our most generous calibration, the rising mismeasurement explains 1.65 point increase in the wedge, the markup now only 0.47 point, and the risk premium 2.08 points. Of course, the magnitude of the mismeasurement is difficult to ascertain. But it is interesting that incorporating realistic mismeasurement would reduce further the implied markup, while leaving the role of risk unaffected.

\subsection{Transitional Dynamics}

Our calculations so far assume that the economy remains along its "risky balanced growth path". However, if the model parameters such as the discount factor or markup change, the economy will experience a transition before it reaches its new balanced growth path. This transition may affect our estimation results.

To evaluate the importance of this bias, we estimated the model, taking into account the transitional dynamics. Specifically, we make the following assumptions. We use the baseline version of the model and assume that the economy starts in 1992 in balanced growth with the parameters that we estimate 


\begin{tabular}{|c|c|c|c|c|c|c|c|c|c|c|c|c|}
\hline & \multicolumn{3}{|l|}{ Baseline } & \multicolumn{3}{|c|}{ Constant bias: $10 \%$} & \multicolumn{3}{|c|}{ Rising bias: $10 \%$ to $20 \%$} & \multicolumn{3}{|c|}{ Rising bias: $10 \%$ to $30 \%$} \\
\hline & $1984-00$ & $2001-16$ & D iff. & $1984-00$ & $2001-16$ & Diff. & $1984-00$ & $2001-16$ & Diff. & $1984-00$ & 2001-16 & Diff. \\
\hline$\beta$ & 961 & 0.972 & 0.012 & 0.961 & 0.972 & 0.012 & 0.961 & 0.972 & 0.012 & 0.961 & 0.972 & 0.012 \\
\hline$\mu$ & 1.079 & 1.146 & 0.067 & 1.070 & 1.136 & 0.066 & 1.070 & 1.125 & 0.055 & 1.070 & 1.111 & 0.041 \\
\hline$p$ & 0.034 & 0.065 & 0.031 & 0.034 & 0.065 & 031 & 0.034 & 0.065 & 0.031 & 0.034 & 0.065 & 0.031 \\
\hline$\delta$ & 2.778 & 3.243 & 0.465 & 2.778 & 3.243 & 0.465 & 2.778 & 3.243 & 0.465 & 2.778 & 3.243 & 0.465 \\
\hline$\alpha$ & 0.244 & 0.243 & -0.000 & 0.264 & 0.263 & -0.000 & 0.264 & 0.287 & 0.023 & 0.264 & 0.315 & 0.051 \\
\hline$g_{P}$ & 1.171 & 1.101 & $0 \cap 60$ & 1.171 & 1.101 & -0.069 & 1.171 & 1.101 & -0.069 & 1.171 & 1.101 & -0.069 \\
\hline$g_{Z}$ & 1.298 & 1.012 & -0.286 & 1.217 & 0.956 & -0.262 & 1.217 & 0.889 & -0.328 & 1.217 & 0.809 & -0.408 \\
\hline$g_{Q}$ & 1.769 & 1.127 & -0.643 & 1.769 & 1.127 & -0.643 & 1.769 & 1.127 & -0.643 & 1.769 & 1.127 & -0.643 \\
\hline$N$ & 62.344 & 60.838 & -1.507 & 62.344 & 60.838 & -1.507 & 62.344 & 60.838 & -1.507 & 62.344 & 60.838 & -1.507 \\
\hline
\end{tabular}

Table 11: The table reports the estimated parameters in each of the two subsamples 1984-2000 and 2001-2016 in the baseline model and in the model with mismeasured capital, for different values of the mismeasurement parameters, using the estimated parameter values for each of the two subsamples 1984-2000 and 2001-2016, as well as the change between samples.

over the first sample. ${ }^{25}$ We then assume that the nine parameters change linearly over 24 years (to end in 2016) from the value we estimated in the first sample to a final value that we will estimate (and which may not be our estimate for the second sample).

We then calculate the transitional dynamics for this economy using a standard shooting method. A key issue is agents' expectations. With perfect foresight, the model cannot fit the data, because agents see the lower interest rates coming, which leads to a boom in the price-dividend ratio. (Furthermore, the long-term interest rate would fall significantly more than the short rate, unlike what we see in the data.) We hence assume myopic expectations: each period, agents observe the new values of the parameters, and they assume (incorrectly, at least for the first 24 years) that these parameters will remain constant forever. ${ }^{26}$

We then numerically find the final parameters such that, when calculating the transition, this procedure yields an average time series for our targets (over the period 2001-2016) that matches what we measured in the data. Figure 13 presents the path obtained for parameter values and figure 14 the path for the moments targeted (we abstract here from parameters that map directly into moments). Table 13 presents the numerical counterpart to these graphs.

As can be seen in figure 14, the model moments, averaged over periods 10-26 (i.e. 2001-2016), match reasonably well the target moments for the second sample (in red). The more surprising result is in figure 13, where we see that the parameter values estimated in this way are quite similar to these obtained in the simple baseline model, which assumes balanced growth. To see this, note that the blue line, averaged

\footnotetext{
${ }^{25}$ We use 1992 to take into account that these parameters are estimated over 1984-2000.

${ }^{26}$ Agents consequently make investment choices that would, eventually, lead to converge to a new steady-state corresponding to today's parameter values. However, the next period, new parameter values (unexpectedly) arrive, leading to new choices and a revised transition path. This process continues until the parameters are indeed constant, and the economy then converges to its final steady-state.
} 


\begin{tabular}{|c|c|c|c|c|c|c|c|c|c|c|c|c|}
\hline & $\begin{array}{l}\text { Baseline } \\
1984-00\end{array}$ & $2001-16$ & Diff. & $\begin{array}{l}\text { Constant } \\
1984-00\end{array}$ & $\begin{array}{l}\text { ias: } 10 \% \\
2001-16\end{array}$ & Diff. & $\begin{array}{l}\text { Rising bi } \\
1984-00\end{array}$ & $\begin{array}{l}\text { s: } 10 \% \text { to } \\
2001-16\end{array}$ & $\begin{array}{l}0 \% \\
\text { Diff. }\end{array}$ & $\begin{array}{l}R \text { ising bi } \\
1984-00\end{array}$ & $\begin{array}{l}\mathrm{s}: 10 \% \text { to } \\
2001-16\end{array}$ & \\
\hline \multicolumn{13}{|l|}{ A. MPK-RF spread } \\
\hline Total spread & 11.22 & 15.24 & 4.02 & 11.22 & 15.24 & 4.02 & 11.22 & 15.24 & 4.02 & 11.22 & 15.24 & 4.02 \\
\hline - Depreciation & 4.55 & 4.37 & -0.18 & 4.55 & 4.37 & -0.18 & 4.55 & 4.37 & -0.18 & 4.55 & 4.37 & -0.18 \\
\hline - Market power & 3.39 & 5.55 & 2.17 & 2.80 & 4.79 & 1.99 & 2.80 & 4.03 & 1.23 & 2.80 & 3.27 & 0.47 \\
\hline - Risk premium & 3.15 & 5.23 & 2.08 & 3.15 & 5.23 & 2.08 & 3.15 & 5.23 & 2.08 & 3.15 & 5.23 & 2.08 \\
\hline - Mismeasurement & 0.13 & 0.09 & -0.05 & 0.72 & 0.85 & 0.13 & 0.72 & 1.61 & 0.89 & 0.72 & 2.37 & 1.65 \\
\hline \multicolumn{13}{|l|}{ B. Rate of returns } \\
\hline Equity return & 5.85 & 4.90 & -0.96 & 5.85 & 4.90 & -0.96 & 5.85 & 4.90 & -0.96 & 5.85 & 4.90 & -0.96 \\
\hline Equity premium & 3.07 & 5.25 & 2.18 & 3.07 & 5.25 & 2.18 & 3.07 & 5.25 & 2.18 & 3.07 & 5.25 & 2.18 \\
\hline Risk-free rate & 2.79 & -0.35 & -3.14 & 2.79 & -0.35 & -3.14 & 2.79 & -0.35 & -3.14 & 2.79 & -0.35 & -3.14 \\
\hline \multicolumn{13}{|l|}{ C. Valuation ratios } \\
\hline Price-dividend & 42.34 & 50.11 & 7.78 & 42.34 & 50.11 & 7.78 & 42.34 & 50.11 & 7.78 & 42.34 & 50.11 & 7.78 \\
\hline Price-earnings & 17.85 & 25.79 & 7.94 & 17.85 & 25.79 & 7.94 & 17.85 & 25.79 & 7.94 & 17.85 & 25.79 & 7.94 \\
\hline Tobin's Q & 2.50 & 3.84 & 1.34 & 2.50 & 3.84 & 1.34 & 2.50 & 3.84 & 1.34 & 2.50 & 3.84 & 1.34 \\
\hline \multicolumn{13}{|l|}{ D. Income shares } \\
\hline Share Labor & 70.11 & 66.01 & -4.10 & 68.79 & 64.82 & -3.97 & 68.79 & 63.39 & -5.40 & 68.79 & 61.65 & -7.14 \\
\hline Share Capital & 22.59 & 21.24 & -1.35 & 24.63 & 23.17 & -1.46 & 24.63 & 25.49 & 0.87 & 24.63 & 28.33 & 3.71 \\
\hline Share Profit & 7.30 & 12.76 & 5.46 & 6.58 & 12.01 & 5.43 & 6.58 & 11.11 & 4.53 & 6.58 & 10.02 & 3.44 \\
\hline \multicolumn{13}{|l|}{$\underline{\text { E. Macroeconomy }}$} \\
\hline $\mathrm{K} / \mathrm{Y}$ & 2.13 & 2.28 & 0.15 & 2.13 & 2.28 & 0.15 & 2.13 & 2.28 & 0.15 & 2.13 & 2.28 & 0.15 \\
\hline $\mathrm{I} / \mathrm{Y}$ & 17.28 & 16.50 & -0.78 & 17.28 & 16.50 & -0.78 & 17.28 & 16.50 & -0.78 & 17.28 & 16.50 & -0.78 \\
\hline Detrend Y ( $\%$ chg $)$ & - & - & -0.30 & - & - & 0.05 & - & - & 5.74 & - & - & 13.60 \\
\hline Detrend I (\% chg) & - & - & -4.95 & - & - & -4.60 & - & - & 1.10 & - & - & 8.95 \\
\hline
\end{tabular}

Table 12: The table reports some moments of interest calculated in the baseline model and in the model with mismeasured capital, for different values of the mismeasurement parameters, using the estimated parameter values for each of the two subsamples 1984-2000 and 2001-2016, as well as the change between samples. 


\begin{tabular}{|c|c|c|c|c|}
\hline & \multicolumn{2}{|c|}{ 1984-2000 } & \multicolumn{2}{|c|}{ 2001-2016 } \\
\hline & Baseline & Transition & Baseline & Transition \\
\hline \multicolumn{5}{|c|}{ Moments } \\
\hline$\Pi / K$ & 14.012 & 14.426 & 14.890 & 14.890 \\
\hline$\Pi / Y$ & 29.887 & 31.194 & 33.992 & 33.991 \\
\hline$R F$ & 2.787 & 1.785 & -0.350 & -0.350 \\
\hline$P D$ & 42.336 & 45.451 & 50.115 & 50.115 \\
\hline$I / K$ & 8.103 & 7.932 & 7.227 & 7.227 \\
\hline \multicolumn{5}{|c|}{ Estimated parameters } \\
\hline$\alpha$ & 0.244 & 0.242 & 0.243 & 0.238 \\
\hline$\mu$ & 1.079 & 1.102 & 1.146 & 1.154 \\
\hline$\beta$ & 0.961 & 0.964 & 0.972 & 0.971 \\
\hline$p$ & 0.034 & 0.046 & 0.065 & 0.073 \\
\hline$\delta$ & 2.778 & 2.642 & 3.243 & 2.334 \\
\hline
\end{tabular}

Table 13: This table reports the target moments in the first and second sample, and the average values over the first and second parts of the transition. The final parameter values are chosen such that the average values match the target moments in each sample. See text for details.

over periods $10-26$, is economically quite similar to the red line (results from the baseline model). The one exception is $\delta$, which now falls slightly instead of rising. Table 13 shows the same result: comparing the third and fourth columns, the estimated parameters are quite similar, except for $\delta$. We view this results as suggesting that, at least in the myopic case, perhaps not much is lost by focusing on the risky balanced growth path. This conclusion might not hold true for all models however; in particular with intangibles if there is significant accumulation during the transition.

\section{Other evidence on market power, risk premia and intangibles}

Our empirical results show that rising risk premia and rising market power appear to be two of the significant drivers of some of the macro-finance trends we focus on, and intangibles have a potential contribution as well. In this section we step outside of the model and present some simpler and independent evidence for these two phenomena. We also discuss some related estimates presented by other researchers, which tend to support our conclusions.

\subsection{Some empirical estimates of the equity risk premium}

We first present some reduced-form estimates of the equity premium. Estimating the equity premium is notoriously difficult, even retrospectively. Using realized excess equity returns is essentially pointless 

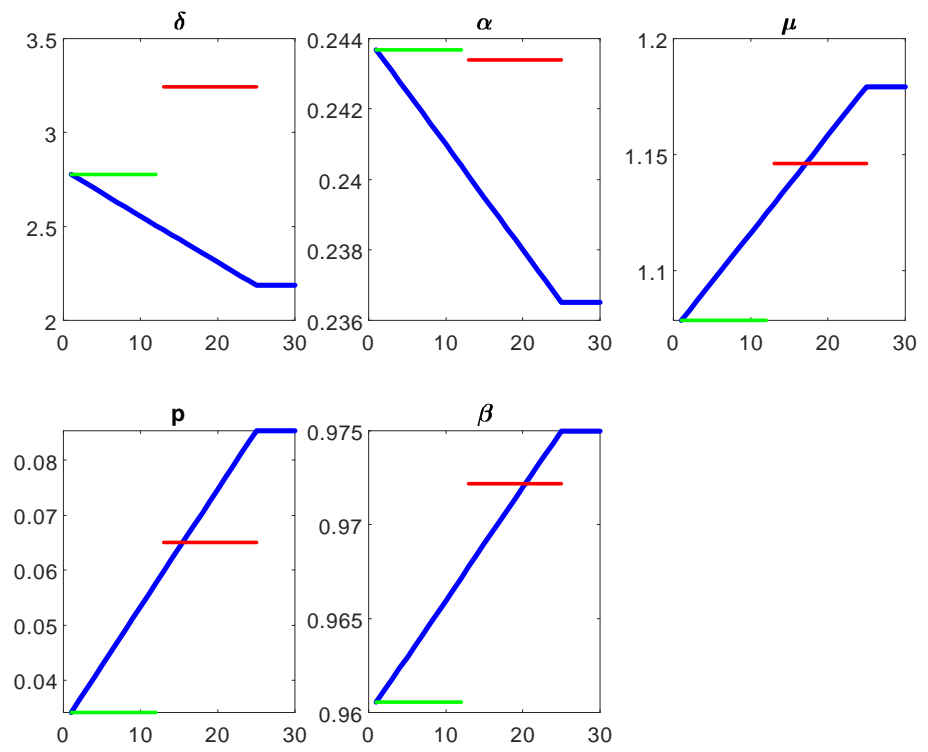

Figure 13: This figure plots the estimated path for the parameters using the transitional dynamics method. The green and red lines denote the values estimated in the baseline approach in the first and second sample.
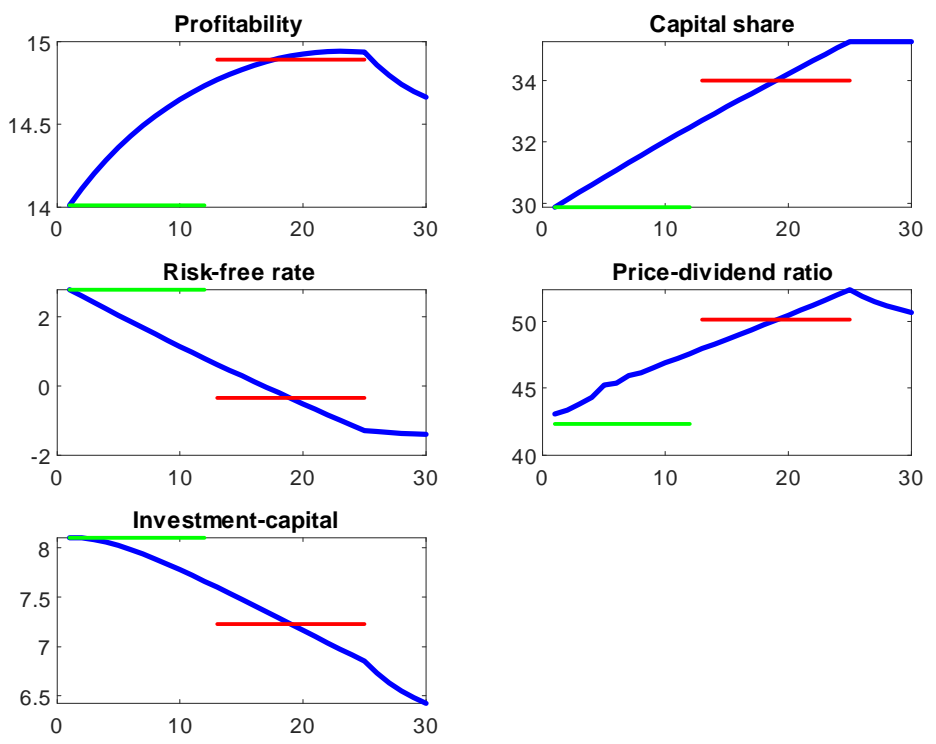

Figure 14: This figure plots the estimated path for the target moments using the transitional dynamics method. The green and red lines denote the values targeted in the baseline approach. In our approach, the red line is the target which the blue line (averaged over periods 10-26) attempts to mimick. 
over short samples, because returns are noisy, ${ }^{27}$ and because an increase in the risk premium may lead, by itself, to lower realized returns. But methods that use standard forecasting return regressions have also been found to be very unstable; Goyal and Welch (2006) argue that none of them outperforms the simple mean out-of-sample. Here we follow a few approaches which have been shown to be somewhat more successful empirically.

Our first approach is simply to use the static Gordon growth formula, which states that the pricedividend ratio is the inverse of the difference between the return on the asset and the dividend growth rate:

$$
\frac{P}{D}=\frac{1}{R-G}
$$

where $R$ is the expected equity return, which can be decomposed into $R=R F+E P$, with $R F$ risk-free and EP the equity premium, and $G$ is the growth rate of dividends. This approach can be used at any point in time, given the observed $P D$ and $R F$ and given an assumption about $G$ going forward. The main difference with our structural estimation above is that we use here data on dividends.

Our second approach builds on Fama and French (2002) who argue that, if the dividend-yield or earnings-yield are stationary, as they ought to be, one can advantageously estimate the mean of $P_{t+1} / P_{t}$ by $D_{t+1} / D_{t}$ or $E_{t+1} / E_{t}$ (which are less volatile). As a result, they suggest estimating

$$
E R P=E\left(\frac{D_{t+1}}{P_{t}}\right)+E\left(\frac{D_{t+1}}{D_{t}}\right)-E(R F),
$$

which amounts to the Gordon growth formula, or replacing dividend growth with earnings growth,

$$
E R P=E\left(\frac{D_{t+1}}{P_{t}}\right)+E\left(\frac{E_{t+1}}{E_{t}}\right)-E(R F) .
$$

This approach is best thought as applying to a long-sample average.

Our third approach follows Campbell and Thompson (2008) who show how combining the current dividend yield and the return on book equity can be used to create a real-time estimate of the equity premium:

$$
E R P=\frac{D}{E} \frac{E}{P}+\left(1-\frac{D}{E}\right) R O E,
$$

and where they suggest smoothing the payout ratio $D / E$, earnings-price ratio $E / P$, and the return on book equity $R O E$ to reduce the effect of influential but transitory observations.

These formulas can be applied either using arithmetic averages or using geometric averages. We report both below in table 14, though we like Campbell and Thompson's recommendation to use the geometric averages. We then incorporate an adjustment of $1 / 2$ the variance of stock returns to produce an estimate of arithmetic equity premium.

The key observation from table 14 is that, while the estimates of the equity premium are clearly different across models and methods, most calculations suggest that the $E R P$ increased from the first

\footnotetext{
${ }^{27}$ For instance, suppose a researcher has a sample of 16 years (as we do) and that the excess equity return has a mean of $8 \%$ with a volatility of $16 \%$. The $95 \%$ confidence interval for the mean excess equity return is [0\%, $16 \%]$. It is clearly impossible to detect a change of the equity premium of even several percentage point based solely on realized returns.
} 


\begin{tabular}{l|lll|lll|}
\hline \hline & \multicolumn{3}{|l|}{ Arithmetic average } & \multicolumn{3}{l}{ Geometric average } \\
\hline & $1984-00$ & $2001-16$ & Change & $1984-$ '00 & 2001 ''16 & Change \\
\hline Real dividend growth & 2.03 & 4.7 & 2.67 & 2.04 & 8.21 & 6.17 \\
Real earnings growth & 6.22 & 16.97 & 10.75 & 10.25 & 12.06 & 1.81 \\
Return on book equity & 10.94 & 10 & -.94 & 10.7 & 9.4 & -1.3 \\
D/P & 2.78 & 1.92 & -.86 & - & - & - \\
D/E & .49 & .47 & -.02 & - & - & - \\
E/P & 5.74 & 4.69 & -1.05 & - & - & - \\
ERP Gordon & .87 & 5.56 & $\mathbf{4 . 6 9}$ & 1.91 & 9.16 & $\mathbf{7 . 2 5}$ \\
ERP Fama-French Earnings & 2.43 & 4.78 & $\mathbf{2 . 3 5}$ & 4.61 & 8.66 & $\mathbf{4 . 0 5}$ \\
ERP Campbell-Thompson & 1.47 & 4.11 & $\mathbf{2 . 6 4}$ & 1.84 & 3.65 & $\mathbf{1 . 8 1}$ \\
ERP Gordon - w. variance adj & - & - & - & 2.43 & 8.26 & $\mathbf{5 . 8 3}$ \\
ERP Fama-French Earnings - w. var. adj. & - & - & - & 4.81 & 10.3 & $\mathbf{5 . 4 9}$ \\
ERP Campbell-Thompson - w. var. adj. & - & - & - & 2.31 & 5.56 & $\mathbf{3 . 2 5}$ \\
\hline \hline
\end{tabular}

Table 14: The table reports estimates of the equity premium for the samples 1984-2000 and 2001-2016. See text for details.

sample to the second sample. Specifically, all nine estimates in bold are positive, ranging from $1.8 \%$ to $7.2 \%$. This reflects that valuation ratios increased moderately, while earnings or dividend growth increased more significantly, and the risk-free rate fell. (For this exercise, we take the risk-free rate to be the 10 year Treasury yield minus SPF inflation expectations over the next 10 year.)

Figure 15 presents graphically estimates of the equity risk premium for each of the three approaches, obtained over centered 11-year rolling windows. We smooth the estimates using a 3-year moving average. Here too, the exact numbers vary quite a bit across models, but all models suggest some increase over the past 15 years or so. (A particular difficulty is how one deals with the very low corporate earnings in 2008 or 2009, which affect the FF-earnings model significantly, leading to the extreme arithmetic implication in the middle panel.)

\subsection{Other measures of changes in risk premia}

We now discuss other evidence on the changes in the risk premium. Duarte and Rosa (2015) provides an exhaustive survey of the different methods that can be used to estimate the equity premium in real time. They distinguish between different methods based on variants of the Gordon growth model, on predictive regressions, and on cross-sectional regressions. Overall, the conclusion is that the equity premium has risen, in line with our findings. ${ }^{28}$ Campbell and Thompson (2008) propose a method to estimate the equity premium in real time. Their estimate also shows a small increase after 2000. Using

\footnotetext{
${ }^{28}$ An earlier literature documented a decline of the equity premium decline during the 1980s and 1990s (Blanchard (1993), Jagannathan and McGrattan (2000), Heaton and Lucas (1999), Lettau and Ludvigson (2007)), which is not inconsistent with our results.
} 


\section{Empirical estimates of ERP}
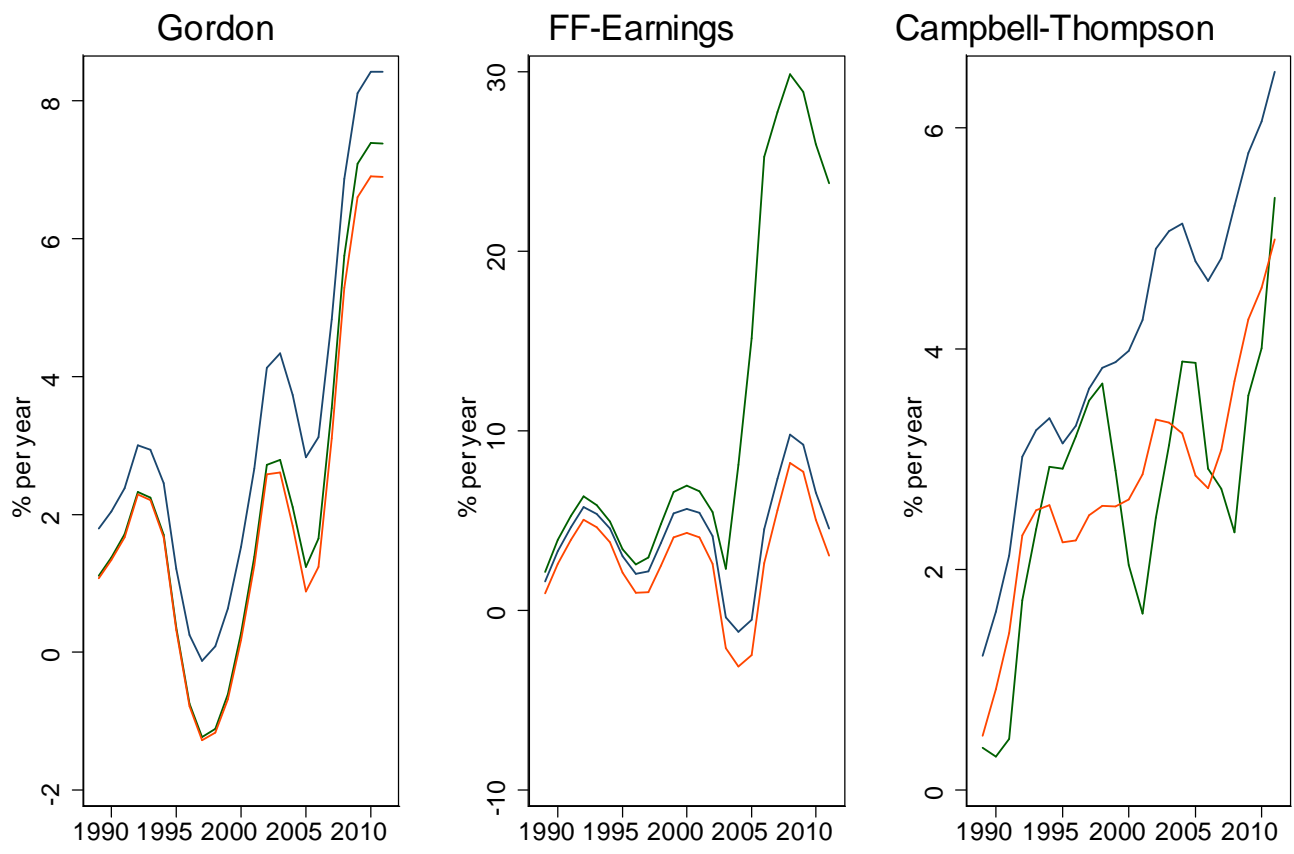

Figure 15: Empirical estimates of the equity risk premium. Left panel: Gordon growth model using dividends; middle panel: Fama-French model using earnings growth instead of dividend growth; right panel: Campbell-Thompson estimates. Red line $=$ arithmetic average; Green $=$ geometric; Blue $=$ geometric + variance adjustment. 


\begin{tabular}{l|l|l|l|l|l|l|l}
\hline \hline & \multicolumn{2}{l}{ Mean } & \multicolumn{3}{l}{ Differences } \\
\hline & $1984-00$ & $2001-2016$ & $2001-16$ ex GFC & \multicolumn{4}{l}{} \\
\hline & $(1)$ & $(2)$ & $(3)$ & $(2)-(1)$ & SE & $(3)-(1)$ & SE \\
\hline spread Gilchrist-Zakrajsek & 1.5 & 2.54 & 2.31 & 1.04 & .24 & .81 & .16 \\
spread BAA-10y & 1.94 & 2.74 & 2.61 & .80 & .19 & .67 & .15 \\
spread AAA-10y & 1.01 & 1.64 & 1.61 & .63 & .13 & .60 & .12 \\
VIX & 18.92 & 20.22 & 18.62 & 1.3 & 2.27 & -.3 & 1.98 \\
Realized volatility & 13.36 & 17.43 & 15.34 & 4.07 & 2.21 & 1.98 & 1.62 \\
\hline
\end{tabular}

Table 15: The table reports the mean of various credit spreads and volatility measures for the samples 1984-2000, 2001-2016, and 2001-2016 excluding the June 2007-June 2009 period. The table also reports the difference between these means and a standard error (calculated using the Newey-West method with 12 monthly lags).

a very different methodology, based on a MLE estimation of a structural model, Avdis and Wachter (2015) reach a fairly similar conclusion. Another important contribution is Martin (2015) who uses an ingenious argument to provide, under a relatively weak condition, a lower bound on the equity premium based on option data. His lower bound has a very high correlation with the VIX index. The estimate is very elevated during the Global Financial Crisis, and remains at a higher level post GFC than pre GFC. However, his lower bound is quite low in the mid-2000s. If the lower bound has a constant bias with the mean, then this series does not behave like the other estimates we discussed above. However, it is possible that the bias between the lower bound he finds and the true expected equity premium is time-varying.

Table 15 presents evidence on the evolution of some other measures of risk; the Gilchrist-Zakrajsek spread, the standard BAA and AAA spreads, the VIX index, and stock market realized volatility (calculated using daily data). The table reports the mean in the two samples, as well as the mean in the second sample excluding the GFC period. We see that all these credit spreads have increased between the two samples, and this conclusion is true even excluding the GFC period. Realized volatility is also somewhat higher. The VIX index exhibits little trend (but is only available starting in 1996). These results are consistent with Del Negro et al. (2017) who show that the premia for safe and liquid assets increased over time. ${ }^{29}$

\subsection{Independent evidence on risking markups}

A number of recent contributions, using different methods, have found that average markups have been increasing. For example, Barkai (2016) uses aggregate data and implements a user cost approach a la Hall-Jorgenson (1967) to decompose the non-labor share into a true capital share and a profit share.

\footnotetext{
${ }^{29}$ One caveat is that the underlying riskiness of the firms issuing corporate bonds may have changed over time, even within credit ratings.
} 
The true capital share is computed by multiplying the capital output ratio by the user cost of capital. The profit share is a residual. The aggregate markup can be directly inferred from the profit share. Because his measure of user cost does not incorporate a meaningful risk premium, Barkai finds that the evolutions of the user cost track those of the interest rate, and so that the user cost has declined substantially over the period 1984-2014. This implies a large decrease in the capital share, a large increase in the profit share, and a large increase in the aggregate markup of about $20 \%$ roughly in line with our macro estimation.

De Loecker and Eeckhout (2016) use firm-level data and estimate firm-level markups using a production function approach which recovers markups as the ratio of the elasticity of production to a flexible input the the share of that input in revenues, where the former is computed by estimating the production function. The aggregate markup computed as a harmonic sales-weighted average of firm-level markups increases by about 25\%. Traina (2018) criticizes the measure of costs used by De Loecker and Eeckhout (2016). Using a broader measure, he finds that the increase in average markups is much smaller. Gutierrez and Philippon (2016) also use firm-level data but they estimate firm-level markups using a user cost approach allowing for sizeable and variable risk premia. They also find a sizeable increase in aggregate markups of about $10 \%$ over the period 1984-2014, somewhat above our baseline results.

\subsection{Rising Intangible Capital}

There is a growing literature that recognizes the importance of intangible capital in the US economy. Corrado et al. (2005, 2009) and Nakamura (2010) present estimates of the size of intangible capital. Bhandari and McGrattan (2017) also contribute to this measurement. Koh, Santaeullia-Llopis and Zheng (2015) argue that rising intangibles help explain the evolution of the labor share. Crouzet and Eberly (2018) argue that growing intangibles help explain both the rising market power and lower capital investment. Caggese and Perez (2017) show how growing intangibles may help account for some of the same macro trends that we focus on in this paper.

\section{Conclusion}

We provide a simple accounting framework that allows decomposing the changes observed over the past 30 years in some key macro-finance trends into "semi-structural" parameters using a fairly clear identification. We say "semi-structural" because, allowing these parameters to vary over time flexibly suggests they are not microfounded and invariant to policy. Yet we find the results useful because deeper explanations have to be consistent with the changes of parameters implied by our approach.

We find that about half of the increase in the spread between the return on private capital and the risk-free rate is due to rising market power, and half due to rising risk. Technical change plays little role. Higher savings supply and higher risk are the prime proximate contributors to the decline of the risk-free rate. Rising market power help explain the evolution of the capital share, profitability, and capital accumulation, but its contribution is substantially overstated if the model is estimated using a macro approach that abstracts from risk. Finally, taking into account intangibles reduces further the 
estimated increase in the market power.

One limitation of our approach is that we treat the parameter changes as independent causal factors, but they might actually be driven by common causes; for instance, higher market power might reduce innovation and hence productivity growth, but we treat these as independent. Our analysis also does not incorporate some factors which could help explain the evolution of some of the big ratios that we study. In particular, we abstract from taxes and from agency issues (e.g. external finance or corporate governance frictions) or market incompleteness, that could also give rise to wedges that might vary over time. Our study of transitional dynamics is only scratching at the vast possibilities. Finally, it would be interesting to study these issues taking into account the specific open economy considerations or at least to study these same facts for a variety of countries. 


\section{References}

Aaronson Dan, Luojia Hu, Arian Seifoddini, and Dan Sullivan (2014). "Declining Labor Force Participation and Its Implications for Unemployment and Employment Growth", Economic Perspectives, Federal Reserve Bank of Chicago, Vol. 38, 4th, 2014.

Acemoglu, Daron and Pascual Restrepo, "The race between man and machine," NBER Working Papers 22252 May 2016.

Andrews, Isaiah, Matthew Gentzknow and Jesse Shapiro, 2017. "Measuring the Sensitivity of Parameter Estimates to Estimation Moments", Quarterly Journal of Economics. 132(4). November 2017.

Autor, David, David Dorn, Lawrence F Katz, Christina Patterson, and John Van Reenen. 2017. "The Fall of the Labor Share and the Rise of Superstar Firms." National Bureau of Economic Research working paper.

Avdis Efstathios, and Jessica Wachter, . "Maximum likelihood estimation of the equity premium", Journal of Financial Economics 125 (3): 589-609.

Bhandari, Anmol, and Ellen R McGrattan. 2018. "Sweat Equity in US Private Business." National Bureau of Economic Research working paper.

Barkai, Simcha, 2016. "Declining Labor and Capital Shares", Working paper, London Business School.

Barro, Robert, Jesús Fernández-Villaverde, Oren Levintal, Andrew Mollerus, 2016. "Safe assets", NBER Working Paper No. 20652.

Barro, Robert, 2006. "Rare disasters and asset markets in the twentieth century", Quarterly Journal of Economics 121(3):823-866.

Campbell, John, "Estimating the Equity Premium," Canadian Journal of Economics, February 2008, $41(1), 1-21$.

Campbell, Jeffrey, Jonas Fisher, Alejandro Justiniano, and Leo Melosi, 2017. "Forward Guidance and Macroeconomic Outcomes Since the Financial Crisis. Chapter in NBER book NBER Macroeconomics Annual 2016, Volume 31 (2017), Martin Eichenbaum and Jonathan A. Parker, editors (p. 283 - 357)

Caballero, Ricardo J., and Emmanuel Farhi, 2018. "The Safety Trap," Review of Economic Studies, 2018, 85 (1).

Caballero, Ricardo J., Emmanuel Farhi and Pierre-Olivier Gourinchas, 2008. "An Equilibrium Model of "Global Imbalances" and Low Interest Rates," American Economic Review, March 2008, 98 (1), 35893.

Caballero, Ricardo J., Emmanuel Farhi and Pierre-Olivier Gourinchas, 2017. "Rents, Technical Change, and Risk Premia Accounting for Secular Trends in Interest Rates, Returns on Capital, Earning Yields, and Factor Shares," American Economic Review, American Economic Association, vol. 107(5), pages 614-620, May.

Carvalho, Carlos, Andrea Ferrero, Fernanda Nechio, 2016. "Demographics and real interest rates: Inspecting the mechanism", European Economic Review, Volume 88, September 2016, Pages 208-226.

Corrado, Carol, Charles Hulten, and Daniel Sichel. 2009. "Intangible capital and US economic growth." Review of income and wealth, 55(3): 661-685. 
Corrado, Carol, Charles Hulten, and Daniel Sichel. 2005. "Measuring capital and technology: an expanded framework." In Measuring capital in the new economy. 11-46. University of Chicago Press.

Crouzet, Nicolas and Janice Eberly, 2018. "Understanding Weak Capital Investment: the Role of Market Concentration and Intangibles", Jackson Hole Economic Policy Symposium,. Federal Reserve Bank of Kansas City.

De Loecker, Jan and Jan Eeckhout, 2017. "The Rise of Market Power and the Macroeconomic Implications", NBER Working paper 23687.

Del Negro, Marco, Domenico Giannone, Marc Giannoni, and Andrea tambalotti, 2017. "Safety, Liquidity, and the Natural Rate of Interest", Brookings Papers on Economic Activity (Spring 2017), pp. $235-294$.

Duarte, Fernando, and Carlo Rosa, 2015. "The Equity Risk Premium: A Review of Models", Federal Reserve Bank of New York Staff Report 714.

Eberly.Janice Investment and Alexander Lewis. "Investement hollowing out." IMF Economic Review, 2017.

Eggertsson, Gauti, Jacob A. Robbins, Ella Getz Wold Kaldor and Piketty's Facts: The Rise of Monopoly Power in the United States, NBER Working paper 24287.

Eggertsson, Gauti, Neil R. Mehrotra, Jacob A. Robbin. "A Model of Secular Stagnation: Theory and Quantitative Evaluation", NBER Working paper 23093.

Elsby, M. W., B. Hobjin, and A. Sahin (2013): "The decline of the US labor share," Brookings Papers on Economic Activity, 2013(2), 1-63.

Fama, Eugene F. and Kenneth R. French, 2002. "The Equity Premium", Journal of Finance, $57(2): 637-659$.

Fernald, John, 2015. "Productivity and Potential Output Before, During, and After the Great Recession", NBER Working Paper No. 20248 and NBER Macroeconomics Annual 2014, Volume 29, Parker and Woodford. 2015.

Fisher, Jonas, 2015. "On the Structural Interpretation of the Smets-Wouters "Risk Premium" Shock", Journal of Money, Credit and Banking, Volume 47, Issue 2-3, March-April 2015, pp. 511-516.

Gabaix, Xavier, 2011. "Disasterization: A Simple Way to Fix the Asset Pricing Properties of Macroeconomic Models", American Economic Review, 101(3): pp 406-409.

Gabaix, Xavier, 2012. "Variable Rare Disasters: An Exactly Solved Framework for Ten Puzzles in Macro-Finance," Quarterly Journal of Economics, May, 645-700.

Gagnon, Etienne, Benjamin Johannsen and David López-Salido, 2016. "Understanding the New Normal: The Role of Demographics," Finance and Economics Discussion Series 2016-080, Board of Governors of the Federal Reserve System.

Gomme, Paul, B. Ravikumar, and Peter Rupert, "The Return to Capital and the Business Cycle," Review of Economic Dynamics, April 2011, 14 (2), 262-278.

Gourio, François, 2012. "Disaster Risk and Business Cycles," American Economic Review, 102(6):273466.

Gourio, François, 2013: "Credit Risk and Disaster Risk," American Economic Journal: Macroeco- 
nomics, 5(3), 1-34.

Gourio, François, Anil Kashyap, and Jae Sim, 2018. "The Tradeoffs in Leaning Against the Wind", IMF Economic Review.

Gourio, François, and Sam Schulhofer-Wohl, 2018. "A note on decomposition for nonlinear models," Mimeo, Federal Reserve Bank of Chicago.

Goyal, Amit, and Ivo Welch. "A Comprehensive Look at the Empirical Performance of Equity Premium Prediction". Review of Financial Studies 21(4) 1455-1508.

Gutierrez, German, and Thomas Philippon. 2017. "Investmentless Growth: An Empirical Investigation.” Brookings Papers on Economic Activity, 2017(2): 89-190

Gutierrez, German, and Thomas Philippon. 2018. "Declining Competition and Investment in the US." National Bureau of Economic Research working paper

Hall, Robert, 2017. "The Role of the Growth of Risk-Averse Wealth in the Decline of the Safe Real Interest Rate", NBER working paper 22196.

Hall, Robert, 2018. "New Evidence on the Markup of Prices over Marginal Costs and the Role of Mega-Firms in the US Economy", Mimeo, Stanford University.

Hamilton, James D., Ethan S. Harris, Jan Hatzius and Kenneth D. West, 2015. "The Equilibrium Real Funds Rate: Past, Present and Future, prepared for the US Monetary Policy forum.

Isore, Marlene, and Urszula Szczerbowicz, 2018. "Disaster Risk and Preference Shifts in a New Keynesian Model", Journal of Economics Dynamics and Control.

Karabarbounis, Loukas and Brent Neiman, 2013. "The Global Decline of the Labor Share," The Quarterly Journal of Economics, 129(1):61-103.

Karabarbounis, Loukas and Brent Neiman, 2018. "Accounting for Factorless Income," NBER Macroeconomics Annual, forthcoming.

Kehrig, Matthias, and Nicolas Vincent, 2017. "Growing productivity without growing wages: The micro-level anatomy of the aggregate labor share decline", Working paper, Duke.

Kilic, Mete and Jessica Wachter, 2018. "Risk, Unemployment, and the Stock Market: A Rare-EventBased Explanation of Labor MarketVolatility", Forthcoming, Review of Financial Studies.

Koh, Dongya, Raul Santaeullia-Llopis, and Yu Zheng, "Labor Share Decline and Intellectual Property Products Capital," Working Papers 927, BGSE September 2016

Kozlowski, Veldkamp and Venky Venkateswaran, "The Tail That Wags the Economy", Working paper, NYU.

Kozlowski, Veldkamp and Venky Venkateswaran, "The Tail That Wags the Risk Free Rate", NBER Macroeconomics Annual.

Martin, Ian, 2013. "Consumption-Based Asset Pricing with Higher Cumulants", Review of Economic Studies, 80(2):745-773.

Martin, Ian, 2017. "What is the Expected Return on the Market?", The Quarterly Journal of Economics, 132(1):367-433.

Marx, Magalie, Benoit Mojon and Francois Velde, 2017. "Why Have Interest Rates Fallen Far Below the Return on Capital", Working Paper, Federal Reserve Bank of Chicago. 
McGrattan, Ellen R. and Edward C. Prescott, 2010, "Unmeasured Investment and the Puzzling U.S. Boom in the 1990s" American Economic Journal: Macroeconomics, 2(4): 88-123.

Mulligan Casey, 2004: "Capital, Interest and Aggregate Intertemporal Substitution”, Working Paper, University of Chicago.

Nakamura, Leonard I. 2010. "Intangible assets and national income accounting." Review of Income and Wealth, 56: S135-S155.

Rachel, Lukasz and Thomas Smith, "Are Low Real Interest Rates Here to Stay?", International Journal of Central Banking, 2017.

Rietz, Thomas, 1988. "The equity premium: a solution", Journal of Monetary Economics 22(1):117131.

Rognlie, Matthew, 2015. "Deciphering the Fall and Rise in the Net Capital Share: Accumulation or Scarcity?", Brookings Papers on Economic Activity (Spring 2015), pp. 1-54

Traina, James, 2018. "Is Aggregate Market Power Increasing? Production Trends Using Financial Statements", Working Paper, U of Chicago.

Wachter, Jessica, 2013. "Can time-varying risk of rare disasters explain aggregate stock market volatility?" Journal of Finance 68:987-1035, June 2013 


\section{Appendix}

\subsection{Data appendix}

Our data and programs are available online. This appendix details our variable construction. We give Haver mnemonics. In many cases we have considered alternative series. However, because we focus on the medium-run trends, differences in cyclical behavior among series have little effect on our target moments.

- Real risk-free interest rate: in our baseline, we use the one-year Treasury constant maturity less current inflation (fcm1@usecon minus ypcuslfe@usecon), though results are nearly identical if other proxies for inflation are used, such as ex-post realized total or core inflation or the median 1-year ahead SPF expected inflation. In the extension, we use also the AAA/AA FTSE index for corporate bond yields minus the median 10 year ahead CPI expected inflation (syct5a@usecon - asacx10@surveys), and we also use the 10 year interest rate minus SPF expected inflation minus the term premium measured by Adrian, Crumb and Moench (fcm10@usecon minus asacx10@surveys minus facm10tv@usecon).

- Price-dividend ratio: we use the cum-dividend and ex-dividend annual returns from CRSP to construct the price-dividend ratio.

- Labor share: we use the gross labor share for nonfinancial corporations, defined as bncomp@usna divided by (bngdp@usna minus bnytpix@usna minus bnbtrn@usna).

- Investment-capital ratio: for investment, we use total nominal fixed investment in private assets over the corresponding capital stock measured at current cost from the Fixed Asset Tables of the BEA (zpt@capstock over ep@capstock). These measures include both nonresidential and residential, and the non-residential part includes equipment, structures and intellectual property products.

- Profitability: to ensure consistency between our measures, we construct profitability as the ratio of (one - our measure of labor share) to the ratio of the capital stock (measured at current cost, ep@capstock) to GDP (nominal, gdp@usna).

- Employment-population ratio: the ratio of civilian employment of people 16 years and over to civilian noninstitutional population of people 16 years old and over, i.e. le@usecon to lnn@usecon. These data are originally from the Current Population Survey.

- Population growth: the growth rate of lnn@usecon.

- TFP growth: we use Fernald's unadjusted total factor productivity for the business sector. We have also experimented with other TFP measures, with only minor effects on our results.

- Investment price growth: the growth of the ratio of the chained index for fixed investment (jf@usna) to the chained index of nondurable consumption and services.

- Leverage: for the extension with leverage, we use data from S\&P to construct aggregate net market leverage as the sum of current debt and long-term debt less cash equivalents, divided by the close price, all on a per share basis, i.e. (lq500@spah + 1t500@spah - aq500@spah)/pc500@spah.

- The empirical estimates of the equity premium in section 7.1 are constructed using monthly data from Shiller. Following Campbell and Thompson (2009), we construct the payout ratio as the ratio of a five-year centered moving average of dividends to earnings; and we use a three-year centered moving 
average of earnings to book equity as the return on equity. We use CRSP daily data to calculate realized volatility. The Gordon equity risk premium (ERP) is estimated as the average $D / P+G_{D}-R F$ where $G_{D}$ is the growth rate of dividend. The Fama-French ERP is estimated as $D / P+G_{E}-R F$ where $G_{E}$ is the growth rate of earnings. The Campbell-Gordon ERP is $\lambda(.5 D / P+.5 E / P)+(1-\lambda) R O E-R F$ where $\lambda$ is the smoothed payout ratio.

- The data from section 7.2 are obtained from the Federal Reserve Board for the Gilchrist-Zakrajsek series; and Haver for the BAA, AAA, and 10 year interest rate, and VIX. Realized volatility is calculated using daily data from CRSP.

\subsection{Model Appendix}

The first subsection discusses aggregation. The second subsection lists the equations characterizing the equilibrium. The third subsection shows how to solve the model. The fourth subsection provides some formulas for the moments of the macroeconomic shock under various distributional assumptions.

\subsubsection{Aggregation}

Given our assumptions that capital and labor can be reallocated frictionlessly across firms at the beginning of each period, and given the constant-return-to-scale technology, firms face a constant (common) marginal cost $m c_{t}$. Each firm sets its price $p_{i t}$ and output $y_{i t}$ to maximize profits, subject to its demand curve:

$$
\begin{aligned}
& \quad \max _{y_{i t}, p_{i t}}\left(p_{i t}-m c_{t}\right) y_{i t}, \\
& \text { s.t. } \quad: \quad y_{i t}=Y_{t}\left(\frac{p_{i t}}{P_{t}}\right)^{-\varepsilon},
\end{aligned}
$$

where $P_{t}$ is the price index, which we can normalize to one as a numeraire. This program leads to the optimal markup, equal to the inverse of the demand elasticity:

$$
\frac{p_{i t}-m c_{t}}{p_{i t}}=\frac{1}{\varepsilon}
$$

Hence all firms set the same price, and in equilibrium we obtain that $n_{i t}=N_{t}, k_{i t}=K_{t}, y_{i t}=Y_{t}$, $p_{i t}=P_{t}=1$ and marginal cost is

$$
m c_{t}=\frac{\varepsilon-1}{\varepsilon} .
$$

Marginal cost can be calculated as the cost of expanding production using either labor or capital, or

$$
m c_{t}=\frac{w_{t}}{M P N_{t}}=\frac{R_{t}}{M P K_{t}}
$$

where $w_{t}$ is the real wage, $R_{t}$ the rental rate of capital, and $M P N_{t}$ and $M P K_{t}$ are the marginal products of labor and capital respectively. This leads to the first order conditions

$$
\begin{aligned}
(1-\alpha) \frac{Y_{t}}{N_{t}} & =\frac{\varepsilon}{\varepsilon-1} w_{t}, \\
\alpha \frac{Y_{t}}{K_{t}} & =\frac{\varepsilon}{\varepsilon-1} R_{t} .
\end{aligned}
$$




\subsubsection{System of equations characterizing the equilibrum}

Utility recursion:

$$
V_{t}=\left((1-\beta) L_{t} c_{p c, t}^{1-\sigma}+\beta E_{t}\left(V_{t+1}^{1-\theta}\right)^{\frac{1-\sigma}{1-\theta}}\right)^{\frac{1}{1-\sigma}}
$$

Utility per capita (since $L_{t}$ is deterministic):

$$
V_{p c, t} \equiv \frac{V_{t}}{L_{t}^{\frac{1}{1-\sigma}}}=\left((1-\beta) c_{p c, t}^{1-\sigma}+\beta \frac{L_{t+1}}{L_{t}} E_{t}\left(V_{p c, t+1}^{1-\theta}\right)^{\frac{1-\sigma}{1-\theta}}\right)^{\frac{1}{1-\sigma}} .
$$

Stochastic discount factor:

$$
M_{t+1}=\beta\left(\frac{c_{p c, t+1}}{c_{p c, t}}\right)^{-\sigma}\left(\frac{V_{p c, t+1}}{E_{t}\left(V_{p c, t+1}^{1-\theta}\right)^{\frac{1}{1-\theta}}}\right)^{\sigma-\theta} .
$$

Stochastic trend:

$$
S_{t+1}=S_{t} e^{\chi_{t+1}}
$$

Production function:

$$
Y_{t}=Z_{t} K_{t}^{\alpha}\left(S_{t} N_{t}\right)^{1-\alpha}
$$

Capital accumulation:

$$
K_{t+1}=\left((1-\delta) K_{t}+Q_{t} X_{t}\right) e^{\chi_{t+1}}
$$

First-order conditions:

$$
\begin{aligned}
(1-\alpha) \frac{Y_{t}}{N_{t}} & =\mu w_{t}, \\
\alpha \frac{Y_{t}}{K_{t}} & =\mu R_{t} .
\end{aligned}
$$

Euler equation:

$$
E_{t}\left[M_{t+1} R_{t+1}^{K}\right]=1
$$

Return on capital:

$$
R_{t+1}^{K}=\left(R_{t+1}+(1-\delta) \frac{1}{q_{t+1}}\right) q_{t} e^{\chi_{t+1}}
$$

Resource constraint:

$$
C_{t}+X_{t}=Y_{t}
$$

\subsubsection{Solution method}

To solve the model involves solving for the constants $y^{*}, x^{*}, k^{*}$, etc. that give the (log) intercept of the solution for each of the macro variables, e.g.:

$$
\log Y_{t}=\log y^{*}+\log S_{t}+\log T_{t}
$$

To obtain these constants, we follow the standard procedure to solve the neoclassical model. We first detrend the equations by $T_{t}$ and $S_{t}$, taking into account the relation between $g_{T}, g_{L}, g_{Q}$, and $g_{Z}$. The Euler equation (7) is hence rewritten along the risky balanced growth path as:

$$
\frac{1}{\beta^{*}}=\left(\frac{\alpha}{\mu} Q^{*}\left(\frac{k^{*}}{\bar{N}}\right)^{\alpha-1} \frac{1}{1+g_{Q}}+\frac{1-\delta}{1+g_{Q}}\right)
$$


which provides an equation in $k^{*}$ given the parameters. We then obtain $y^{*}=k^{* \alpha} \bar{N}^{1-\alpha}$ from the detrended production function and $x^{*}$ from the detrended capital accumulation equation:

$$
x^{*}=k^{*}\left(\left(1+g_{Q}\right)\left(1+g_{T}\right)-(1-\delta)\right),
$$

and finally $c^{*}=y^{*}-x^{*}$. The calculation of the risk-free rate and price-dividend ratio follows immediately from the formula for the SDF (12).

\subsubsection{Explicit formulas for some distributions of macro shocks}

The expressions for the "big ratios" involve expectations of the macro shocks $\chi_{t+1}$. It is useful to spell out these expectations in some interesting special cases. Technically, following Martin (2013), we recognize that we can rewrite these moments using the moment-generating function, defined for $x \in \mathbb{R}$ as $\phi(x)=E\left(e^{x \chi_{t+1}}\right)$. In particular, defining $\widehat{\beta}=\beta\left(1+g_{P C}\right)^{-\sigma}$, we have:

$$
\begin{gathered}
\log \beta^{*}=\log \widehat{\beta}+\frac{1-\sigma}{1-\theta} \log \phi(1-\theta), \\
\log R F=-\log \widehat{\beta}-\frac{\theta-\sigma}{1-\theta} \log \phi(1-\theta)-\log \phi(-\theta), \\
\log E R P=\log \phi(1)+\log \phi(-\theta)-\log \phi(1-\theta) .
\end{gathered}
$$

While in our paper we will focus on the case where $\chi$ is a rare disaster, nothing in our analysis precludes using a different distribution. One that is particularly tractable is the lognormal case, i.e. $\chi$ is normal with mean $\mu_{\chi}$ and variance $\sigma_{\chi}^{2}$. In particular, setting $\mu_{\chi}=-\sigma_{\chi}^{2} / 2$, an increase in $\sigma_{\chi}$ is a pure risk shock (i.e. in the sense of second order stochastic dominance). In that case, we have $\phi(x)=e^{-x(1-x) \frac{\sigma_{\chi}^{2}}{2}}$, and hence, as noted in section 3.4.1,

$$
\begin{aligned}
\log \beta^{*} & =\log \widehat{\beta}-(1-\sigma) \theta \frac{\sigma_{\chi}^{2}}{2}, \\
\log R F & =-\log \widehat{\beta}-(1+\sigma) \theta \frac{\sigma_{\chi}^{2}}{2}, \\
\log E R P & =\theta \sigma_{\chi}^{2} .
\end{aligned}
$$

Another tractable case is the compound Poisson process. Suppose that for $j \geq 0$,

$$
\operatorname{Pr}\left(\chi_{t+1}=-j b\right)=\frac{\lambda^{j}}{j !} e^{-\lambda}
$$

i.e. instead of at most a single disaster realization per period, there are potentially several of these shocks, and that the number of shocks follows a Poisson distribution, with intensity $\lambda \approx p$. (Because $p$ is small, this compound Poisson process case is very close quantitatively to the simple binomial case, but leads to somewhat more elegant formulas.) The moment generating function is $\phi(x)=e^{\lambda\left(e^{-x b}-1\right)}$, and the objects of interest are:

$$
\begin{aligned}
\log \beta^{*} & =\log \widehat{\beta}+\frac{1-\sigma}{1-\theta} \lambda\left(e^{-(1-\theta) b}-1\right) \\
\log R F & =-\log \widehat{\beta}+\frac{\theta-\sigma}{1-\theta} \lambda\left(e^{-(1-\theta) b}-1\right)-\lambda\left(e^{\theta b}-1\right) \\
\log E R P & =\lambda\left(e^{-b}+e^{\theta b}-e^{-(1-\theta) b}-1\right)
\end{aligned}
$$


It is straightforward to extend this calculation to the case of random size of shocks $b$, as in Kilic and Wachter (2017).

In our application we will assume that $\chi_{t+1}$ follows a three-point distribution, i.e.

$$
\begin{aligned}
\chi_{t+1} & =0 \text { with probability } 1-2 p \\
\chi_{t+1} & =\log (1-b) \text { with probability } p, \\
\chi_{t+1} & =\log \left(1+b_{H}\right) \text { with probability } p,
\end{aligned}
$$

where $b$ and $b_{H}$ and are chosen so that $E\left(e^{\chi+1}\right)=1$. The second state is a "disaster": output and consumption fall permanently by a factor $1-b$. The third state is a "windfall" or "bonanza" state that offsets the mean effect of the disaster. One could also use a more traditional two-point process, without the third state, which would then not satisfy $E\left(e^{\chi+1}\right)=1$, and in that case a change in $p$ would have both a first moment and second moment effect. 